\title{
ANÁLISE COMPARATIVA DO ENCADEAMENTO DE VIAGENS DE TRÊS ÁREAS URBANAS
}

\section{Pablo Brilhante de Sousa}

Dissertação apresentada à Escola de Engenharia de São Carlos da Universidade de São Paulo, como parte dos requisitos para obtenção do título de Mestre em Engenharia Civil com ênfase em Transportes.

Orientador: Prof. Dr. Eiji Kawamoto

São Carlos

Fevereiro

2004 
"No fim tudo dá certo. Se não deu certo, é porque ainda não chegou ao fim".

Fernando Sabino 
Dedico este trabalho aos meus pais, João e Soila, e aos meus irmãos, Patrícia e Patrick, pelo amor, carinho e amizade de sempre. 


\section{Agradecimentos}

Ao professor Eiji Kawamoto pelos ensinamentos e experiência de vida passados ao longo deste trabalho.

Ao Conselho Nacional de Desenvolvimento Cientifico e Tecnológico - CNPQ, pela bolsa de estudos concedida.

Ao METRÔ-SP - Companhia do Metropolitano de São Paulo, pela cessão dos dados da pesquisa de origem e destino da Região Metropolitana de São Paulo.

À JICA - Agência de Cooperação Internacional do Japão e ao Governo do Estado do Pará, pela cessão dos dados da pesquisa domiciliar da Região Metropolitana de Belém.

À EMDURB - Empresa Municipal de Desenvolvimento Urbano e Rural de Bauru, pela cessão dos dados da pesquisa origem e destino da cidade de Bauru.

Aos professores e funcionários do Departamento de Transportes da EESC-USP por toda colaboração.

A todos os meus amigos do Departamento de Transportes da EESC-USP pelo companheirismo e ajuda.

Aos amigos Cira, Márcia Lika, Cinthia Egami e Giovane Zito pelo auxílio constante na sala "XYZ".

Ao amigo especial Marcelo pela força e companheirismo diário.

À Andressa pela ternura dos instantes mágicos que compartilhamos.

Aos meus amigos de muitos anos de Belém do Pará: Mário, André, Paulo, Lobato e Álvaro.

À Massa Goto pela ajuda com os dados da RMB.

Aos amigos de pelada do STT: Cláudio, Rominho, Renato, Vítor, Fábio, Fred, Marcos, Mané Lucas e Genival.

Aos grandes amigos que já partiram do STT com destino às cidades natais: Alexandre "Parêia”, Renatinho e Ricardinho.

À minha família, dedico um especial agradecimento por toda torcida. 



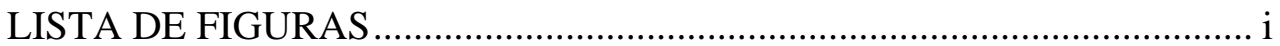

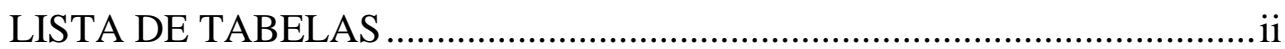

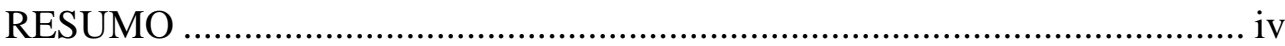

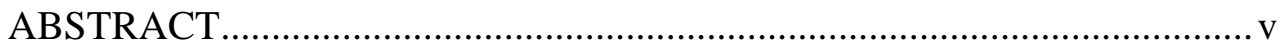

CAPÍTULO 1 - INTRODUÇÃO ....................................................... 1

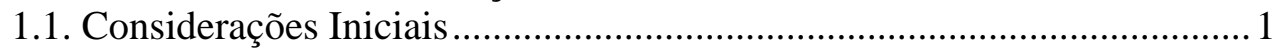

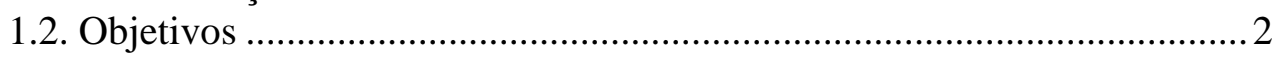

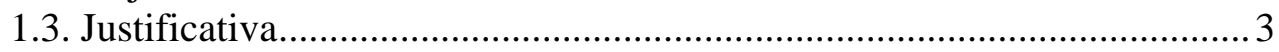

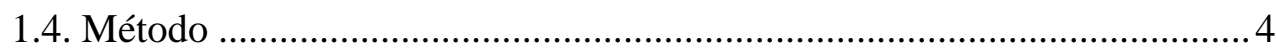

1.5. Estrutura do Trabalho ...................................................................... 5

CAPÍTULO 2 - ANÁLISE DE DEMANDA POR TRANSPORTES

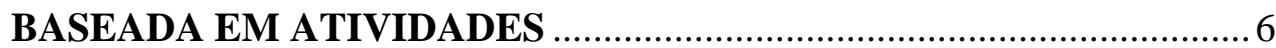

2.1. Definições e Características Principais ........................................................ 6

2.2. Um Breve Histórico e Futuras Direções da Análise Baseada

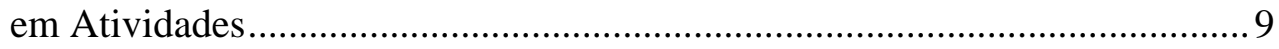

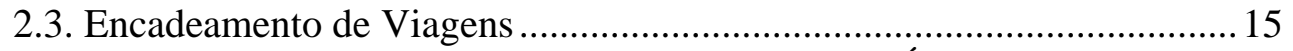

2.4. Estudos Comparativos de Regiões Distintas sob a Ótica da

Análise de Atividades .................................................................................... 18

2.5. Breve Descrição de Variáveis que Influem no Encadeamento

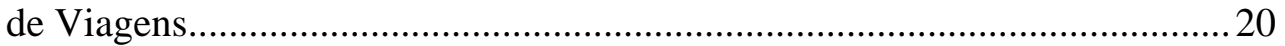

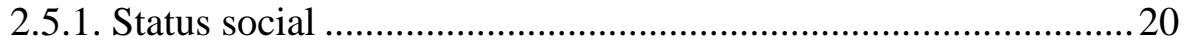

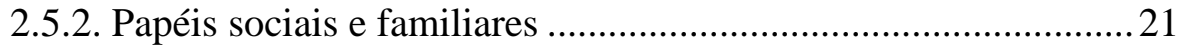

2.5.3 Estágio no ciclo de vida............................................................. 22

CAPÍTULO 3 - DESCRIÇÃO DO MÉTODO ............................................ 24

3.1. Árvores de Decisão e Classificação: Definições e Propriedades Gerais... 25

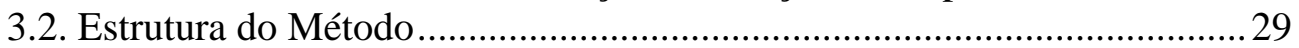

3.2.1. Fase 1: Obtenção de três conjuntos de dados comparáveis .........29

3.2.2. Fase 2: Caracterização dos padrões de viagens encadeadas ........ 30

3.2.3. Fase 3: Processamento da Árvore de Decisão e Classificação ... 31

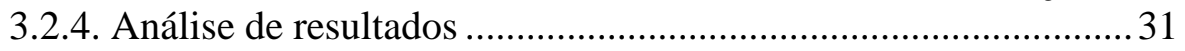

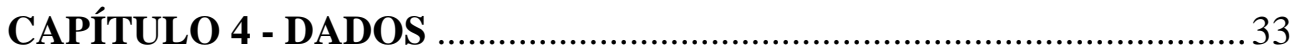

4.1. A Pesquisa Origem-Destino na RMSP ................................................... 33

4.2. A Pesquisa Origem-Destino na RMB ........................................................ 35

4.3. A Pesquisa Origem-Destino na cidade de Bauru ......................................... 36

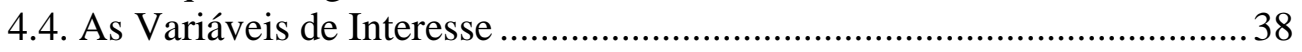

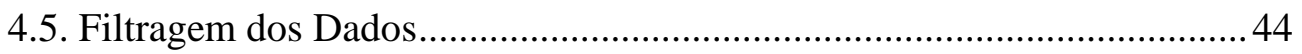

CAPÍTULO 5 - CARACTERIZAÇÃO DOS PADRÕES DE

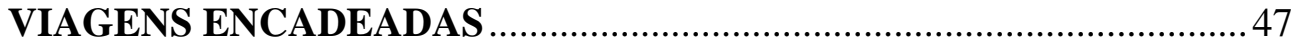

5.1. Etapa 1: Motivo, número de viagens e modo de transporte ....................... 48

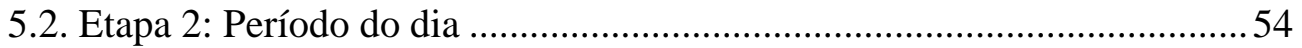




\section{CAPÍTULO 6 - PROCESSAMENTO DA ÁRVORE DE DECISÃO}

E CLASSIFICAÇÃO E RESULTADOS

6.1. Processamento da Árvore de Decisão e Classificação .................................62 62

6.2. Resultado do Relatório Emitido pelo S-Plus ................................................66

CAPÍTULO 7 - ANÁLISE DE RESULTADOS ........................................ 75

7.1. Parte 1: Indivíduos que não trabalham e não estudam ................................78

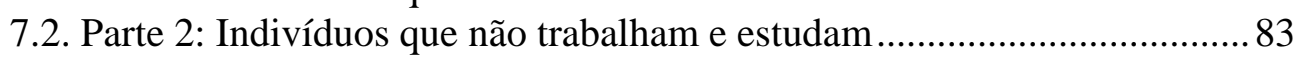

7.3. Parte 3: Indivíduos que trabalham e não estudam ........................................90

7.4. Parte 4: Indivíduos que trabalham e estudam..........................................98

CAPÍTULO 8 - CONCLUSÕES E RECOMENDAÇÕES PARA

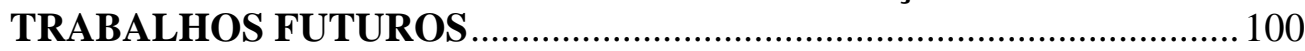

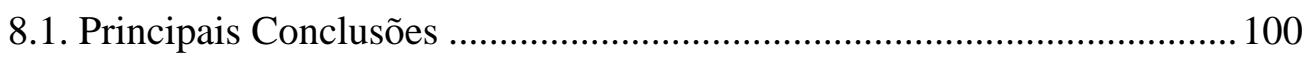

8.2. Recomendações para Futuros Trabalhos ................................................. 103

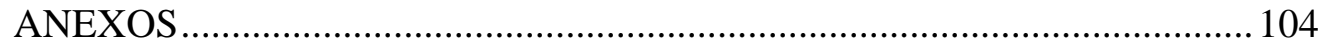

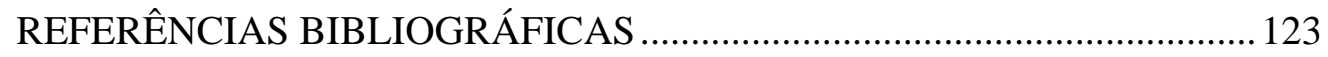




\section{CAPÍTULO 2}

Figura 2.1 Estrutura de decisões de viagens e atividades - Baseada

em Bowman e Bem-Akiva (1997) 8

Figura 2.2 Exemplos de encadeamento de viagens - Exemplo adaptado

de Ichikawa et. al. (2002).

\section{CAPÍTULO 3}

Figura 3.1 Exemplo hipotético das principais características da Árvore de Classificação para um problema com dois valores de variável resposta (I e II) e quatro preditoras (ID, SF, ES e RF) ...................... 27

Figura 3.2 Estrutura do método proposto.

\section{CAPÍTULO 4}

Figura 4.1 Região Metropolitana de São Paulo.............................................. 34

Figura 4.2 Região Metropolitana de Belém .................................................. 36

Figura 4.3 Divisão da cidade de Bauru em zonas de tráfego (destaque

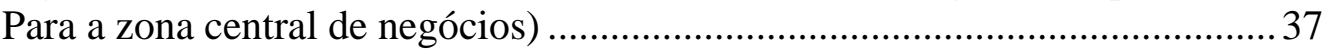

\section{CAPÍTULO 5}

Figura 5.1 Procedimento utilizado para caracterização dos padrões

de viagens

Figura 5.2 Resultado do procedimento adotado para eliminação da viagem por motivo "Transbordo" da amostra da RMB

Figura 5.3 Quatro padrões mais freqüentes nesta etapa .................................. 53

Figura 5.4 Agrupamento proposto para o período do dia ............................... 54

Figura 5.5 Quatro padrões mais freqüentes nas três amostras nesta etapa....... 57

\section{CAPÍTULO 6}

Figura 6.1 Árvore de Decisão e Classificação gerada pelo S-Plus com desvio mínimo adotado de 0,02

\section{CAPÍTULO 7}

Figura 7.1 Pontos similares encontrados na árvore gerada pelo S-Plus com desvio mínimo adotado de 0,02.

Figura 7.2 Características importantes para segregação dos dados da

Parte 1

Figura 7.3 Nós terminais similares formados pela RMSP e RMB..................89

Figura 7.4 Grupos similares e homogêneos formados em relação aos padrões de viagens escolhidos pela RMSP e RMB.

Figura 7.5 Grupos similares e homogêneos formados em relação aos

padrões de viagens escolhidos pela RMSP e RMB.

Figura 7.6 Grupos homogêneos em relação aos padrões de viagens 


\section{CAPÍTULO 4}

Tabela 4.1 As variáveis domiciliares e individuais de interesse presentes nos três conjuntos de dados. Codificação adotada pelo METRO-SP/87, EMDURB/97 e JICA-Governo do Pará/2000.

Tabela 4.2 Uniformização da variável "Grau de instrução”.

Tabela 4.3 As características de viagem de interesse presentes

nos três conjuntos de dados. Codificação adotada pelo METRO-SP/87, EMDURB/97 e JICA-Governo do Pará/2000...................................................43

Tabela 4.4 Resumo da filtragem dos dados nos três conjuntos de dados......... 46 Tabela 4.5 Total de indivíduos analisados por número de viagens

\section{CAPÍTULO 5}

Tabela 5.1 Agrupamento dos motivos de viagens

Tabela 5.2 Agrupamento dos modos de viagens.

Tabela 5.3 Padrões segundo motivo e modo, respectivos códigos e

Freqüência (\%).

Tabela 5.4 Padrões segundo período do dia com seus respectivos códigos e

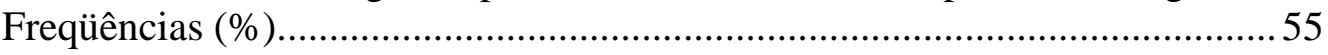

Tabela 5.5 Padrões finais analisados e respectivas freqüências (\%)................58

\section{CAPÍTULO 6}

Tabela 6.1 Padrões predominantes encontrados nas classes finais de indivíduos

Tabela 6.2 Padrões predominantes encontrados nos nós terminais da

Árvore.

\section{CAPÍTULO 7}

Tabela 7.1 Padrões predominantes encontrados para pessoas que não trabalham, não estudam e não possuem auto nas três amostras.

Tabela 7.2 Padrões predominantes encontrados para pessoas que não trabalham, não estudam e possuem auto nas três amostras.

Tabela 7.3 Padrões predominantes encontrados para pessoas que não trabalham, estudam, possuem grau de instrução 1 e 2 e renda familiar até 14,95 salários mínimos.

Tabela 7.4 Padrões predominantes encontrados para pessoas que não trabalham, estudam, possuem grau de instrução 3 e 4 e renda familiar até 17,85 salários mínimos ....

Tabela 7.5 Características socioeconômicas e padrões consolidados do Tipo HSH presentes nos nós terminais similares dentre as regiões metropolitanas 
Tabela 7.6 Padrões predominantes encontrados para pessoas que trabalham, não possuem auto e não estudam .93

Tabela 7.7 Padrões predominantes encontrados para pessoas que trabalham, possuem auto e não estudam 


\section{RESUMO}

SOUSA, P.B. (2004) Análise Comparativa do Encadeamento de Viagens de Três Áreas Urbanas. São Carlos, 2004. (130 p.) Dissertação (Mestrado) - Escola de Engenharia de São Carlos, Universidade de São Paulo.

O objetivo principal deste trabalho é identificar se e como as áreas urbanas interferem nos padrões de viagens encadeadas dos viajantes urbanos. Para atingir os objetivos, as diferenças e similaridades notadas entre os principais grupos socioeconômicos das áreas urbanas em relação aos padrões de viagens encadeadas serão discutidas. O método para comparação dos comportamentos relacionados às viagens encadeadas baseia-se na compatibilização das variáveis das três áreas e posterior aplicação do minerador de dados denominado Árvore de Decisão e Classificação, disponível no pacote estatístico S-Plus 6.1. As viagens encadeadas foram representadas através da codificação inicialmente proposta por Ichikawa (2002) e ampliada por Pitombo (2003). Foram codificados os motivos, modos e período do dia em que cada viagem foi realizada. A análise foi baseada nas pesquisas origem-destino realizadas na Região Metropolitana de São Paulo pelo METRÔ-SP, em 1997, na Região Metropolitana de Belém pela JICA/Governo do Estado do Pará, em 2000, e na cidade de Bauru pela EMDURB, em 1997. Concluiu-se que, em geral, o comportamento de viajantes urbanos são influenciados pelas políticas urbanas regionais, características socioeconômicas e espaciais de cada região.

Palavras-chave: viagens encadeadas; análise de demanda; mineração de dados; padrões de viagens. 


\begin{abstract}
SOUSA, P.B. (2003) Comparative Analysis of the Chained Trips of Three Urban Areas. São Carlos, 2004. (130 p.) Dissertação (Mestrado) - Escola de Engenharia de São Carlos, Universidade de São Paulo.
\end{abstract}

The main aim of this work is to identify whether and how the urban areas interfere in the urban trips makers' trip chaining pattern. For attaining the aims, the differences and similarities observed among the behaviour of trip makers belonging to the main socioeconomic groups living in the three urban areas will be discussed. The method to compare the behavior related to trip chaining is based on the compatibilization of the variables of three areas and subsequent application of the data miner named Decision and Classification Tree, available in the S-Plus 6.1 statistical package. The chained trips were coded by using the process initially proposed by Ichikawa (2002) and amplified later by Pitombo (2003). The trip purpose, travel mode and period of the day in which each trip occurs were coded. The analysis was based on the origin-destination home-interview surveys carried out in São Paulo Metropolitan Área by METRÔ-SP, in 1997, Belém Metropolitan Área by JICA/Pará State Government, in 2000, and Bauru city by EMDURB, in 1997. The main finding is that urban trip makers' behaviour are affected by regional urban policy, socioeconomic features and geographical characteristics of each area.

Keywords: trip-chaining; demand analysis; data-mining; travel patterns. 


\section{INTRODUÇÃO}

\section{Capítulo}

O presente trabalho constitui uma das linhas de pesquisa em desenvolvimento no Departamento de Transportes da Escola de Engenharia de São Carlos (EESC/USP) que busca relacionar vários aspectos do encadeamento de viagens com características socioeconômicas dos habitantes de áreas urbanas.

\subsection{Considerações Iniciais}

Nos últimos 30 anos, pesquisadores e planejadores de transportes têm estudado o comportamento referente ao encadeamento de viagens. Importantes mudanças nos paradigmas de modelagem da demanda por transportes permitiram significativos avanços nesta área. Tais mudanças dizem respeito aos novos estudos que procuram compreender o comportamento dos viajantes urbanos que, segundo Jones et al. (1990), é derivado dos estilos de vida e das atividades desempenhadas pelas pessoas.

A idéia básica da abordagem de viagens encadeadas é que demanda por viagens é derivada dos desejos das pessoas de realizarem diferentes atividades. As relações entre tais atividades; as características socioeconômicas dos indivíduos e das famílias; e a incorporação de limites espaciais e temporais, restrições institucionais e características da rede de transporte, fazem parte dos estudos que tratam da análise desta abordagem. 
A comparação do encadeamento de viagens entre áreas urbanas distintas surge como desafio aos pesquisadores de transportes da área de análise de atividades. O entendimento de diferenças culturais, políticas regionais e de características espaciais das respectivas áreas possivelmente permitirá melhor compreensão do comportamento dos viajantes urbanos.

\subsection{Objetivos}

O primeiro trabalho desta linha de pesquisa do Departamento de Transportes da EESC/USP foi proposto por Ichikawa (2002). Foi verificada a viabilidade do uso da técnica de mineração de dados denominada “Arvore de Decisão e Classificação”, para analisar relações entre características socioeconômicas e padrões de viagens encadeadas. Posteriormente, Pitombo (2003) atribuiu outros aspectos relacionados às viagens encadeadas e estudou o comportamento subjacente de viajantes urbanos através da mesma técnica. Como a empreitada teve êxito, pretende-se aplicar tal técnica em um conjunto de dados que engloba indivíduos da Região Metropolitana de São Paulo (RMSP), de Belém (RMB) e da cidade de Bauru com os seguintes objetivos:

a) Identificar se e como as áreas urbanas interferem nos padrões de viagens encadeadas dos viajantes urbanos;

b) Analisar as similaridades e diferenças encontradas em relação aos encadeamentos de viagens dentre os grupos de indivíduos formados pelas três áreas urbanas, para que se possa melhor compreender o comportamento de viajantes urbanos.

A finalidade do estudo é de analisar, em geral, o comportamento referente às viagens dos principais grupos socioeconômicos formados a partir da aplicação da técnica de mineração nas três áreas urbanas. Assim, o objetivo principal do trabalho é procurar compreender as diferenças e similaridades do comportamento referente ao encadeamento de viagens destes grupos nas áreas em questão. 


\subsection{Justificativa}

Nota-se que, na maioria das vezes, os indivíduos tendem a realizar um processo de decisão que resulta na combinação mais adequada entre atividades e viagens, formando uma seqüência de viagens no espaço urbano ao longo do dia, ou seja, o encadeamento de viagens.

A análise dos deslocamentos como resultado da seqüência de atividades exercidas em diferentes localidades implica uma expansão no âmbito analítico, pois seu tópico não é limitado apenas a viagens independentes. Este fato leva a maiores requerimentos em termos de dados e complexidade de análise. As vantagens oferecidas, em particular a habilidade de superar as limitações dos modelos convencionais, são de grande importância para o planejamento de transportes, prevalecendo sob as desvantagens (Ichikawa et. al., 2002).

O estudo do encadeamento de viagens possibilita uma boa compreensão do comportamento do viajante pois assume a interdependência espaço-temporal existente entre as viagens realizadas por indivíduos em determinado período de tempo.

Da análise prévia da literatura existente acerca do assunto, verificaram-se poucos estudos realizados na comparação do comportamento referente ao encadeamento de viagens de áreas urbanas distintas, o que estimulou mais ainda o autor a seguir com a proposta do trabalho.

Particularmente, a comparação deste encadeamento em áreas urbanas distintas permitirá que os tomadores de decisão, ou seja, os planejadores de transportes, obtenham discernimento das relações existentes entre características socioeconômicas e aspectos relacionados à viagem intrínsecos de cada área urbana, a fim de que possam adotar programas de planejamento de transporte regionais eficazes. 


\subsection{Método}

A fim de alcançar os objetivos propostos, serão seguidos os seguintes passos:

- O primeiro passo será a revisão da literatura com intuito de aprofundar conhecimentos teóricos e práticos acerca da análise da demanda por transporte baseada nas atividades e de mineradores de dados (ferramenta a ser utilizada neste trabalho). Procurar-se-á também estudos comparativos do encadeamento de viagens realizados em áreas urbanas distintas;

- Em seguida, far-se-á a filtragem e tratamento dos dados com os objetivos de separar a amostra final, eliminando dados incompletos ou aqueles que não fazem parte dos objetivos da análise. Neste passo também será feita a compatibilização de variáveis socioeconômicas obtidas diferentemente pelas pesquisas domiciliares das áreas urbanas em análise, com intuito de se obter três conjunto de dados comparáveis;

- O passo seguinte será a codificação dos padrões de viagens encadeadas. Esta codificação é crucial para viabilizar o uso do minerador de dados e será feita seguindo basicamente a proposta por Ichikawa (2002) e ampliada por Pitombo (2003). Novamente, algumas adaptações poderão ocorrer a fim de compatibilizar os dados das três áreas em estudo;

- Aplicar-se-á então o minerador de dados denominado Árvore de Decisão e Classificação, contido no pacote estatístico S-PLUS 6.1, em uma amostra que engloba os três conjuntos de dados. Ressalta-se que nesta amostra global, haverá uma variável que identificará a área urbana. Tal variável servirá para identificar se e como as áreas urbanas interferem no comportamento do viajante;

- De posse dos resultados gerados pelo minerador de dados, serão identificadas diferenças e similaridades entre grupos socioeconômicos das três áreas 
urbanas em relação aos padrões de viagens encadeadas. Aspectos relacionados às políticas regionais, diferenças socioeconômicas e de características espaciais intrínsecos de cada área servirão de base para elucidar tais diferenças e similaridades encontradas.

\subsection{Estrutura do Trabalho}

O presente trabalho é constituído de oito capítulos, além dessa introdução, conforme descrição a seguir:

Capítulo 2 - Faz-se uma revisão da literatura sobre a análise da demanda por transporte baseada nas atividades e o encadeamento de viagens e expõem-se alguns estudos comparativos de áreas diferentes, anteriormente realizados, nesta área;

Capítulo 3 - Mostra-se uma descrição do método a ser utilizado neste trabalho;

Capítulo 4 - Apresenta-se uma breve descrição dos dados a serem utilizados neste trabalho, compatibilização de variáveis de interesse e filtragens realizadas para se obter as amostras finais;

Capítulo 5 - Apresenta-se a codificação proposta para os padrões de viagens e relatam-se algumas diferenças encontradas, entre os três conjuntos de dados, nas variáveis de interesse para a análise;

Capítulo 6 - Mostra-se o processamento da árvore e os resultados obtidos na forma gráfica e tabular;

Capítulo 7 - Traz todas as análises realizadas;

Capítulo 8 - Contém as principais conclusões e recomendações para a realização de novos trabalhos. 


\section{ANÁLISE $\quad$ DE DEMANDA POR TRANSPORTE BASEADA EM ATIVIDADES}

\section{Capítulo}

\subsection{Definições e Características Principais}

A análise de demanda por transporte baseada em atividades fundamenta-se no fato de que os indivíduos tendem a organizar suas viagens em função, entre outras, das atividades a serem exercidas, do horário de início e término de cada atividade e das características dos modos disponíveis para ir do local de uma atividade para o local da atividade seguinte. Por isso, um princípio largamente aceito no Planejamento de Transporte é o de que a demanda de viagens é derivada da demanda por atividades. E este princípio vem fundamentando cada vez mais os estudos da demanda por transporte baseada em atividades.

Aceita-se que as decisões de viagens são dirigidas por um conjunto de atividades exercidas pelos indivíduos. Outro princípio importante é que cada conjunto de atividade pode gerar uma seqüência de deslocamentos que não devem ser analisados isoladamente pois as atividades que as pessoas realizam em um período de tempo, geralmente, estão ligadas umas às outras, no tempo e no espaço, através de viagem.

Com relação ao embasamento teórico a respeito da análise de demanda por transporte baseada em atividades é importante compreender, inicialmente, quatro idéias básicas que servem para explicar o comportamento dos viajantes. São elas: 
- A demanda por viagem é derivada da demanda por atividades (Jones, 1977);

- As restrições espaciais, temporais e interpessoais afetam a realização das atividades (Hägerstrand, 1970);

- O domicílio afeta as atividades do indivíduo e a sua decisão de viagem (Chapin, 1974; Jones et al., 1983);

- As decisões acerca das viagens e atividades são dinâmicas (Goodwin et al., 1990).

A análise de viagens baseada em atividades deve contemplar as restrições de espaço, tempo e interpessoais que afetam a realização das atividades, bem como as escolhas que as pessoas fazem entre viajar ou não para realizar suas atividades. Existem opções, tais como a internet ou o telefone, que permitem que as pessoas possam trabalhar, resolver problemas bancários, realizar negócios e compras etc., sem sair de casa.

A decisão de realizar atividades e, conseqüentemente, de viajar ou não depende do contexto familiar. Por exemplo, a participação do filho em um curso de idiomas, geralmente, é decidida pelo chefe da família. Ou seja, pode se afirmar que a decisão de um indivíduo em viajar ou não pode ser influenciada por outros membros da família.

Nota-se também que as decisões acerca das viagens e atividades são dinâmicas. Por exemplo, é normal que os indivíduos tomem decisões impulsivas como ir ao cinema ou visitar algum parente após o trabalho e isto caracteriza a realização de outras atividades e viagens antes não programadas. Portanto, é válido analisar o processo de escolhas de atividades e viagens de maneira dinâmica pois é comum haver mudanças significativas no seqüenciamento de deslocamentos dos indivíduos.

A estrutura mostrada na Figura 2.1, proposta por Bowman e Ben-Akiva (1997), serve para entender como um indivíduo organiza as decisões a respeito das atividades e 
viagens em um contexto que engloba desenvolvimento urbano, decisões individuais e desempenho do sistema de transporte.

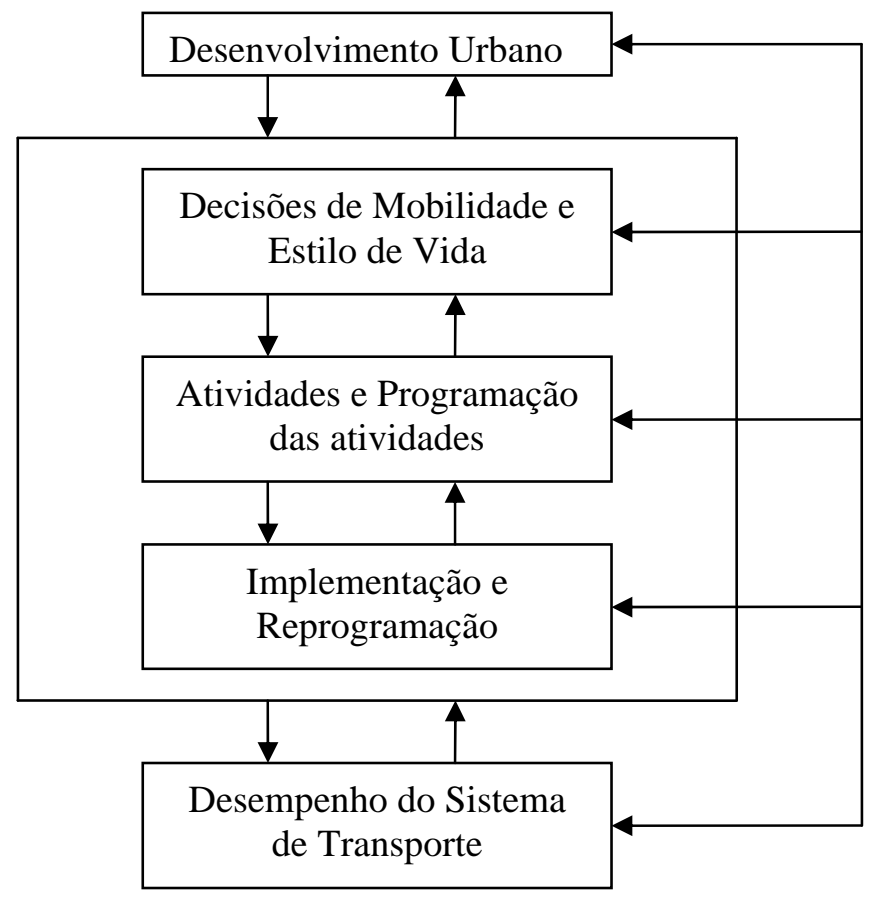

Figura 2.1: Estrutura de decisões de viagens e atividades - Baseada em Bowman e Ben-Akiva (1997)

O desenvolvimento urbano é conduzido pelos governantes que tomam decisões, entre outras, quanto às implementações de escolas públicas e melhorias de serviços de transporte público; pelos planejadores, que podem oferecer oportunidades para instalações de empresas e zonas residenciais; e pelos empresários, que determinam os locais de oportunidades de empregos. Pode-se dizer, então, que o desenvolvimento urbano influencia diretamente as decisões de viagens individuais e domiciliares (decisões sobre mobilidade e estilo de vida, atividades e programação das atividades, implementação e reprogramação).

As decisões relacionadas à mobilidade e estilo de vida como a localização da residência e do emprego e de possuir ou não automóvel, ocorrem em intervalos irregulares e não muito freqüentes, dentro de uma escala de anos. Já as decisões a respeito das atividades e programação das atividades ocorrem em intervalos 
regulares e mais freqüentes, numa escala de dias ou semanas, englobando um conjunto de atividades e suas prioridades, a alocação de atividades de cada membro da família, a seqüência de atividades e as respectivas localizações, horários e modos das viagens. A implementação e reprogramação das atividades ocorrem num curto intervalo de tempo, em um período do dia, em função da realização de atividades não programadas (Bowman e Ben-Akiva, 1997).

Tanto o desenvolvimento urbano quanto as decisões individuais e familiares afetam o desempenho do sistema de transporte que se manifesta através do volume de viagens, das velocidades, dos congestionamentos e dos impactos ambientais. O sistema de transporte alterado afeta, por sua vez, o desenvolvimento urbano e decisões individuais, formando um ciclo.

\subsection{Um Breve Histórico e Futuras Direções da Análise Baseada em Atividades}

A idéia de que viagem é uma demanda derivada das atividades tem sido aceita por planejadores e pesquisadores da área de transportes desde que foi inicialmente concebida por Oi e Schuldiner (1962) em seus trabalhos originais de demanda de viagens urbanas. A partir daí, a análise de demanda baseada em atividades vem recebendo atenção especial e os trabalhos realizados por Chapin (1971), Hägerstrand (1970) e Cullen e Godson (1975) são considerados como a base para muitas pesquisas na área da análise baseada em atividades.

Chapin (1971) desenvolveu a teoria de que os desejos do homem pela sobrevivência, por encontros sociais e pela satisfação pessoal interagem para revelar padrões de participação nas atividades.

Por outro lado, Hägerstrand (1970) enfatizou três limites impostos aos indivíduos que realizam atividades. Estes limites se referem a distribuição espacial e temporal de oportunidades para participação em atividades e são descritos da seguinte forma: “Limites de capacidade” - são limites biológicos relacionados a, por exemplo, necessidade de comer e dormir dos indivíduos; “Limites de dependência” - refletem 
que certas atividades, como reuniões por exemplo, requerem que as pessoas estejam presentes em um dado local num determinado horário; e "Limites de autoridade” são restrições previamente estabelecidas como horários de abertura de Shopping Centers e horários de entrada e saída dos trabalhos. Estas considerações espaciais e temporais determinam, segundo Hägerstrand (1970), o prisma “espaço-tempo", dentro do qual os indivíduos agem.

Já Cullen e Godson (1975) argumentaram que os limites espaciais e temporais identificados por Hägerstrand são fundamentalmente caracterizados por uma variabilidade de graus de rigidez (ou flexibilidade). Ambos realizaram extensa análise empírica para indicar que limites temporais são mais rígidos do que os limites espaciais e que a rigidez temporal está bastante relacionada com o tipo de participação em atividades. Verificou-se, por exemplo, que as atividades relacionadas com o motivo trabalho são mais rígidas quanto aos horários do que as atividades de lazer.

Diversos temas têm sido estudados na área de análise de atividades e Pas (1985) alinhavou tais temas da seguinte forma:

- Análise de demanda para participação em atividades (e análise de viagem como demanda derivada);

- Programação de atividades no tempo e no espaço;

- As restrições espaço-temporais e interpessoais de atividades e escolha de viagens;

- As interações entre atividades e escolhas referentes as viagens ao longo do dia ou outro período e interações entre indivíduos;

- A estrutura familiar e o papel dos membros da família na escolha de viagens;

- Uso do tempo e sua relação com modelagem de demanda de viagem (Pas e Harvey, 1991).

Os modelos baseados em atividades descrevem quais as atividades realizadas pelas pessoas, a influência das suas localizações, quando e por quanto tempo tais atividades são desempenhadas, os modos de transporte envolvidos e a forma como as 
pessoas organizam seus deslocamentos, dadas as localizações geográficas, características da rede de transportes, aspectos institucionais e características pessoais e familiares.

Diversos modelos surgiram ao longo dos anos e Arentze e Timmermans (1997) destacaram três grupos principais: os modelos baseados na Teoria da Utilidade ("Utility-based Models”), a abordagem baseada em restrições ("Constraints-based approach”) e a abordagem baseada em regras ("Rule-based approach”).

Os modelos baseados na Teoria da Utilidade estão, entre todos os mencionados acima, mais relacionados com os modelos de demanda de viagem convencionais. Um progresso substancial é que a “unidade básica de análise” são os padrões de viagens/atividades diários, ao invés de viagens isoladas. O modelo mais geral deste tipo é o STARCHILD (Recker et al., 1986a e 1986b). Neste modelo, a participação nas atividades é formulada como um processo individual de escolha sujeita ao resultado de geração e alocação de atividades em uma estrutura temporal definida. Depois de vários passos de pré-processamento, a última escolha é formulada como um problema de maximização da utilidade de um padrão diário de atividades. Um recente modelo desta abordagem é o “The Portland Model”, proposto por Bowman e Ben-Akiva (2000), inicialmente aplicado em Boston, Estados Unidos, que possui estrutura teórica baseada na maximização da utilidade, através do modelo logit aninhado.

A abordagem baseada em restrições aponta principalmente a identificação de flexíveis programações de atividades, levando em conta as restrições de espaçotempo e institucionais. A entrada para estes modelos são os "programas de atividades”, que descrevem uma gama de atividades, com uma certa duração, que são executadas em períodos particulares. Tais programas de atividades são derivados de padrões de atividades observados. A restrição espaço-tempo é definida em função da localização, atributos, modos de transportes e tempo de viagem entre a origem e a localização da atividade considerando o modo de transporte utilizado. Para examinar a viabilidade de um programa de atividade, um algoritmo combinatório é usado para 
gerar todas as possíveis seqüências de atividades. A viabilidade de cada sucessão é testada da seguinte forma:

- O intervalo entre o início da atividade anterior e o começo da próxima é suficiente para executar a atividade anterior e cobrir o tempo de viagem associado;

- Não são violadas as condições de seqüência de atividades.

O modelo PCATS (do inglês, Prism-Constrained Activity-Travel Simulator), proposto por Kitamura e Fujii (1996), é um exemplo da abordagem baseada em restrições. Neste modelo, o dia (ou qualquer outra unidade de tempo) é dividido em dois tipos de período: os períodos ditos “abertos”, onde os indivíduos possuem a opção de viajar e se engajar em atividades flexíveis; e os períodos ditos “bloqueados”, que representam períodos do dia em que os indivíduos, obrigatoriamente, estão encarregados de realizar atividades fixas. Ressalta-se que as atividades flexíveis podem ser realizadas entre os intervalos das atividades fixas. Utilizando os conceitos de Hägerstrand, do prisma espaço-tempo de atividades, o modelo tenta preencher os períodos abertos. A velocidade de viagem, localizações e horários das atividades fixas definem os prismas.

A terceira abordagem caracteriza-se por um conjunto de regras que se referem a prioridade de atividades, a proximidade espacial das atividades e o tempo de espera previsto pela programação. O resultado é uma seqüência de atividades executada em localizações especificas e a rota seguida entre estas localizações. O AMOS (do inglês, Activity-Mobility Simulator), proposto por Pendyala et al. (1997), é um exemplo desta abordagem e funciona da seguinte forma: (1) Inicia-se com um padrão de atividades de um individuo; (2) Um padrão modificado é gerado como adaptação a alguma mudança ou a condições externas; (3) Depois há uma avaliação, baseada em regras, para concluir se o padrão é adequado ou não. Se o padrão não for aceito, o processo continua até que outro padrão aceitável seja encontrado. 
Outro modelo é o ALBATROSS (do inglês, A Learning Based Transportation Oriented Simulation System) desenvolvido por Arentze e Timmermans (2000), que também possui a idéia básica do modelo AMOS, ou seja, é uma ferramenta capaz de avaliar conseqüências de mudanças externas.

A análise de viagens baseada em atividades aplicada ao estudo de previsão da demanda por transportes é um caminho relativamente novo na busca de modelos que, embora mais complexos, tentam representar de maneira realista a forma como os indivíduos programam suas atividades e, conseqüentemente, os seus itinerários de viagem.

Bhat e Koppelman (2000) levantaram as linhas de pesquisas futuras na análise de atividades e nota-se o desejo contínuo de compreender o fenômeno "viagens urbanas” através do comportamento de viagem e necessidades humanas. As linhas de pesquisas são:

- Interações entre indivíduos e sua influência na participação de atividades: segundo os autores, as interações entre indivíduos de uma mesma família e o efeito de tais interações no comportamento individual de realização de atividades ainda é uma área que tem recebido atenção limitada na literatura de análise de atividades. Estas interações podem ajudar a definir quem e de que forma certas atividades seriam realizadas e pode, inclusive, conduzir “limites” aos modelos baseados em atividades;

- Interações espaço-tempo na análise de atividades: é outra área que necessita de atenção substancial pois a maioria dos estudos encontrados na literatura consideram isoladamente os aspectos temporais e espaciais (Bhat e Koppelman, 2000). Thill e Thomas (1987) apud Bhat e Koppelman (2000) escreveram o seguinte: “Apesar de vários dispositivos que auxiliam na descoberta de ligações entre decisões, nenhum dispositivo parece ser apropriado em restaurar a simultaneidade de aspectos envolvidos nas escolhas pretendidas...é necessário conceber uma estrutura que combine 
juntamente aspectos temporais e espaciais na escolha de viagens e que considere o comportamento de múltiplos propósitos e, portanto, de múltiplas paradas como uma unidade multidimensional”. Verifica-se que até hoje esta declaração é válida;

- Substituição das atividades anteriormente realizadas "fora" do domicilio: atividades realizadas “dentro” ou "fora” do domicilio possuem implicações totalmente diferentes para a demanda por viagens pois uma atividade em casa não envolve viagem, enquanto que uma atividade a ser realizada fora de casa requer viagem. Por isso, diz-se que a decisão de participação de atividades dentro ou fora do domicilio tem um impacto importante na geração de viagens. Entender esta substituição é importante, particularmente agora quando oportunidades de entretenimento e serviços em casa estão aumentando devido à facilidade de acesso aos computadores, qualidade de áudio e vídeo avançada, quase uma infinidade de filmes que podem ser vistos em casa, sistema de entrega a domicílio, pagamentos via internet etc.;

- A unidade de análise: a unidade típica de modelos de viagens baseados nas atividades é o dia da semana. Esta suposição implica em uma pequena variação nos padrões de viagens e atividades entre os diferentes dias da semana, além de não permitir a interação com os dias de final de semana (Bhat e Koppelman, 2000). Sugere-se então, uma investigação mais apurada em relação a esta unidade, implicando inclusive, no desenvolvimento de técnica de coleta de dados que permita que seja coletado um “diário”, sem um custo elevado, de pelo menos uma semana das atividades e viagens realizadas pelos indivíduos;

- O mecanismo de decisão: verifica-se que não há na literatura existente um bom entendimento quanto ao mecanismo de decisão definido para revelar os padrões de viagens e atividades dos indivíduos. Estas dúvidas são pertinentes e, com certeza, deverão ser objetivos de pesquisas futuras. 
A comparação, sob enfoque da análise de atividades, entre o comportamento dos usuários de transporte residentes em locais diferentes também é outra linha de pesquisa pouco explorada. Tal comparação pode permitir tirar conclusões que transcendem a análise isolada dos dados de uma única área urbana como, por exemplo, os efeitos das dimensões das regiões ou das diferenças culturais.

\subsection{Encadeamento de Viagens}

As viagens realizadas no dia-a-dia pelos indivíduos são agrupadas de acordo com itinerários e horários de viagens mais convenientes individualmente e a necessidade de realizar determinadas atividades. Como resultado da decisão de cada indivíduo acerca da combinação mais adequada entre atividades e viagens, forma-se uma seqüência de viagens denominada encadeamento de viagens.

A identificação da correlação existente entre os atributos destas viagens (modos de transporte utilizados, duração e período do dia, por exemplo) e as atividades desenvolvidas estabelecem o foco principal do encadeamento de viagens. O entendimento deste encadeamento constitui então, uma forma para analisar as séries de viagens realizadas pelas pessoas ao longo do dia, ajudando a esclarecer possíveis razões para escolhas modais e de períodos do dia para realização das viagens.

Salienta-se que a análise baseada nas atividades engloba o estudo das viagens encadeadas, visto que estas viagens são derivadas e estão diretamente relacionadas com uma organização espacial e temporal de um conjunto de atividades.

Para Bhat e Koppelman (1991), viagens encadeadas podem ser definidas como uma apropriada seqüência de viagens, realizadas com o objetivo de desempenhar diversas atividades, relacionadas a um programa de atividades de cada indivíduo. Golob (1999) define viagens encadeadas como sendo maneiras que as pessoas encontram de realizar várias atividades no período de um dia, organizando suas viagens. Já Ichikawa et al. (2002) definiram as viagens encadeadas como a união seqüenciada de viagens realizadas em determinado período. 
A Figura 2.2 representa exemplos encadeamento de viagens realizados por indivíduos. Os números romanos indicam a seqüência de realização das viagens.

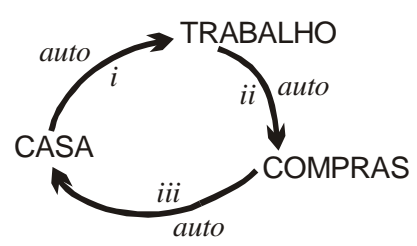

Exemplo 1

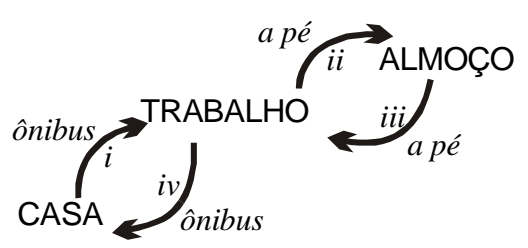

Exemplo 2

Figura 2.2: Exemplos de encadeamento de viagens - Exemplo adaptado de Ichikawa et al. (2002)

Embora ainda não exista uma definição formal de viagens encadeadas, pois o assunto está sujeito a uma série de abordagens e conceitos variados, diferentes termos existem a respeito de quais tipos de viagens podem ser considerados como parte de uma cadeia ou ciclo. Por exemplo, os padrões de viagem acima podem ser considerados como viagens isoladas (três viagens e quatro viagens nos exemplos 1 e 2, respectivamente) ou como viagens encadeadas, com início e término na residência.

Bowman (1998) denominou as viagens isoladas de "trip", que significa a viagem com origem e destino final distintos (ex: casa - trabalho), e de "tour” a seqüência de vários segmentos de viagens (“trips”), onde o ponto inicial da primeira viagem corresponde ao ponto final da última viagem (ex: casa - trabalho - casa).

Strathman e Dueker (1995) definiram que as viagens encadeadas podem ser do tipo “journey” simples, que significa viagem de casa a um dado destino e o seu retorno à residência, ou do tipo “journey” complexo, que envolve uma seqüência de mais de duas viagens que começa e termina em casa.

Estudos do “The Natiowide Personal Transportation Survey” (NTPS, 1990), revelam que as pessoas geralmente agrupam viagens relacionadas a atividades diversas 
(banco, compras, médico) e viagens relacionadas ao trabalho, resultando em uma rede de viagens pessoais com motivos diversos ancoradas a viagens principais (trabalho, escola e obrigações, por exemplo).

Kumar e Levinson (1995) analisaram o encadeamento de viagens na cidade de Montgomery, Estados Unidos, e concluíram que os indivíduos que residem mais próximos do centro realizam menos viagens, por motivos diversos, ancoradas a viagens principais, do que os indivíduos que residem em áreas periféricas. Verificaram também que atividades como compras, negócios pessoais e atividades sociais são mais comumente unidas às viagens com motivo trabalho.

A caracterização espacial da cidade pode ser então considerada como um fator importante aos padrões de viagens realizados visto que, segundo Kumar e Levinson (1995), cidades com zonas residenciais relativamente próximas ao centro tendem a gerar viagens encadeadas mais simples (“journey” simples) do que cidades com áreas habitacionais afastadas. A comparação de resultados, obtidos de diferentes conjuntos de dados, pode ajudar a compreender o quão esta variável afeta as pessoas ao realizarem viagens encadeadas.

Gomide (2003) analisou as características de deslocamentos de pessoas pobres na Região Metropolitana de São Paulo e afirmou que tais deslocamentos dependem muito da estrutura de ocupação de cada localidade. Segundo o autor, o padrão de ocupação do solo urbano e da localização espacial dos mais pobres pode variar de lugar para lugar, gerando padrões de viagens bastante diferentes. Citou-se, por exemplo, que a RMSP, onde as favelas estão concentradas nas periferias, apresenta maiores distâncias e tempos de deslocamentos para os pobres do que em outras capitais no Brasil como o Rio de Janeiro e Recife, onde as favelas se concentram nas áreas centrais.

Poucas pesquisas foram encontradas a respeito do encadeamento de viagens de indivíduos residentes em locais diferentes. A seguir, descrevem-se sucintamente estas pesquisas. 


\subsection{Estudos Comparativos de Regiões Distintas sob a Ótica da Análise de Atividades}

Bhat e Singh (2000) dividiram o dia em períodos e analisaram os aspectos espacial e temporal de mobilidade dos trabalhadores residentes em duas regiões metropolitanas dos Estados Unidos. Foram analisados os números de "tours” por dia, números de paradas por "tour”, motivos dos "tours” e paradas, a interação entre as paradas e modos de transportes escolhidos. Apesar de não ser um objetivo do trabalho, pode-se notar que os resultados apresentados entre as duas regiões tiveram mais semelhanças do que diferenças, talvez devido às características espaciais e culturais das áreas serem parecidas.

Cirillo e Axhausen (2002), utilizando a mesma metodologia proposta por Bhat e Singh (2000), levantaram a idéia de transferibilidade dos modelos de viagens baseados em atividades entre países. Os autores compararam dados de pesquisas belgas e alemãs e acrescentaram a distância entre paradas e a duração das atividades aos aspectos ligados à mobilidade. Segundo a análise dos autores, os resultados apresentaram-se coerentes entre belgas e alemães, variando em alguns casos em função de diferenças culturais e das políticas de transportes adotadas nos países.

Jou e Mahmassani (1997) realizaram uma investigação das paradas feitas nos caminhos “casa-trabalho” e "trabalho-casa” observados no início e final do dia, respectivamente, em duas cidades dos Estados Unidos, Dallas e Austin. A investigação identificou as seguintes variáveis: freqüência, motivo, duração, características espaciais e variação dia-a-dia destas paradas. Os resultados indicaram que o encadeamento de viagens é mesmo uma característica intrínseca dos indivíduos. Os autores também levantaram a hipótese de transferibilidade de modelos baseados em atividades. A pesquisa utilizou o teste estatístico qui-quadrado, que revelou que as variáveis possuem mais semelhanças do que diferenças nas duas cidades e que tais diferenças podem ser explicadas, por exemplo, por uma maior oportunidade de negócios em Dallas do que em Austin ou tamanhos e características espaciais distintos. 
Kasturirangan e Pendyala (2001) realizaram uma análise comparativa detalhada da programação e seqüência de atividades feitas por trabalhadores residentes em duas áreas norte-americanas: Miami e San Francisco Bay. As comparações entre as áreas mostraram que, durante o período de trabalho, as atividades empreendidas são bastante parecidas pois os indivíduos são limitados pela pouca flexibilidade de horários. Algumas diferenças são notadas antes do período do trabalho e, principalmente, depois do período de trabalho. Verifica-se que os trabalhadores de Miami estão mais propensos em empreender atividades enquanto estão no caminho “trabalho-casa” do que após retornarem às suas residências. Isto é atribuído, segundo os autores, às diferenças notadas em relação à renda, estrutura domiciliar e modos de transportes entre as duas áreas. Por exemplo, Miami apresenta grande uso do automóvel por parte da população, facilitando o encadeamento de viagens para realizar outras atividades logo após o trabalho.

Nota-se que o estudo comparativo de áreas diferentes faz com que os pesquisadores busquem outras variáveis que justifiquem o comportamento dos indivíduos em relação aos padrões de viagens escolhidos. O entendimento das diferenças culturais e de características espaciais das regiões, e seus respectivos impactos na demanda apresentam-se como desafio para os pesquisadores da área de análise de atividades.

A principal justificativa para a realização de estudos que comparam conjuntos de dados coletados em regiões diferentes, levantada pelos autores Jou e Mahmassani (1997) e Cirillo e Axhausen (2002) em seus trabalhos, foi propor um passo inicial à possibilidade de transferência espacial de modelos de demanda por transporte. Cabe aqui salientar que esta possibilidade não se concretizou em modelos de viagens baseados em atividades, o que estimula mais estudos com a finalidade, mesmo que indiretamente, de conceber modelos de demanda de transporte transferíveis.

Atualmente, grande parte dos pesquisadores tenta compreender como a influência das características dos deslocamentos das pessoas são influenciadas pelas características socioeconômicas, localizações das atividades e do sistema de 
transporte. Nota-se também a existência de poucos modelos que capturam as relações entre características socioeconômicas, participação em atividades e comportamento referente às viagens encadeadas.

\subsection{Breve Descrição de Variáveis que Influem no Encadeamento de Viagens}

Pitombo (2003) mostra que a escolha do padrão de viagem está fortemente relacionada ao status social, tradicionais divisões de papéis sociais e familiares e estágio no ciclo da vida.

\subsubsection{Status social}

Hanson e Hanson (1981) consideram o tipo de ocupação do indivíduo, assim como o seu grau de instrução, renda e posse de automóveis, as variáveis padrões que caracterizam o status socioeconômico.

Provavelmente tais variáveis afetam diretamente o comportamento referente às viagens, particularmente em relação a escolhas modais, freqüência e distância de viagem.

Kitamura et al. (1981) verificaram a relação entre cadeias de viagens e número de automóveis e observaram que as viagens encadeadas crescem com o número de automóveis disponíveis.

O tipo de ocupação do indivíduo claramente afeta o número de viagens com motivo trabalho e também influencia a quantidade de tempo disponível para atividades relacionadas a outros motivos. Estudos comparativos de padrões de viagens realizados por pessoas que trabalham em tempo integral, meio expediente e donasde-casa mostraram freqüência de viagens mais reduzidas nas duas últimas categorias de indivíduos, assim como maior número proporcional de viagens não relacionadas ao trabalho (Hanson, 1977). 


\subsubsection{Papéis sociais e familiares}

As necessidades individuais ou sociais definem as tarefas a serem desempenhadas pelas pessoas com a finalidade de cumprir seu papel social. Allaman et al. (1982) agrupam as funções em quatro classes principais: familiar, trabalho, interpessoal e lazer.

Percebe-se que o papel do indivíduo na família e na sociedade não está definido apenas pela sua participação no mercado de trabalho, mas também está relacionado ao sexo, estado civil, situação familiar, etc.

De acordo com o observado por Mcgukin e Murakami (1999), as mulheres, em sua maioria, realizam mais viagens ligadas às atividades relacionadas à família, tais como compras ou outras atividades como levar os filhos à escola. Observaram também a participação da mulher na força de trabalho, mas que os padrões de viagens ao trabalho das mulheres são diferentes em relação aos dos homens, variando com a situação familiar e a idade dos integrantes do domicílio.

Mulheres classificadas como não cônjuges e não chefes efetuam um maior número de viagens diárias. Provavelmente por exercerem atividades de trabalho com maior regularidade e também por não serem diretamente responsáveis pelas tarefas de manutenção do domicílio ou atendimento a possíveis crianças existentes. Já as mulheres classificadas como cônjuges ou chefes, com a presença de crianças, apresentam uma diminuição na taxa de viagens com motivo trabalho (Strambi e Van de Bilt, 1998).

Fox (1983) mostrou que as diferenças entre os padrões de viagens das mulheres que trabalham quando comparadas aos dos homens podem estar relacionadas à presença de crianças na família.

De acordo com o último Censo, de 1991 a 2000 triplicou a proporção de mulheres responsáveis pelos domicílios. Em São Paulo, por exemplo, as mulheres chefiam 
24\% das famílias, conforme informações da Fundação Estadual de Análise de Dados de São Paulo (SEADE). Por conciliar o trabalho com outras atividades, como tomar conta das crianças (levá-las e buscá-las em creche ou escola), as mulheres quando comparadas com os homens chefes-de-família, possuem padrões de viagens diferentes.

Observou-se que (1) os domicílios influenciam as decisões sobre atividades, (2) os efeitos diferem por tipo de domicílio, tamanho, relacionamento entre os membros, idade e gênero e (3) as crianças, em particular, impõem de forma significativa a realização de mais viagens (escola, médico, por exemplo) e ao mesmo tempo limitam a realização de viagens de outros membros do domicílio (Ichikawa, 2002).

\subsubsection{Estágio no ciclo de vida}

De acordo com Tandel (1997), indicadores referentes ao ciclo de vida familiar auxiliam na identificação do potencial de participação das famílias na sociedade e, conseqüentemente, de viajar ou não para exercer atividades. Tais indicadores estão intimamente ligados à idade e ao papel do indivíduo dentro da estrutura familiar.

O ciclo de vida das pessoas é constituído por diversos estágios e que, ao longo dos anos, sofre mudanças marcantes que geram impactos no comportamento referentes às viagens. Van de Bilt (2002) apontou importantes mudanças no contexto familiar que afetam elementos referentes às viagens:

- Nascimento de crianças;

- Chegada das crianças à idade escolar;

- Saída do jovem da casa dos pais;

- Adultos atingindo idade para aposentadoria.

Tais variáveis podem ser úteis em diversas aplicações, principalmente em programas de gerenciamento de demanda de viagens. As características individuais, como sexo e ocupação, usadas juntamente com características familares como, por exemplo, 
renda e número de crianças na família, podem ser fundamentais para a efetiva compreensão de futuras demandas de viagens.

Deve-se atentar, no entanto, às mudanças sociais, econômicas e demográficas que acontecem ao longo dos anos, mostrando tendências de desenvolvimento populacional e conseqüentes transformações comportamentais, inclusive relacionadas às características de viagens. A comparação de conjuntos de dados, obtidos em épocas diferentes, pode ajudar na compreensão das mudanças ocorridas e a de prever tendências futuras nos padrões de viagem.

No Brasil por exemplo, um país de dimensões continentais, nota-se que o desenvolvimento regional tem variado consideravelmente ao longo dos anos e de estado para estado. Conseqüentemente, os padrões de viagens podem diferir significamente de um lugar para outro. A compreensão do comportamento de viajantes urbanos através da comparação de resultados pode ajudar a determinar a influência das variáveis socioeconômicas, espaciais e de sistemas de transportes na demanda de viagens e auxiliar os órgãos competentes na adoção de políticas de transportes regionais mais eficazes. 


\section{DESCRIÇÃO DO MÉTODO}

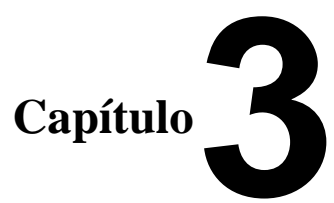

Uma das etapas essenciais na pesquisa é a definição do método a ser adotado para se atingir os objetivos estabelecidos. No caso deste trabalho, a técnica estatística a ser empregada estava decidida. Ela seria a Árvore de Decisão e Classificação visto que dois trabalhos que precederam a este, no Departamento de Transportes da EESCUSP, haviam-na aplicado e verificado a sua utilidade para o tipo de trabalho ora desenvolvido.

O ponto que causava dúvida era a forma como os resultados da aplicação da técnica seriam utilizados para se afirmar que determinados grupos de indivíduos se comportam de maneira semelhantes ou diferentes.

A primeira tentativa foi a de obter os parâmetros de classificação a partir dos dados de uma única área urbana e aplicá-los aos dados das outras duas áreas. E, através de testes estatísticos como qui-quadrado $\left(X^{2}\right)$ ou Kolmogorov-Smirnov, seriam estabelecidos critérios para julgar sobre semelhanças ou diferenças encontradas. $\mathrm{O}$ problema é que esse método requer um grande volume de trabalho pois seis testes (no caso, dois para cada conjunto de parâmetros) deveriam ser realizados, o que demandaria muito tempo para a sua conclusão e posterior análise.

Decidiu-se então adotar outro procedimento que consiste em incluir os dados de todas as três áreas urbanas em um único arquivo e aplicar a técnica de Árvore de 
Decisão e Classificação ao conjunto de dados cujos casos estão individualmente identificados com a área urbana de origem.

Portanto, antes de iniciar as discussões acerca da estrutura do método utilizado para comparação do comportamento referente às viagens encadeadas das três áreas urbanas em análise, é importante destacar algumas considerações sobre a técnica de mineração de dados utilizada neste trabalho.

\section{1. Árvores de Decisão e Classificação: Definições e Propriedades Gerais}

A técnica de mineração de dados utilizada neste trabalho é a de Árvore de Decisão e Classificação, considerada uma forma simples de representação de relações existentes em um conjunto de dados. Possui este nome porque a sua estrutura, de fácil entendimento e assimilação, se assemelha a uma árvore. Os dados são divididos em subgrupos, com base nos valores das variáveis. O resultado é uma hierarquia de declaração do tipo “Se...então...” que são utilizadas, principalmente, para classificar dados.

Quinlan (1983), considerado por muitos na indústria de mineração de dados como o “pai das árvores de decisão”, afirmou que essa técnica busca uma ou mais relações existentes em um conjunto de dados, classificando uma base de dados em um número finito de classes através de regras hierárquicas, organizando os dados de maneira compacta e fornecendo uma visão real da natureza da relação.

As relações entre os padrões de viagens encadeadas e as variáveis socioeconômicas dos habitantes das áreas urbanas serão obtidas através da Árvore de Decisão e Classificação contida no pacote estatístico S-Plus 6.1. A principal razão pela opção do S-Plus 6.1 é o fato de que a escolha entre diferentes padrões de encadeamento de viagens é representada em termos probabilísticos.

A variável resposta, ou dependente, é aquela característica que se deseja prever ou classificar pela árvore de acordo com as variáveis preditoras, ou independentes, que 
estão potencialmente relacionadas à primeira. Neste trabalho, as variáveis resposta correspondem aos padrões de viagens encadeadas e as variáveis preditoras dizem respeito às características socioeconômicas dos indivíduos presentes nas três áreas urbanas.

O algoritmo embutido na árvore de decisão e classificação do S-Plus 6.1, variante do algoritmo CART, estabelece uma relação entre variáveis preditoras e variáveis resposta. As variáveis preditoras, mais importantes para segregação dos dados, e as variáveis resposta, são representadas por uma estrutura de árvore binária, onde cada nó corresponde a uma divisão. A Figura 3.1 mostra um exemplo hipotético das principais características de uma árvore de decisão para um dado problema (2 valores de variável resposta e 5 para variáveis preditoras).

Ressalta-se que tanto as variáveis resposta quanto as preditoras podem assumir valores contínuos ou categóricos. Se a variável for contínua, o modelo é conhecido como árvore de regressão e o modelo assume uma distribuição normal (gaussiana), caso seja categórica, o modelo é denominado árvore de classificação e segue uma distribuição multinomial. 


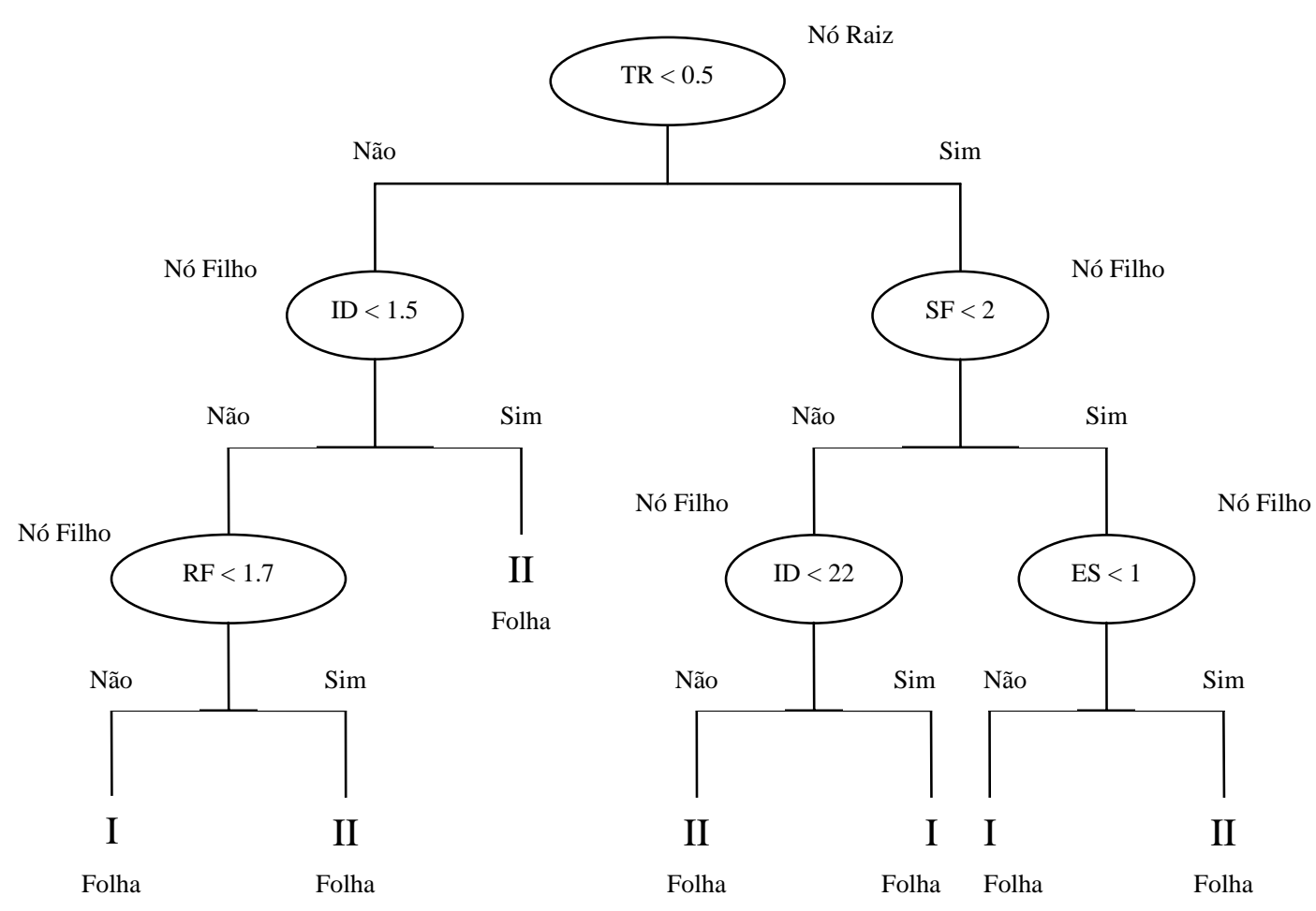

Figura 3.1: Exemplo hipotético das principais características da Árvore de Decisão para um problema com dois valores de variável resposta (I e II) e cinco preditoras (TR, ID, SF, ES e RF).

A função contida no S-Plus permite analisar até 128 valores de variáveis resposta categóricas e 32 para variáveis preditoras, pois se há K níveis de variáveis preditoras, então ocorrerão “ $2^{(k-1)}-1$ ” divisões, que serão examinadas, impondo alta demanda de processamento computacional.

Para o término das divisões, o S-Plus utiliza dois critérios:

A. Se a homogeneidade é menor que um dado índice;

B. O número de observações no nó é menor do que um valor mínimo absoluto.

Neste trabalho foram adotados para o caso A, “0,02” (denominado desvio mínimo) e para o caso B, 20 observações (número mínimo de observações por nó terminal). 
O S-Plus trata a árvore como modelo de probabilidade, empregando o desvio como critério de divisão. Nas árvores de classificação, a heterogeneidade de cada nó é medida pelo desvio global (D):

$$
D=-2 \sum_{t} \sum_{j \in t} n(j \mid t) \log P(j \mid t)
$$

Em que: n(j|t) é o número de casos no nó t com a resposta categórica j;

$\mathrm{P}(\mathrm{j} \mid \mathrm{t})$ denota a proporção dos casos na categoria j do nó t.

Isto significa que na árvore do S-Plus 6.1 o desvio foi definido como recíproco da função verossimilhança elevada ao quadrado. Portanto, o desvio significa uma medida da heterogeneidade dos grupos resultantes.

O S-Plus gera resultados de forma gráfica (Árvore de Decisão e Classificação) e tabular (relatório). Tal relatório apresenta detalhadamente os resultados da árvore: número do nó, total de observações no nó, desvio, padrão predominante e as probabilidades de ocorrência de todos os padrões da análise.

Como já dito anteriormente, um dos principais motivos que levaram à escolha da árvore de classificação é a sua capacidade de representar a natureza probabilística do objeto analisado, que no caso representa os padrões de viagens encadeadas. Ela é um modelo que reconhece que “indivíduos homogêneos" podem tomar diferentes decisões, e associa a probabilidade às diferentes respostas possíveis. 


\subsection{Estrutura do Método}

Esta seção apresenta todas as fases adotadas para comparação do comportamento referente às viagens encadeadas de indivíduos residentes nas regiões metropolitanas de São Paulo e Belém e da cidade de Bauru. A Figura 3.2 mostra a estrutura do método e as fases que o constituem.

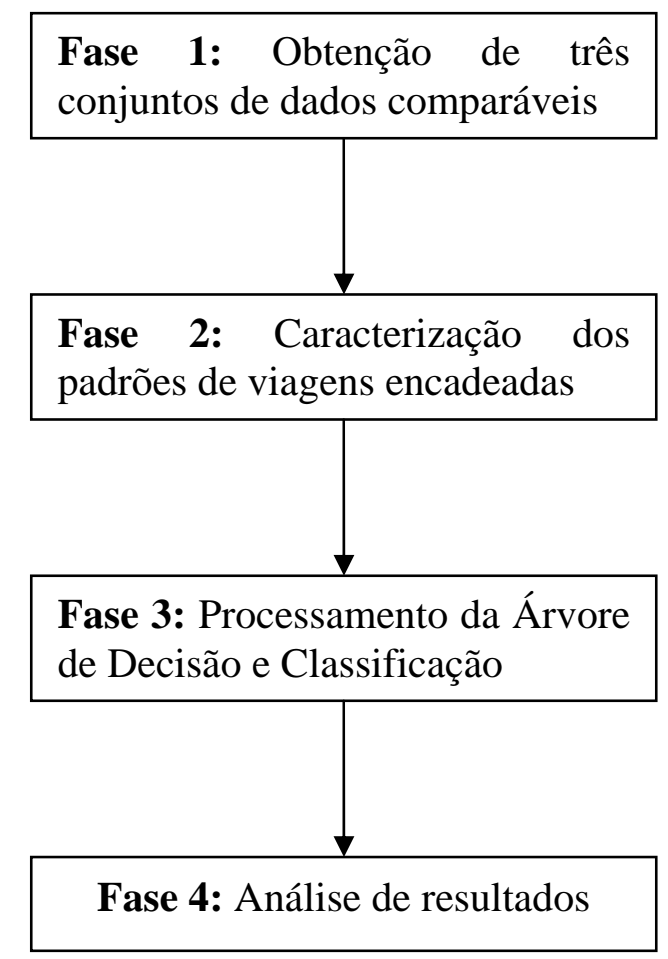

Figura 3.2: Estrutura do método proposto.

\subsubsection{Fase 1: Obtenção de três conjuntos de dados comparáveis}

As pesquisas domiciliares utilizadas no referido trabalho foram desenvolvidas por órgãos diferentes presentes nas três áreas urbanas. Logo, é de se esperar que o público-alvo das pesquisas e que determinadas variáveis socioeconômicas dos entrevistados fossem catalogadas de formas diferentes entre os órgãos responsáveis pelas pesquisas nas três áreas.

Portanto, esta fase tem como objetivo obter três conjuntos de dados comparáveis através da compatibilização do público-alvo das pesquisas e das variáveis 
socioeconômicas de interesse presentes nos três bancos de dados das áreas em análise. Como já dito anteriormente, tais variáveis socioeconômicas correspondem às variáveis preditoras necessárias para o processamento da árvore de decisão contida no S-Plus 6.1. Para almejar o objetivo, serão investigadas junto aos órgãos responsáveis pelas pesquisas as diferentes formas de coleta de dados.

Nesta fase será aplicado um procedimento de filtragem e tratamento dos dados nas três amostras com o intuito de uniformizar o público-alvo das pesquisas e de eliminar:

a) Dados inconsistentes ou incompletos;

b) Indivíduos que realizam uma ou mais de quatro viagens e que não tiveram a primeira e a última viagem do dia como motivo a residência.

Ressalta-se que o último objetivo do procedimento de filtragem e tratamento dos dados nas três amostras se deve ao fato de o S-Plus 6.1 permitir analisar até 128 variáveis resposta, ou seja, até 128 padrões de viagens encadeadas.

\subsubsection{Fase 2: Caracterização dos padrões de viagens encadeadas}

Esta fase tem como objetivo caracterizar os padrões de viagens das três áreas urbanas em função do motivo, modo e período do dia em que a viagem foi realizada. Salienta-se que tal caracterização foi inicialmente proposta por Ichikawa (2002) e ampliada por Pitombo (2003).

Provavelmente, as características de viagens referentes aos motivos e aos modos de viagem foram catalogadas diferentemente nos três bancos de dados, e a compatibilização destas variáveis dar-se-á em função da proposta de caracterização dos padrões de viagens encadeadas. Ressalta-se que tal proposta é bastante abrangente uma vez que engloba diversos motivos em um só. 
Por fim, após a compatibilização do público-alvo das pesquisas e de todas as variáveis socioeconômicas e de características de viagens, as três bases de dados serão agrupadas em um só banco de dados para que, então, sejam selecionados os 128 padrões de viagens encadeadas mais freqüentes. Como já dito, o S-Plus 6.1 pode analisar até 128 padrões de viagens encadeadas.

\subsubsection{Fase 3: Processamento da Árvore de Decisão e Classificação}

Inicialmente, nesta fase será criada uma variável preditora denominada “área urbana” com a função de identificar a área urbana no banco de dados que engloba todas as três regiões em análise. Tal variável é de grande valia pois a partir dela é possível identificar se e como as áreas urbanas interferem no comportamento do viajante.

Após a compatibilização do público-alvo das pesquisas, das variáveis preditoras de interesse (variáveis socioeconômicas), da caracterização e seleção dos 128 padrões de viagens encadeadas (variáveis resposta) e da criação da variável preditora "área urbana”, a árvore então será processada com valores dos critérios de desvio mínimo e de número mínimo de observações estabelecidos pelo autor. Salienta-se que quanto menor o desvio, maior o número de classes de indivíduos formados e, conseqüentemente, mais detalhada e complexa se torna a classificação.

O S-plus gera resultados na forma gráfica (Árvore de Decisão e Classificação) e tabular (relatório). Estes resultados serão trabalhados com intuito de torná-los melhor perceptíveis à análise de resultados.

\subsubsection{Fase 4: Análise de resultados}

Nesta fase serão identificados os principais grupos socioeconômicos formados a partir das variáveis resposta e preditoras estabelecidas para a análise e dadas as condições de desvio mínimo e número mínimo de observações por nó terminal adotadas. 
Presume-se que a variável “área urbana” irá distinguir os grupos socioeconômicos intrínsecos de cada região, bem como os grupos similares dentre as amostras das regiões que se comportam homogeneamente em relação aos padrões de viagens.

Analisar-se-á então as similaridades e diferenças encontradas em relação ao encadeamento de viagens dentre os principais grupos socioeconômicos formados pelas três áreas urbanas para que se possa ter melhor compreensão do comportamento de viajantes urbanos.

A busca de informações a respeito dos aspectos relacionados às políticas regionais, diferenças socioeconômicas e de características espaciais das respectivas áreas urbanas ajudarão a análise dos resultados obtidos. 


\section{$\mathscr{D A D O S}$}

\section{caprinut 4}

O presente estudo baseia-se nos dados referentes à Pesquisa Origem-Destino (O/D) da RMSP, realizada em 1997, pela Companhia do Metropolitano de São Paulo (METRÔ-SP), à Pesquisa Domiciliar, realizada em 2000, pela JICA (Agência de Cooperação Internacional do Japão) e Governo do Estado do Pará na RMB e à Pesquisa O/D, realizada em 1997, pela Empresa Municipal de Desenvolvimento Urbano e Rural de Bauru (EMDURB). Todas as pesquisas foram feitas por meio de entrevista domiciliar e obtiveram informações detalhadas acerca das características socioeconômicas e dos deslocamentos da população no dia anterior ao da entrevista.

\subsection{A Pesquisa Origem-Destino na RMSP}

A pesquisa Origem-Destino na RMSP foi realizada entre agosto e novembro de 1997. Na época, a RMSP contava com uma população de aproximadamente 17 milhões de habitantes em uma área de cerca de $8.051 \mathrm{~km}^{2}$, correspondentes aos 39 municípios.

Para efeito da Pesquisa O/D, a região foi subdividida em 389 zonas onde todos os dados de deslocamentos das pessoas entrevistadas, independentemente da idade, foram registrados, exceto as viagens a pé pelos motivos diversos (trabalho, estudo, compras etc.) que foram coletados quando superiores a 500 metros. Entretanto, quando as viagens a pé feitas por motivos de compras, negócios etc., eram encadeadas aos motivos estudo e trabalho, estas viagens foram catalogadas independentemente da distância. 
O banco de dados da RMSP é composto de 47.326 homens (47,9\% da amostra) e 51.455 mulheres (52,1\%), totalizando 98.780 indivíduos entrevistados. Em relação a amostra, os números de estudantes e de trabalhadores representam 29,66\% (29.298 indivíduos) e 41,98\% (41.474 indivíduos), respectivamente. Segundo o METRÔ-SP, o índice de motorização da região atinge aproximadamente 0,184 veículos/habitantes.

A amostra da RMSP totalizou 26.278 domicílios entrevistados. Este total de domicílios representa $0,61 \%$ do total de domicílios existentes na RMSP.

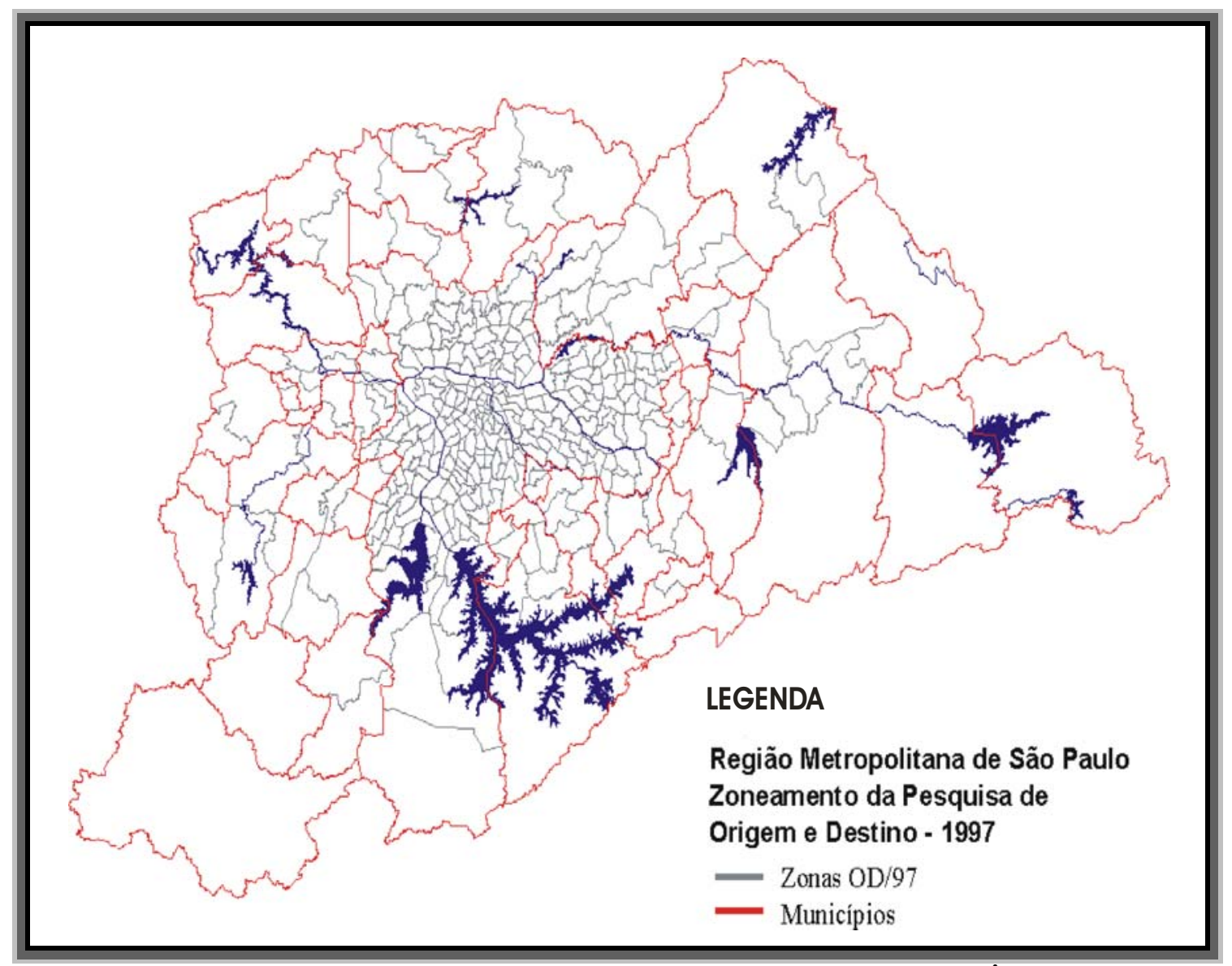

Figura 4.1: Região Metropolitana de São Paulo. Fonte: METRÔ-SP 


\subsection{A Pesquisa Domiciliar na RMB}

A Pesquisa Domiciliar na RMB foi executada no período de 24 de maio a 30 de junho de 2000. Para viabilizar a pesquisa domiciliar, a área de estudo foi subdividida em 100 zonas de tráfego, onde todas estas zonas tiveram domicílios entrevistados, totalizando a amostra de sete mil domicílios e um total de 32.467 entrevistados. De acordo com a Contagem de 1996, realizada pelo Instituto Brasileiro de Geografia e Estatística (IBGE), este total de residências componentes da amostra pesquisada representa 2,02\% do total de domicílios da RMB.

Ressalta-se que a referida pesquisa catalogou todos os deslocamentos, independentemente da distância, feitos por indivíduos maiores ou iguais a seis anos de idade.

O banco de dados da RMB é composto de 14.963 homens (46,1\% da amostra) e 17.504 mulheres (53,9\%). Os números de estudantes e de trabalhadores representam 32,08\% (10.415 indivíduos) e 31,77\% (10.314 indivíduos), respectivamente, da amostra. O índice de motorização da região metropolitana tem o valor aproximado de 0,110 veículos/habitantes.

No período da pesquisa, a RMB contava com uma população de cerca de 1.800 .000 habitantes, distribuída em uma área de aproximadamente $1.820 \mathrm{~km}^{2}$, correspondentes aos cinco municípios.

A Figura 4.2 mostra a divisão da cidade em zonas de tráfego e, onde há tonalidade escura, zonas com maior densidade populacional na RMB. 


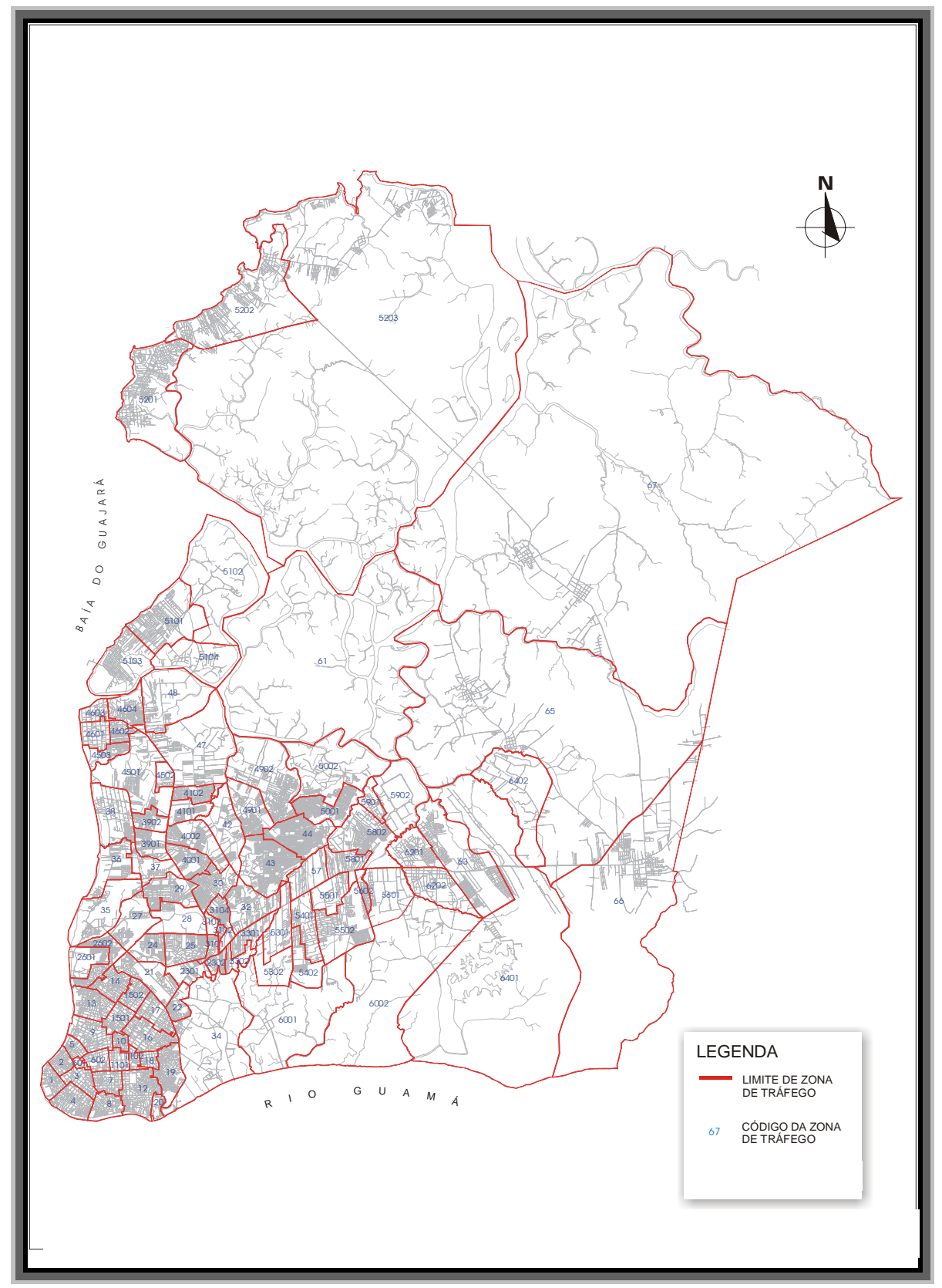

Figura 4.2: Região Metropolitana de Belém. Fonte: PDTU/2001

\subsection{A Pesquisa Origem-Destino na Cidade de Bauru}

A cidade de Bauru localiza-se na região centro-oeste do estado de São Paulo, a 325 km da capital. Na época da pesquisa, Bauru possuía pouco mais de 300.000 habitantes, distribuídos em uma área de $674 \mathrm{~km}^{2}$, e contava com aproximadamente 89.800 famílias. 
A pesquisa Origem-Destino do tipo domiciliar feita na cidade de Bauru foi realizada entre os meses de maio e junho do ano de 1997 e abrangeu 4 mil domicílios representando, na época, cerca de 4,5\% do total. Foram catalogadas 13.127 entrevistas e os deslocamentos realizados com distância acima de 300 metros, independentemente da idade. Para efeito de pesquisa, a área urbana também foi dividida em 98 zonas de tráfego (Figura 4.3).

O banco de dados da cidade de Bauru é composto de 6.143 homens (46,8\% da amostra) e 6.984 mulheres (53,2\%). Já os números de estudantes e de trabalhadores representam 21,64\% (2.841 indivíduos) e 32,47\% (4.262 indivíduos), respectivamente. O índice de motorização da cidade de Bauru tem o valor de 0,243 veículos/habitantes.

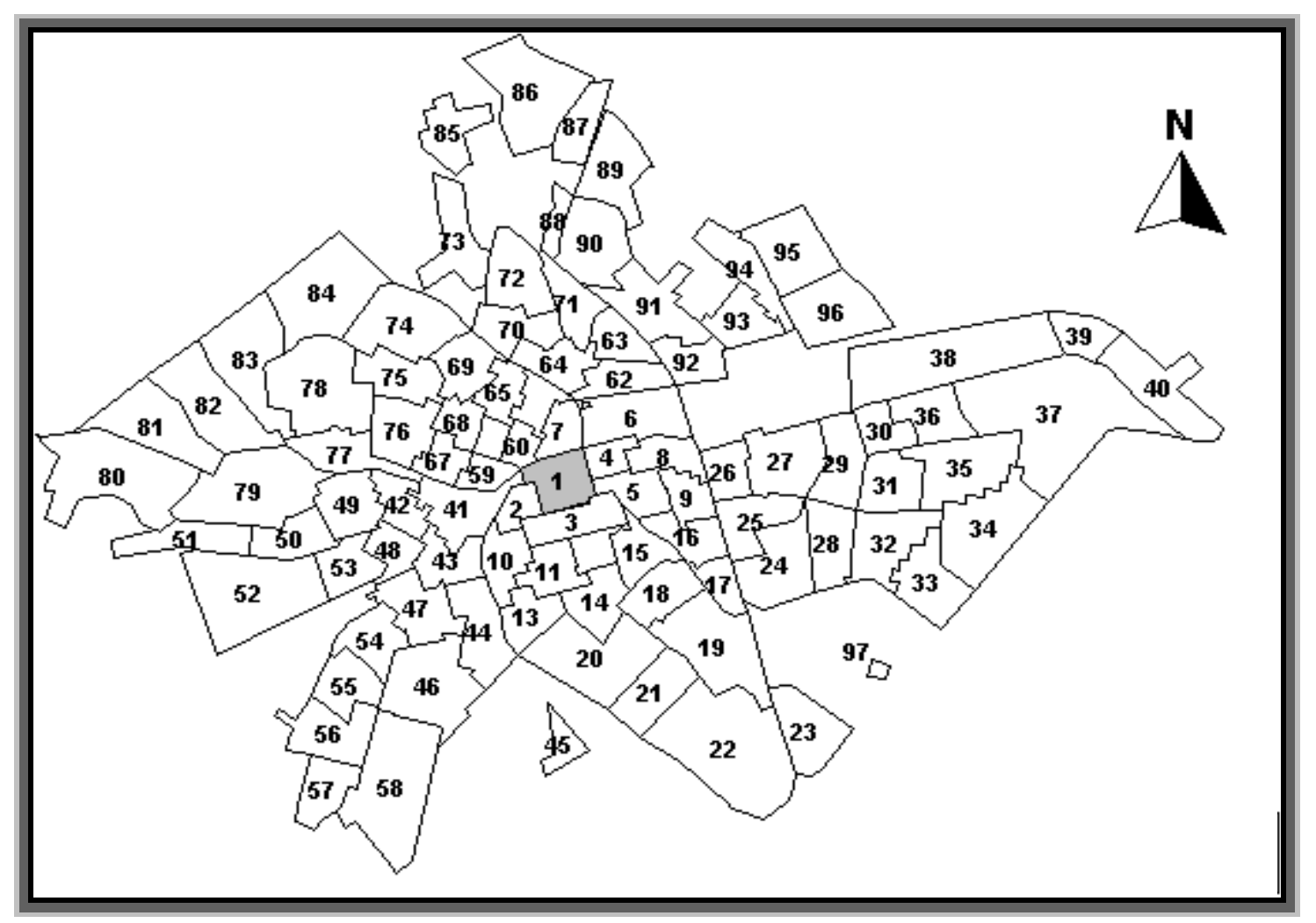

Figura 4.3: Divisão da cidade de Bauru em zonas de tráfego (destaque para a zona central de negócios). Fonte: Raia Jr. (2000) 


\subsection{As Variáveis de Interesse}

As variáveis de interesse utilizadas neste trabalho e suas descrições realizadas pelos órgãos responsáveis das pesquisas encontram-se nas Tabelas 4.1 e 4.3. Verifica-se a existência de semelhanças e diferenças na codificação das variáveis dos diferentes conjuntos de dados. Salienta-se que tais diferenças encontradas causam a necessidade de compatibilização das variáveis no decorrer do trabalho, com o intuito de obter três conjuntos de dados comparáveis.

As variáveis socioeconômicas individuais "Trabalha" e "Estuda" presentes na Tabela 4.1 foram criadas pelo autor a partir de campos presentes nos bancos de dados das regiões metropolitanas de São Paulo e Belém. Tais variáveis, no banco de dados da cidade de Bauru, já estavam categorizadas na forma desejada para o desenvolvimento deste trabalho.

A variável "Trabalha” no banco de dados da RMSP foi obtida a partir do campo “Condição de Atividade”. Os indivíduos que declararam estarem “ocupado” e “ocupado eventualmente” foram considerados trabalhadores. Já a variável "estuda” foi obtida a partir do campo “Estuda Atualmente?”, onde foram considerados “estudantes” os indivíduos que declararam estarem na "Creche/Pré-escola", “1 $1^{\circ} / 2^{\circ} . / 3^{\circ}$. Graus” e “Outros” (ver Anexo C - Questionário RMSP). Vale ressaltar que a codificação “Outros” representa 3,87\% (1.133 indivíduos) dos estudantes da RMSP.

Na RMB, a variável “Trabalha” foi obtida através de uma ligação entre os campos “Classe de atividade” e "Condição de atividade”. Os indivíduos considerados “trabalhadores” pelo autor declararam estarem em qualquer uma das categorias do campo “Condição de Atividade”, exceto a última denominada “Sem ocupação”, e nas seguintes classes de atividades, codificadas pelo órgão responsável pela pesquisa: 01 - Agropecuária, extração e pesca; 02 - Indústria; 03 - Construção Civil; 04 Comércio; 05 - Transporte e Comunicação; 06 - Prestação de serviços; 07 Administração; 08 - Outras Atividades. Já a variável “Estuda” foi obtida a partir do 
campo “classe de atividade”, opção “10 - estudante” (ver Anexo C - Questionário $\mathrm{RMB})$.

É valido ressaltar que a pesquisa domiciliar da RMB criou campos que identificam a atividade principal e a atividade secundária dos entrevistados, ou seja, se o indivíduo declara que trabalha e estuda, provavelmente, a atividade principal foi preenchida com informações acerca da classe de atividade e condição de atividade da atividade "trabalho" e a atividade secundária teve somente o campo "classe de atividade" preenchido com a opção 10 marcada (ver Anexo C - Questionário RMB).

Segundo consulta ao órgão responsável pela pesquisa na RMB, qualquer tipo de curso, seja do $1^{0}$., $2^{\circ}$., $3^{\circ}$. graus ou cursos técnicos profissionalizantes ou de idiomas, foram catalogados como atividades de estudo e os respectivos indivíduos classificados como “estudantes”. Pode-se verificar no Questionário da pesquisa domiciliar da RMB que não foram discriminados os casos de indivíduos que cursam o ensino oficial $\left(1^{\circ}\right.$., $2^{\circ}$., $3^{\circ}$. graus) daqueles que cursam outros tipos de cursos.

Verifica-se que tanto a variável “Trabalha” quanto a variável "Estuda” ficaram uniformizadas entre as regiões metropolitanas. Já em relação a cidade de Bauru, não foi possível uniformizar tais variáveis devido o órgão responsável pela pesquisa considerar somente "estudantes” aqueles indivíduos que cursam o ensino oficial $\left(1^{\circ} . / 2^{\circ} . / 3^{\circ}\right.$. graus) e como "trabalhadores" os indivíduos que estão ocupados diariamente em atividades de trabalho.

Portanto, o autor ficou impossibilitado de compatibilizar a variável "Estuda" entre as três regiões. Com relação a variável “Trabalha”, o autor poderia ter feito a compatibilização entre as três regiões, no entanto, este procedimento geraria também polêmica visto que a atual conjuntura das relações trabalhistas mostra que a informalidade supera as relações formais nas regiões metropolitanas.

Salienta-se que o percentual dos indivíduos que declararam estar “ocupado eventualmente” representa 4,06\% (1.685 indivíduos), na RMSP, e 3,38\% (349 indivíduos), na RMB, dos trabalhadores destas regiões. 
Contudo, optou-se por seguir com a proposta de comparar as três áreas urbanas com intuito de obter informações que transcendem a análise isolada de um único banco de dados.

Tabela 4.1: As variáveis domiciliares e individuais de interesse presentes nos três conjuntos de dados. Codificação adotada pelo METRÔ-SP/97, EMDURB/97 e JICA-Governo do Pará/2000.

\section{DADOS UTILIZADOS}

\begin{tabular}{|c|c|c|c|}
\hline \multicolumn{4}{|c|}{ Características socioeconômicas } \\
\hline \multirow{2}{*}{ A) Domiciliares } & \multicolumn{3}{|c|}{ Descrição } \\
\hline & RMSP & RMB & Bauru \\
\hline$N^{\circ}$ de pessoas na família & \multicolumn{3}{|c|}{0 até o número máximo encontrado } \\
\hline$N^{o}$ de automóveis na família & \multicolumn{3}{|c|}{0 até o número máximo encontrado } \\
\hline Renda familiar & Salários min. 1997 & Salários min. 2000 & Salários min. 1997 \\
\hline \multirow{2}{*}{ B) Individuais } & \multicolumn{3}{|c|}{ Descrição } \\
\hline & RMSP & RMB & Bauru \\
\hline Idade & \multicolumn{3}{|c|}{0 até o número máximo encontrado } \\
\hline Sexo & \multicolumn{3}{|c|}{$\begin{array}{l}1 \text { - Homem } \\
2 \text { - Mulher }\end{array}$} \\
\hline Situação Familiar & $\begin{array}{l}1 \text { - Chefe } \\
2 \text { - Cônjuge } \\
3 \text { - Filho (a) } \\
4 \text { - Parente / Agregado } \\
5 \quad \text { - Empregada } \\
\text { doméstica residente } \\
6 \text { - Visita }\end{array}$ & Não foi coletado & $\begin{array}{l}1 \text { - Chefe } \\
2 \text { - Cônjuge } \\
3 \text { - Filho } \\
4 \text { - Parente } \\
5 \text { - Agregado } \\
6 \quad \text { - Empregada } \\
\text { doméstica residente } \\
7 \text { - Visita }\end{array}$ \\
\hline Renda Individual & Salários min. 1997 & Não foi coletado & Salários min. 1997 \\
\hline Trabalha & $\begin{array}{l}\text { Adotada pelo } \\
\text { autor }\end{array}$ & $\begin{array}{l}\text { Adotada pelo } \\
\text { autor }\end{array}$ & $\begin{array}{l}1-\operatorname{Sim} \\
0-\mathrm{Não}\end{array}$ \\
\hline Estuda & $\begin{array}{l}\text { Adotada pelo } \\
\text { autor }\end{array}$ & $\begin{array}{l}\text { Adotada pelo } \\
\text { autor }\end{array}$ & $\begin{array}{l}1-\mathrm{Sim} \\
0-\mathrm{Não}\end{array}$ \\
\hline
\end{tabular}




\section{DADOS UTILIZADOS}

\begin{tabular}{|c|c|c|c|}
\hline \multicolumn{4}{|c|}{ Características socioeconômicas } \\
\hline A) Individuais (continuação) & & Descrição & \\
\hline Grau de instrução & $\begin{array}{l}1 \text { - Não - Alfabetizado } \\
2 \text { - Pré-escola } \\
3 \text { - } 1^{\circ} \text { grau incompleto } \\
4 \text { - } 1^{\circ} \text { grau completo } \\
5 \text { - } 2^{\circ} \text { grau incompleto } \\
6 \text { - } 2^{\circ} \text { grau completo } \\
7 \\
\text { incompleto } \\
8 \text { - Superior completo }\end{array}$ & 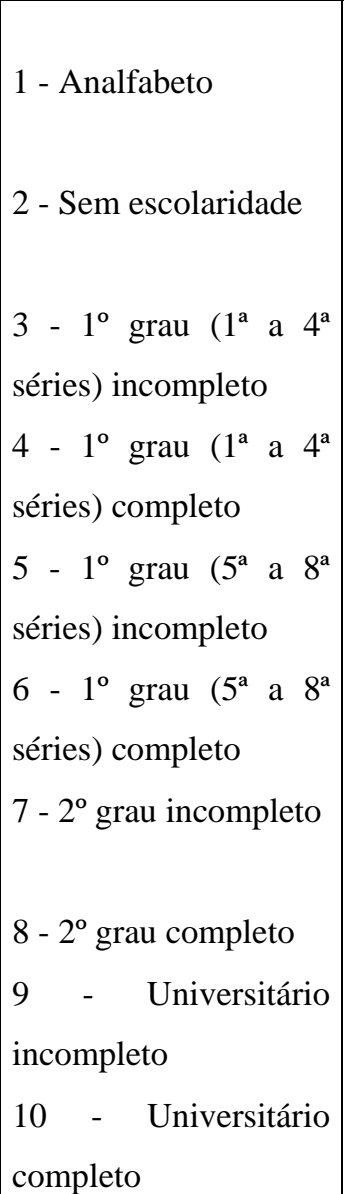 & 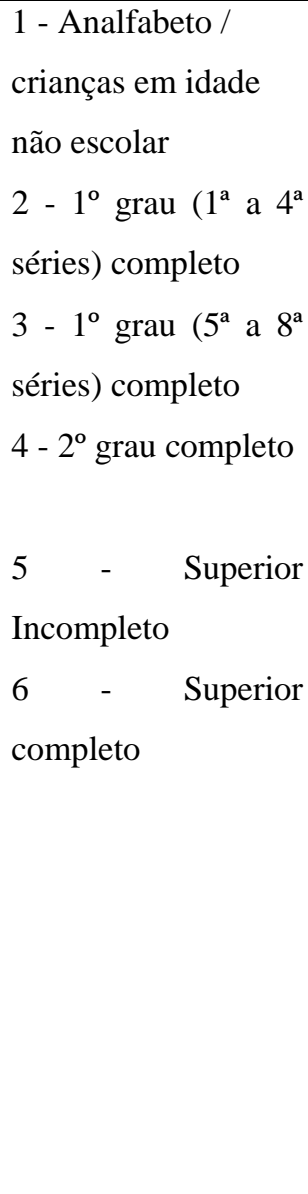 \\
\hline
\end{tabular}

A variável "Grau de instrução" necessitou ser uniformizada nas três amostras. Na RMB, esta variável foi expressa em dez categorias de estudo, enquanto na RMSP e em Bauru foi expressa em 8 e 6 categorias, respectivamente. A solução adotada no estudo tomou por base a classificação mostrada na Tabela 4.2, agrupando-se as categorias existentes nos três bancos de dados. 
Tabela 4.2: Uniformização da variável “Grau de instrução”.

\begin{tabular}{|c|c|c|c|c|c|}
\hline $\begin{array}{c}\text { Banco de } \\
\text { dados }\end{array}$ & $\begin{array}{c}\text { Analfabeto/4 } \\
\text { série incompleta } \\
\text { (1) }\end{array}$ & $\begin{array}{c}1^{0} \text { grau inc./4a } \\
\text { série completa } \\
(2)\end{array}$ & $\begin{array}{c}1^{\circ} \text { grau completo } \\
\text { (3) }\end{array}$ & $\begin{array}{c}2^{o} \text { grau completo } \\
\text { (4) }\end{array}$ & $\begin{array}{c}\text { Superior completo } \\
\text { (5) }\end{array}$ \\
\hline RMSP & $\begin{array}{l}1 \text { - Não - } \\
\text { Alfabetizado } \\
2 \text { - Pré-escola }\end{array}$ & $\begin{array}{l}3 \text { - } 1^{\circ} \text { grau } \\
\text { incompleto }\end{array}$ & $\begin{array}{l}4-1^{\circ} \text { grau } \\
\text { completo } \\
5-2^{\circ} \text { grau } \\
\text { incompleto }\end{array}$ & $\begin{array}{l}6 \text { - } 2^{\circ} \text { grau } \\
\text { completo } \\
7 \text { - Superior } \\
\text { incompleto }\end{array}$ & $\begin{array}{l}8 \text { - Superior } \\
\text { completo }\end{array}$ \\
\hline RMB & $\begin{array}{l}1 \text { - Analfabeto } \\
2 \text { - Sem } \\
\text { escolaridade } \\
3 \text { - } 1^{\circ} \text { grau ( } 1^{\mathrm{a}} \text { a } \\
4^{\mathrm{a}} \text { séries) } \\
\text { incompleto }\end{array}$ & $\begin{array}{l}4 \text { - } 1^{\mathrm{o}} \text { grau }\left(1^{\mathrm{a}}\right. \\
\text { a } 4^{\mathrm{a}} \text { séries) } \\
\text { completo } \\
5 \text { - } 1^{\mathrm{o}} \text { grau ( } 5^{\mathrm{a}} \\
\text { a } 8^{\mathrm{a}} \text { séries) } \\
\text { incompleto }\end{array}$ & $\begin{array}{l}6-1^{\circ} \text { grau ( } 5^{\mathrm{a}} \mathrm{a} \\
8^{\mathrm{a}} \text { séries) } \\
\text { completo } \\
7 \text { - } 2^{\mathrm{o}} \text { grau } \\
\text { incompleto }\end{array}$ & \begin{tabular}{|l}
8 - $2^{\circ}$ grau \\
completo \\
9 - Universitário \\
incompleto
\end{tabular} & $\begin{array}{l}10 \text { - Universitário } \\
\text { completo }\end{array}$ \\
\hline BAURU & $\begin{array}{l}1 \text { - Analfabeto / } \\
\text { crianças em } \\
\text { idade não escolar }\end{array}$ & $\begin{array}{l}2 \text { - } 1^{\mathrm{o}} \text { grau }\left(1^{\mathrm{a}}\right. \\
\left.\mathrm{a} 4^{\mathrm{a}} \text { séries }\right) \\
\text { completo }\end{array}$ & $\begin{array}{l}3-1^{\mathrm{o}} \text { grau }\left(5^{\mathrm{a}} \mathrm{a}\right. \\
\left.8^{\mathrm{a}} \text { séries }\right) \\
\text { completo }\end{array}$ & $\begin{array}{l}4-2^{\circ} \text { grau } \\
\text { completo } \\
5 \text { - Superior } \\
\text { Incompleto }\end{array}$ & $\begin{array}{l}6 \text { - Superior } \\
\text { completo }\end{array}$ \\
\hline
\end{tabular}

A Tabela 4.3 mostra as variáveis de interesse relacionadas as características de viagem utilizadas neste trabalho e suas respectivas descrições adotadas pelos órgãos responsáveis.

Ressalta-se que a uniformização das variáveis referentes as características de viagem ocorrerá no capítulo posterior, que tratará da caracterização dos padrões de viagens. 
Tabela 4.3: As características de viagem de interesse presentes nos três conjuntos de dados. Codificação adotada pelo METRÔ-SP/97, EMDURB/97 e JICAGoverno do Pará/2000.

\begin{tabular}{|c|c|c|c|}
\hline \multicolumn{4}{|c|}{ Características de viagem } \\
\hline & \multicolumn{3}{|c|}{ Descrição } \\
\hline & RMSP & RMB & Bauru \\
\hline Número de viagens por dia & \multicolumn{3}{|c|}{0 até o número máximo encontrado } \\
\hline Tempo de viagem & \multicolumn{3}{|c|}{ Variável (minutos) } \\
\hline Horário de Saída & \multicolumn{3}{|c|}{ Horário de saída da origem } \\
\hline Horário de Chegada & \multicolumn{3}{|c|}{ Horário de chegada ao destino } \\
\hline & \multicolumn{3}{|c|}{ Descrição } \\
\hline & RMSP & RMB & Bauru \\
\hline Motivo & $\begin{array}{l}1 \quad \text { - Trabalho / } \\
\text { Indústria } \\
2 \quad \text { - Trabalho / } \\
\text { Comércio } \\
3 \text { - Serviços } \\
4 \quad \text { - Escola / } \\
\text { educação } \\
5 \text { - Compras } \\
6 \quad \text { - Médico / } \\
\text { Dentista / Saúde } \\
7 \text { - Recreação / } \\
\text { visita } \\
8 \text { - Residência } \\
9 \text { - Outros }\end{array}$ & $\begin{array}{l}1 \text { - Residência } \\
2 \text { - Trabalho } \\
3 \text { - Estudo } \\
4 \text { - Negócios } \\
5 \text { - Retorno ao } \\
\text { trabalho } \\
6 \text { - Compras } \\
7 \\
\text { pessoais } \\
8 \text { - Lazer Assuntos } \\
9 \text { - Saúde } \\
10 \text { - Escala } \\
11 \text { - Transbordo - Outros }\end{array}$ & $\begin{array}{l}1 \text { - Trabalho } \\
\text { Indústria } \\
2 \text { - Trabalho } \\
\text { Comércio } \\
3 \text { - Serviços } \\
4 \quad \text { - Escola } \\
\text { educação } \\
5 \text { - Compras } \\
6 \text { - Negócios } \\
7 \text { - Saúde } \\
8 \text { - Recreação } \\
\text { visita } \\
9 \text { - Residência }\end{array}$ \\
\hline
\end{tabular}




\begin{tabular}{|c|c|c|c|}
\hline \multicolumn{4}{|c|}{ Características de viagem (continuação) } \\
\hline & \multicolumn{3}{|c|}{ Descrição } \\
\hline & RMSP & RMB & Bauru \\
\hline Modos de Transporte & 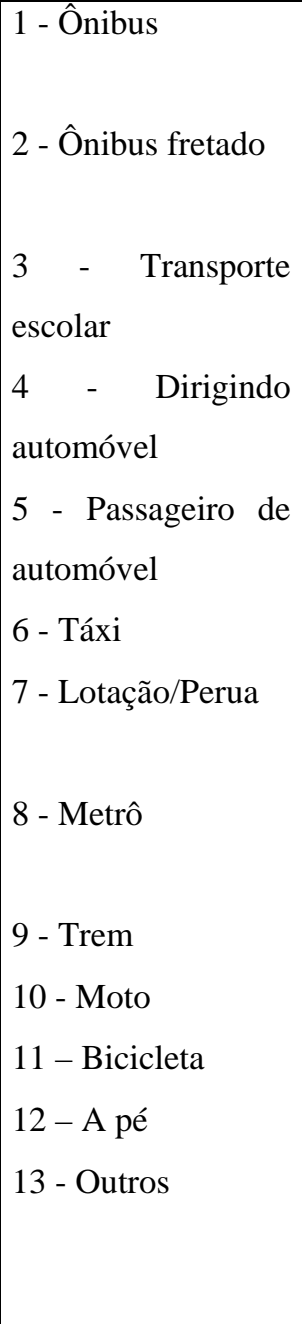 & $\begin{array}{l}1 \text { - Ônibus } \\
2 \text { - Micro-ônibus } \\
3 \text { - Alternativo } \\
4 \text { - Condutor de } \\
\text { auto } \\
5 \text { - Passageiro de } \\
\text { auto } \\
6 \text { - Táxi } \\
7 \quad \text { - Transporte } \\
\text { fretado } \\
8 \\
\text { Escolar } \quad \text { Transporte } \\
9 \text { - Moto } \\
10 \text { - Ciclomotor } \\
11 \text { - Bicicleta } \\
12 \text { - A pé } \\
13 \text { - Barco } \\
14 \text { - Caminhão } \\
15 \text { - Outros }\end{array}$ & $\begin{array}{l}1 \text { - Condutor de } \\
\text { auto/moto } \\
2 \text { - Passageiro de } \\
\text { auto/moto } \\
3 \text { - ônibus } \\
4 \text { - Bicicleta / A pé }\end{array}$ \\
\hline
\end{tabular}

\subsection{Filtragem dos Dados}

A filtragem dos dados utilizados neste trabalho seguiu os passos feitos por Ichikawa (2002) para os dados da RMSP, de 1987. A seguir, mostra-se uma síntese de cada passo nesta filtragem.

- Eliminação dos dados incompletos (Passo 1): os bancos de dados iniciais apresentam dados completos, ou seja, entrevistados que responderam a todas as perguntas do questionário, e dados incompletos que, portanto, não foram considerados; 
- Eliminação de indivíduos que realizam uma ou mais de quatro viagens

(Passo 2): indivíduos que realizam uma viagem ou mais de quatro viagens ao dia foram eliminados da análise devido a necessidade de limitar o número total de padrões de viagens. Logo, a análise foi feita com indivíduos que não viajaram ou realizaram duas, três ou quatro viagens;

- Uniformização do público-alvo das pesquisas (Passo 3): tanto na RMSP como em Bauru, todos os indivíduos, independentes da idade, tiveram seus dados socioeconômicos e de deslocamentos coletados, enquanto que, na RMB isto aconteceu somente para indivíduos com idades maiores ou iguais a seis anos. Logo, fez-se necessário eliminar os indivíduos menores de seis anos das amostras de RMSP e Bauru, promovendo assim, a uniformização das amostras;

- Eliminação dos indivíduos que não tiveram como origem inicial e destino final a residência (Passo 4): neste passo foram eliminados os indivíduos em que a primeira e a última viagem do dia não tiveram como motivo a residência. Tal passo foi feito devido à limitação do software em analisar até 128 variáveis-resposta;

- Amostra final (Passo 5): por fim, eliminaram os indivíduos cujos padrões de encadeamento de viagens estão além do $128^{\circ}$ padrão de viagem. Tal passo será mostrado no capítulo posterior.

Ressalta-se que os conjuntos de dados estavam intactos, sem qualquer tratamento, o que levou o autor a despender grandes recursos de tempo no tratamento dos dados da pesquisa, armazenados em extensas planilhas eletrônicas, para torná-los viáveis ao trabalho ora desenvolvido.

A Tabela 4.4 mostra um resumo dos passos de 1 a 4 desenvolvidos na filtragem das amostras. 
Tabela 4.4: Resumo da filtragem dos dados nos três conjuntos de dados.

\begin{tabular}{|c|c|c|c|c|}
\hline \multirow[b]{2}{*}{ Passos } & \multirow[b]{2}{*}{ Descrição } & \multicolumn{3}{|c|}{ Áreas } \\
\hline & & $\begin{array}{c}\text { RMSP } \\
\text { (\% em relação a } \\
\text { Amostra inicial) }\end{array}$ & $\begin{array}{c}\text { RMB } \\
\text { (\% em relação a } \\
\text { Amostra inicial) }\end{array}$ & $\begin{array}{c}\text { BAURU } \\
\text { (\% em relação a } \\
\text { Amostra inicial) }\end{array}$ \\
\hline \multirow{3}{*}{1} & Dados Completos & $98.363(99,58 \%)$ & $28.996(89,31 \%)$ & $12.939(98,57 \%)$ \\
\hline & Dados Incompletos & $417(0,42 \%)$ & $3.411(10,69 \%)$ & $188(1,43 \%)$ \\
\hline & Amostra inicial & 98.780 & 32.467 & 13.127 \\
\hline 2 & $\begin{array}{l}\text { Pessoas eliminadas } \\
\text { devido a realização de } \\
\text { uma ou mais de quatro } \\
\text { viagens }\end{array}$ & $\begin{array}{c}6.159 \\
(6,23 \%)\end{array}$ & $\begin{array}{c}683 \\
(2,10 \%)\end{array}$ & $\begin{array}{c}231 \\
(1,76 \%)\end{array}$ \\
\hline 3 & $\begin{array}{l}\text { Crianças eliminadas } \\
\text { da amostra por terem } \\
\text { idade inferior a seis } \\
\text { anos }\end{array}$ & $\begin{array}{c}9.176 \\
(9,29 \%)\end{array}$ & - & $\begin{array}{c}680 \\
(5,18 \%)\end{array}$ \\
\hline \multirow[t]{2}{*}{4} & \begin{tabular}{lrr} 
Pessoas & \multicolumn{2}{r}{ eliminadas } \\
devido ao fato da \\
primeira e última \\
viagem não terem \\
como motivo a \\
residência \\
\end{tabular} & $\begin{array}{c}1.496 \\
(1,51 \%)\end{array}$ & $\begin{array}{c}128 \\
(0,39 \%)\end{array}$ & $\begin{array}{c}95 \\
(0,72 \%)\end{array}$ \\
\hline & Amostra Parcial & 81.532 & 28.245 & 11.933 \\
\hline
\end{tabular}

A amostra parcial de cada banco de dados ficou caracterizada, em termos de número de viagens, da seguinte forma:

Tabela 4.5: Total de indivíduos analisados por número de viagens realizadas no dia.

\begin{tabular}{c|c|c|c|c|c|c}
\hline \multirow{2}{*}{$\begin{array}{c}\text { Número de } \\
\text { Viagens }\end{array}$} & \multicolumn{2}{|c|}{ RMSP } & \multicolumn{2}{c|}{ RMB } & \multicolumn{2}{c}{ BAURU } \\
\cline { 2 - 7 } & $\begin{array}{c}\text { Total de } \\
\text { Indivíduos }\end{array}$ & $\mathbf{\%}$ & $\begin{array}{c}\text { Total de } \\
\text { Indivíduos }\end{array}$ & $\mathbf{\%}$ & $\begin{array}{c}\text { Total de } \\
\text { Indivíduos }\end{array}$ & $\%$ \\
\hline 0 & 29265 & 35,89 & 6741 & 23,87 & 3558 & 29,82 \\
\hline 2 & 40587 & 49,78 & 18229 & 64,54 & 6630 & 55,56 \\
\hline 3 & 3766 & 4,62 & 600 & 2,12 & 150 & 1,26 \\
\hline 4 & 7914 & 9,71 & 2675 & 9,47 & 1595 & 13,37 \\
\hline Total & 81.532 & 100,00 & 28.245 & 100,00 & 11.933 & 100,00 \\
\hline
\end{tabular}




\section{CARACTERIZAÇÃO DOS PADRÕES DE VIAGENS}

\section{ENCADEADAS}

\section{Capítulo}

Seguindo o procedimento iniciado por Ichikawa (2002) e ampliado por Pitombo (2003), os padrões de viagens foram caracterizados de acordo com o esquema a seguir:

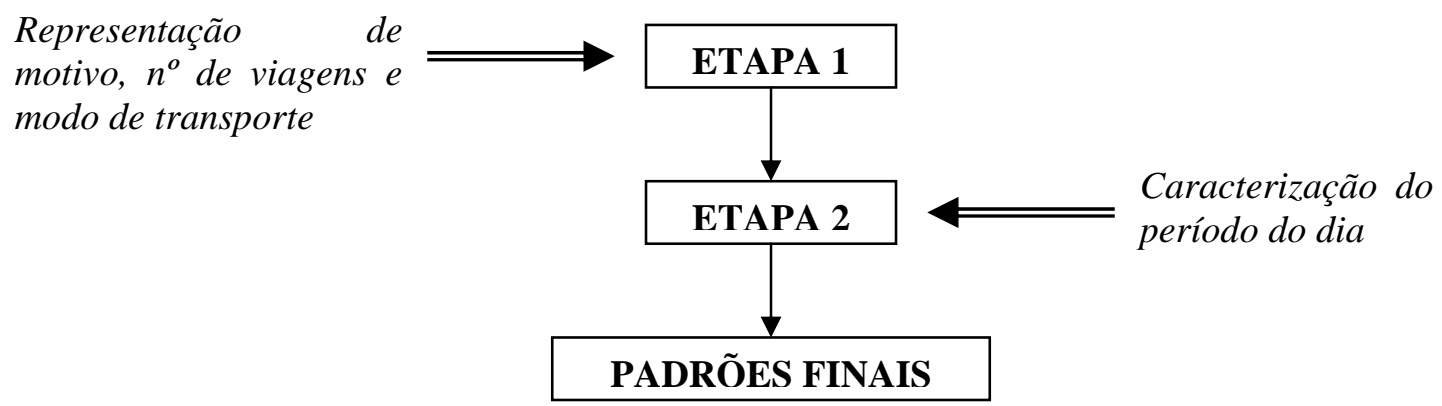

Combinação das etapas anteriores

Figura 5.1: Procedimento utilizado para caracterização dos padrões de viagens

Ressalta-se que a caracterização do tempo de viagem, utilizada como etapa 3 por Pitombo (2003), foi excluída deste trabalho pois é notório que esta variável é bastante diferente entre Bauru, considerada uma cidade de porte médio, e as regiões metropolitanas de São Paulo e Belém. Tal etapa, após formação dos padrões finais, poderia causar a necessidade de eliminação de padrões com freqüência relativa alta nas regiões metropolitanas devido a limitação do pacote estatístico S-Plus 6.1, que permite processar apenas 128 padrões de viagens encadeadas. 


\subsection{Etapa 1: Motivo, número de viagens e modo de transporte}

Primeiramente, foi necessário agrupar os diversos motivos (em quatro categorias) e modos (em três categorias) contidos nas amostras. As Tabelas 5.1 e 5.2 mostram os agrupamentos propostos.

Tabela 5.1: Agrupamento dos motivos de viagens

\begin{tabular}{c|cccc}
\hline Banco de dados & Residência (H) & Trabalho (W) & Escola (S) & Outras Atividades (A) \\
\hline \multirow{3}{*}{ RMSP } & Residência (8) & Indústria (1) & Escola / & Compras (5) \\
& & Comércio (2) & Educação (4) & Médico / Dentista \\
& & Serviços (3) & & Saúde (6) \\
& & & & Recreação / Visita (7) \\
& & & Outros (9) \\
\hline \multirow{2}{*}{ RMB } & Residência (1) & Trabalho (2) & Estudo (3) & Negócios (4) \\
& & Retorno ao & & Compras (6) \\
& & Trabalho (5) & & Assuntos pessoais (7) \\
& & & & Lazer (8) \\
& & & & Saúde (9) \\
& & & & Outros (12) \\
\hline & Residência (9) & Indústria (1) & Escola / & Compras (5) \\
& & Comércio (2) & Educação (4) & Negócios (6) \\
& & Serviços (3) & & Saúde (7) \\
& & & & Recreação / Visita (8) \\
\hline
\end{tabular}

As viagens por motivos "Escala (10)" e “Transbordo (11)" foram eliminadas do banco de dados da RMB, devido ao fato de não representarem o real motivo da viagem. Salienta-se que nenhum indivíduo viaja com intuito de fazer escala ou transbordo e quando esta viagem acontece é porque não há alternativa que permita realizar uma viagem direta entre a origem e o destino da atividade principal.

Adotou-se o seguinte procedimento na eliminação das viagens por motivo "Escala” e "Transbordo":

(1) Verificação do motivo principal (trabalho, escola, outras atividades ou residência); 
(2) Uma vez identificado o motivo, adotaram-se os seguintes critérios para identificar o modo principal da viagem: (a) Quando uma das viagens da cadeia que continha o transbordo ou escala era realizada por modo não-motorizado (A pé e bicicleta) e a outra por modo motorizado (carro, ônibus, moto etc.), adotava-se o modo motorizado; (b) Quando ambas as viagens eram feitas por modo motorizado, considerava-se como modo principal aquele cujo tempo de viagem era maior.

(3) A duração da viagem foi obtida subtraindo a hora de chegada no destino final da hora de saída da origem, ou seja, desta forma incluem-se os tempos de viagens de cada modo mais o tempo de espera no local de transbordo ou escala.

O exemplo da Figura 5.2 demonstra o procedimento adotado para eliminação das viagens por motivo “Transbordo”.

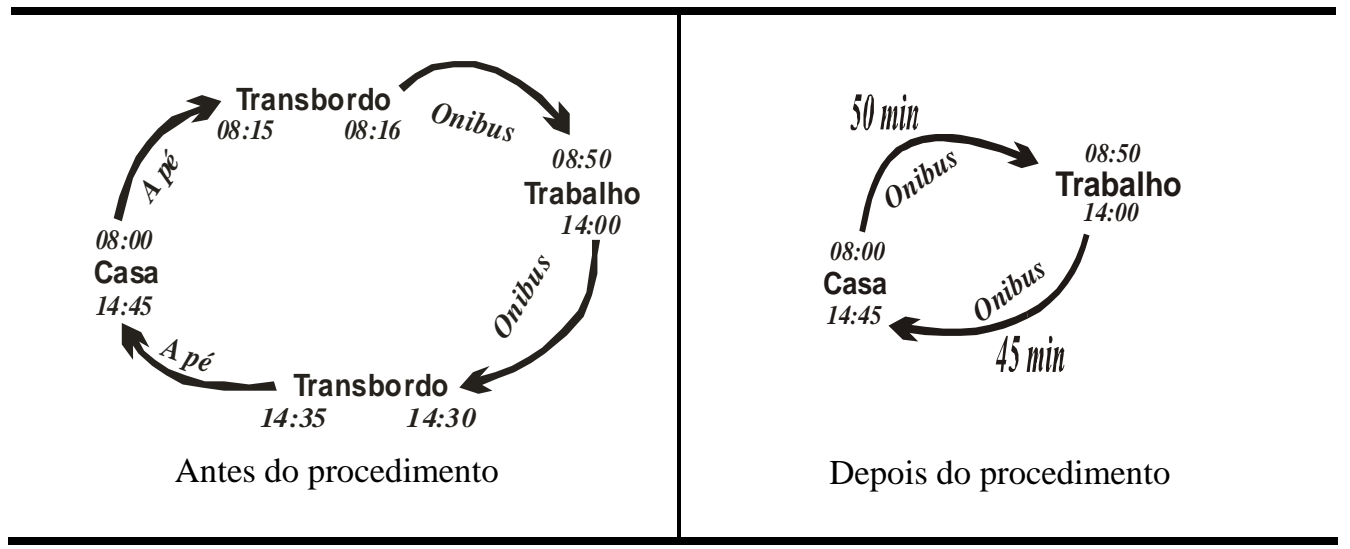

Figura 5.2: Resultado do procedimento adotado para eliminação da viagem por motivo “Transbordo” da amostra da RMB.

Neste exemplo, a pessoa sai de casa às 08:00h com destino ao trabalho. Realiza uma caminhada de quinze minutos e ainda espera um minuto no ponto de transbordo até conseguir tomar o ônibus até o destino final. De acordo com o procedimento, elimina-se a viagem “casa-transbordo” e "transbordo-trabalho”, substituindo por uma só da casa até o trabalho. O modo principal é o ônibus e a duração da viagem obtida através da diferença entre o horário de chegada ao destino final do horário de saída da origem resultando, no exemplo, em 50 minutos. No retorno, esta pessoa toma o 
ônibus e desce num ponto de transbordo e realiza também caminhada para chegar a residência 45 minutos depois de ter saído do trabalho.

Os modos de transporte contidos nas pesquisas foram agrupados em três categorias:

(1) Modo individual motorizado, (2) Modo coletivo, (3) Modo não-motorizado.

Tabela 5.2: Agrupamento dos modos de viagem

\begin{tabular}{|c|c|c|c|}
\hline Banco de dados & $\begin{array}{l}\text { Modo Individual } \\
\text { Motorizado - } 1\end{array}$ & $\begin{array}{l}\text { Modo Coletivo, incluindo } \\
\text { Semi-Público - } 2\end{array}$ & $\begin{array}{c}\text { Modo Individual não } \\
\text { Motorizado }-3\end{array}$ \\
\hline RMSP & $\begin{array}{c}\text { Dirigindo Automóvel (4) } \\
\text { Passageiro de } \\
\text { Automóvel (5) } \\
\text { Moto (6) }\end{array}$ & $\begin{array}{c}\text { Ônibus (1) / Ônibus } \\
\text { Fretado (2) } \\
\text { Transporte Escolar (3) } \\
\text { Táxi (6) } \\
\text { Lotação / Perua (7) } \\
\text { Metrô (8) } \\
\text { Trem (9) }\end{array}$ & $\begin{array}{l}\text { Bicicleta (11) } \\
\text { A pé (12) }\end{array}$ \\
\hline RMB & $\begin{array}{c}\text { Condutor de auto (4) } \\
\text { Passageiro de auto (5) } \\
\text { Moto (9) } \\
\text { Ciclomotor (10) } \\
\text { Caminhão (14) }\end{array}$ & $\begin{array}{c}\text { Ônibus (1) } \\
\text { Micro-ônibus (2) } \\
\text { Alternativo (3) } \\
\text { Táxi (6) } \\
\text { Transporte Fretado (7) } \\
\text { Transporte Escolar (8) }\end{array}$ & $\begin{array}{l}\text { Bicicleta (11) } \\
\text { A pé (12) }\end{array}$ \\
\hline Bauru & $\begin{array}{l}\text { Condutor de auto / } \\
\text { moto (1) } \\
\text { Passageiro de auto / } \\
\text { Moto (2) }\end{array}$ & Ônibus (3) & Bicicleta / A pé (4) \\
\hline
\end{tabular}

Devido à possibilidade de o modo de transporte "Barco" (13), presente na amostra da RMB, ser classificado como modo individual motorizado ou como modo coletivo, optou-se por eliminar desta amostra os indivíduos que utilizam tal modo de transporte (53 indivíduos). Também, eliminaram-se os indivíduos que realizam viagem através do modo "Outros” da RMB (25 indivíduos) e da RMSP (182 indivíduos). Após esta eliminação, as amostras da RMB e da RMSP contabilizaram 28.167 e 81.350 indivíduos, respectivamente. Já a amostra de Bauru, como não houve a necessidade de eliminação de indivíduos, continuou com 11.933 indivíduos.

Para completar esta etapa, foram agrupados os motivos e os modos das viagens. Desta forma, as letras indicam as atividades desempenhadas pelos indivíduos no dia 
anterior à entrevista e os números entre as letras indicam os modos de transporte utilizados para realizar as respectivas atividades. Ressalta-se que a seqüência das letras significa a ordem cronológica em que as atividades foram desenvolvidas. A Tabela 5.3 mostra a caracterização proposta e as respectivas freqüências para cada uma das amostras.

Tabela 5.3: Padrões segundo motivo e modo, respectivos códigos e freqüência (\%)

\begin{tabular}{|c|c|c|c|c|c|c|c|c|c|}
\hline Cod & Padrões & RMSP & RMB & Bauru & Cod & Padrões & RMSP & RMB & Bauru \\
\hline 01 & $\mathrm{H}$ & 35,97 & 23,87 & 29,82 & 91 & H2W1A1H & 0,01 & 0,01 & \\
\hline 02 & H3S3H & 11,41 & 16,37 & 8,08 & 92 & Н3W3Н1A1H & 0,06 & 0,02 & 0,09 \\
\hline 03 & $\mathrm{H} 2 \mathrm{~W} 2 \mathrm{H}$ & 11,65 & 12,58 & 9,91 & 93 & $\mathrm{H} 2 \mathrm{~S} 2 \mathrm{H} 2 \mathrm{~W} 2 \mathrm{H}$ & 0,04 & 0,04 & 0,05 \\
\hline 04 & H1W1H & 6,17 & 1,73 & 9,75 & 94 & Н3АЗН2А2Н & 0,02 & 0,13 & 0,10 \\
\hline 05 & НЗW3Н & 4,13 & 4,34 & 3,70 & 95 & H1W1H2S2H & 0,01 & 0,01 & 0,06 \\
\hline 06 & $\mathrm{H} 2 \mathrm{~A} 2 \mathrm{H}$ & 4,04 & 8,98 & 5,30 & 96 & H2A2H2S2H & 0,04 & 0,11 & 0,05 \\
\hline 07 & $\mathrm{H} 2 \mathrm{~S} 2 \mathrm{H}$ & 3,51 & 8,77 & 3,02 & 97 & H2S2H3S3H & 0,06 & 0,04 & 0,04 \\
\hline 08 & H1A1H & 2,51 & 1,12 & 5,72 & 98 & H1S1S1H & 0,06 & & \\
\hline 09 & НЗАЗН & 2,04 & 8,51 & 4,53 & 99 & H1A1H1W1H & 0,05 & 0,03 & 0,17 \\
\hline 10 & H1S1H & 2,16 & 0,61 & 5,10 & 100 & H3S3S3H & 0,05 & & \\
\hline 11 & Н3W3НЗW3Н & 0,96 & 1,35 & 0,79 & 101 & H2W2S1H & 0,04 & & \\
\hline 12 & H3S3H3S3H & 0,99 & 0,32 & 0,39 & 102 & H3W3S3H & 0,03 & 0,01 & \\
\hline 13 & H2W2H3S3H & 0,36 & 0,22 & 0,22 & 103 & $\mathrm{H} 2 \mathrm{~S} 2 \mathrm{H} 2 \mathrm{~A} 2 \mathrm{H}$ & 0,04 & 0,12 & 0,13 \\
\hline 14 & H2W2S2H & 0,34 & 0,18 & 0,04 & 104 & Н3А1Н & 0,05 & 0,04 & \\
\hline 15 & H1W1H1W1H & 0,54 & 0,51 & 2,71 & 105 & H1A1S1H & 0,02 & & 0,03 \\
\hline 16 & H1S2H & 0,40 & 0,17 & 0,04 & 106 & H2S2H3A3H & 0,03 & 0,13 & 0,07 \\
\hline 17 & $\mathrm{H} 2 \mathrm{~W} 2 \mathrm{~A} 2 \mathrm{H}$ & 0,19 & 0,07 & 0,05 & 107 & НЗАЗН1А1Н & 0,03 & 0,01 & 0,06 \\
\hline 18 & $\mathrm{H} 2 \mathrm{~A} 2 \mathrm{~A} 2 \mathrm{H}$ & 0,29 & 0,29 & 0,05 & 108 & $\mathrm{H} 1 \mathrm{~W} 2 \mathrm{~S} 2 \mathrm{H}$ & 0,02 & 0,004 & \\
\hline 19 & $\mathrm{H} 2 \mathrm{~W} 2 \mathrm{H} 2 \mathrm{~S} 2 \mathrm{H}$ & 0,19 & 0,25 & 0,44 & 109 & H2A2H2W2H & 0,02 & 0,03 & 0,13 \\
\hline 20 & H1A1A1H & 0,32 & 0,08 & 0,26 & 110 & H3A2A2H & 0,03 & 0,04 & 0,04 \\
\hline 21 & H1W1H1A1H & 0,28 & 0,07 & 0,85 & 111 & H1A3H & 0,02 & 0,03 & 0,04 \\
\hline 22 & H3W3H3S3H & 0,27 & 0,18 & 0,11 & 112 & H2W2A1H & 0,02 & 0,00 & 0,01 \\
\hline 23 & H1W1A1H & 0,23 & 0,03 & 0,05 & 113 & H3W2S2H & 0,02 & 0,01 & \\
\hline 24 & H2W1H & 0,24 & 0,08 & 0,03 & 114 & H2S2H3W3H & 0,03 & 0,01 & 0,03 \\
\hline 25 & H1S3H & 0,29 & 0,09 & 0,04 & 115 & H2S2A2H & 0,03 & 0,05 & 0,02 \\
\hline 26 & H1A1H1A1H & 0,21 & 0,10 & 0,75 & 116 & H2W2A2A2H & 0,01 & & \\
\hline 27 & H1S1H1S1H & 0,33 & 0,04 & 0,33 & 117 & H3W2A2H & 0,02 & 0,02 & \\
\hline 28 & H1W2H & 0,19 & 0,12 & 0,03 & 118 & H2W2W2W2H & 0,04 & 0,02 & \\
\hline 29 & НЗSЗНЗАЗН & 0,17 & 0,32 & 0,3 & 119 & H2W3A3W2H & 0,29 & 0,05 & 0,01 \\
\hline 30 & H1W1W1H & 0,30 & 0,04 & 0,08 & 120 & H2W1A2H & 0,01 & 0,00 & \\
\hline 31 & H2A3A2H & 0,15 & 0,16 & 0,03 & 121 & H3S3H2S2H & 0,04 & 0,05 & 0,08 \\
\hline 32 & H1S1W1H & 0,20 & 0,03 & 0,01 & 122 & H3W3H1S1H & 0,03 & 0,00 & 0,03 \\
\hline 33 & $\mathrm{H} 2 \mathrm{~W} 2 \mathrm{H} 1 \mathrm{~A} 1 \mathrm{H}$ & 0,09 & 0,02 & 0,08 & 123 & H2A2A1H & 0,02 & 0,01 & \\
\hline 34 & H1W1H1S1H & 0,18 & 0,03 & 0,48 & 124 & НЗАЗНЗWЗН & 0,02 & 0,05 & 0,03 \\
\hline 35 & НЗАЗНЗАЗН & 0,13 & 0,86 & 0,47 & 125 & Н3А3Н2S2H & 0,01 & 0,04 & 0,03 \\
\hline 36 & H1S1H1A1H & 0,14 & 0,02 & 0,44 & 126 & H2A2S2H & 0,02 & 0,04 & 0,02 \\
\hline 37 & H2W2H2W2H & 0,05 & 1,01 & 0,61 & 127 & H3А3H2W2H & 0,01 & 0,03 & 0,05 \\
\hline
\end{tabular}




\begin{tabular}{|c|c|c|c|c|c|c|c|c|c|}
\hline Cód & Padrões & RMSP & RMB & Bauru & Cód & Padrões & RMSP & RMB & Bauru \\
\hline 38 & H1W1S1H & 0,20 & 0,01 & 0,05 & 128 & H2W2H3W3H & 0,01 & 0,03 & 0,01 \\
\hline 39 & H2W2H3АЗН & 0,07 & 0,21 & 0,22 & 129 & H3W3H2W2H & 0,01 & 0,03 & 0,02 \\
\hline 40 & НЗАЗАЗН & 0,12 & 0,21 & 0,03 & 130 & H2A2H3W3H & 0,03 & 0,02 & 0,03 \\
\hline 41 & H2A1H & 0,13 & 0,11 & 0,06 & 131 & H3A2W2H & 0,01 & 0,02 & \\
\hline 42 & $\mathrm{H} 2 \mathrm{~W} 2 \mathrm{H} 2 \mathrm{~A} 2 \mathrm{H}$ & 0,07 & 0,13 & 0,17 & 132 & H2A2W2A2H & 0,02 & 0,02 & \\
\hline 43 & H2W2W2H & 0,12 & 0,09 & 0,03 & 133 & H2A2W3H & 0,01 & 0,02 & \\
\hline 44 & H3W3H2S2H & 0,08 & 0,11 & 0,06 & 134 & H2S3A2H & 0,03 & 0,02 & 0,01 \\
\hline 45 & H2W3H & 0,06 & 0,07 & 0,02 & 135 & НЗАЗWЗН & 0,01 & 0,02 & 0,02 \\
\hline 46 & H1W1A1W1H & 0,11 & 0,02 & & 136 & H1S2H1A1H & 0,01 & 0,02 & \\
\hline 55 & H3S3H2A2H & 0,09 & 0,07 & 0,15 & 137 & H1S2H2S2H & 0,00 & 0,02 & \\
\hline 56 & H3S1H & 0,06 & 0,03 & 0,03 & 138 & H2A2A3A2H & 0,01 & 0,02 & \\
\hline 57 & H2W2A3H & 0,07 & 0,01 & & 139 & Н2АЗАЗН & 0,01 & 0,02 & 0,04 \\
\hline 58 & H2W2S3H & 0,07 & 0,04 & & 140 & H3А2А3А2H & 0,00 & 0,02 & \\
\hline 59 & $\mathrm{H} 2 \mathrm{~A} 2 \mathrm{H} 2 \mathrm{~A} 2 \mathrm{H}$ & 0,07 & 0,40 & 0,23 & 141 & НЗАЗАЗАЗН & 0,03 & 0,02 & 0,01 \\
\hline 60 & H1A1W1H & 0,07 & 0,02 & 0,09 & 142 & H3S2A2H & 0,02 & 0,02 & \\
\hline 61 & H1W1W1W1H & 0,16 & 0,03 & & 143 & Н1А1Н3АЗН & 0,02 & 0,01 & 0,11 \\
\hline 62 & $\mathrm{H} 2 \mathrm{~S} 1 \mathrm{H}$ & 0,11 & 0,07 & & 144 & H2S2S2H & 0,03 & 0,01 & \\
\hline 63 & НЗWЗНЗАЗН & 0,06 & 0,20 & 0,10 & 145 & H2W1H1W2H & 0,00 & 0,01 & \\
\hline 64 & H1A2H & 0,08 & 0,08 & 0,02 & 146 & Н3A3H1S1H & 0,01 & 0,01 & 0,03 \\
\hline 65 & НЗАЗНЗSЗН & 0,08 & 0,19 & 0,1 & 147 & HЗWЗАЗW3Н & 0,05 & 0,01 & \\
\hline 66 & H2S3H & 0,10 & 0,19 & 0,03 & 148 & H1W1Н3АЗН & 0,01 & 0,01 & 0,07 \\
\hline 67 & Н2А2Н3АЗН & 0,04 & 0,23 & 0,13 & 149 & H1W1H2W2H & 0,01 & 0,00 & 0,06 \\
\hline 68 & H2А3Н & 0,10 & 0,12 & 0,01 & 150 & H1S1Н3АЗН & 0,01 & 0,00 & 0,06 \\
\hline 69 & $\mathrm{H} 2 \mathrm{~A} 2 \mathrm{~A} 2 \mathrm{~A} 2 \mathrm{H}$ & 0,06 & 0,06 & 0,01 & 151 & H1S1H2S2H & 0,01 & 0,01 & 0,06 \\
\hline 70 & H3W3H2A2H & 0,04 & 0,06 & 0,08 & 152 & H1A1H3S3H & 0,02 & 0,00 & 0,05 \\
\hline 71 & Н3S3НЗW3Н & 0,07 & 0,01 & 0,03 & 153 & Н3АЗН1W1H & 0,00 & 0,00 & 0,04 \\
\hline 72 & H2S2W2H & 0,05 & 0,01 & & 154 & H1S1H2A2H & 0,01 & & 0,04 \\
\hline 73 & H3W2H & 0,05 & 0,07 & 0,04 & 155 & H2S2H1S1H & 0,01 & & 0,03 \\
\hline 74 & H2S2H1A1H & 0,03 & 0,01 & 0,03 & 156 & H2A2H1W1H & 0,01 & 0,01 & 0,03 \\
\hline 75 & H1W1A1A1H & 0,03 & 0,01 & & 157 & H1S1H3S3H & 0,01 & 0,00 & 0,03 \\
\hline 76 & H2A2А3H & 0,04 & 0,03 & & 158 & H1S1H2W2H & 0,02 & & 0,03 \\
\hline 77 & $\mathrm{H} 2 \mathrm{~A} 2 \mathrm{~W} 2 \mathrm{H}$ & 0,04 & 0,05 & 0,01 & 159 & H1W3A3W1H & 0,16 & & \\
\hline 78 & НЗS3АЗН & 0,07 & 0,06 & 0,01 & 160 & H1S1W1S1H & 0,06 & & \\
\hline 79 & H1W3H & 0,03 & 0,03 & 0,03 & 161 & H1A1W1A1H & 0,04 & & \\
\hline 80 & H3W1H & 0,05 & 0,01 & 0,02 & 162 & H3S2W2H & 0,04 & & \\
\hline 81 & H1S1H1W1H & 0,08 & 0,004 & 0,03 & 163 & H1S1A1A1H & 0,03 & & \\
\hline 82 & $\mathrm{H} 2 \mathrm{~W} 2 \mathrm{~A} 2 \mathrm{~W} 2 \mathrm{H}$ & 0,01 & 0,03 & 0,01 & 164 & H3S3W3H & 0,03 & 0,004 & \\
\hline 83 & Н3А2Н & 0,06 & 0,12 & 0,01 & 165 & H2W3W2H & 0,03 & 0,007 & \\
\hline 84 & H1W1H3S3H & 0,06 & 0,01 & 0,07 & 166 & H3S3H1S1H & 0,03 & 0,004 & \\
\hline 85 & H2А2H1A1H & 0,05 & 0,01 & 0,07 & 167 & H1S1S1W1H & 0,02 & & \\
\hline 86 & H3W3АЗН & 0,03 & 0,05 & & 168 & H3S3W3S3H & 0,02 & & \\
\hline 87 & H3S2H & 0,06 & 0,10 & & 169 & H2W1W1W2H & 0,02 & & \\
\hline 88 & H3S3H2W2H & 0,05 & 0,004 & 0,03 & 170 & H1S1S1S1H & 0,02 & & \\
\hline 89 & H1A1H1S1H & 0,05 & 0,02 & 0,04 & 171 & H1S3H1A1H & 0,02 & & \\
\hline 90 & H2A3А3А2H & 0,03 & 0,02 & 0,01 & 172 & H1S1W1A1H & 0,02 & & \\
\hline
\end{tabular}


H1W1H, H2S2H e H3A3H são exemplos de padrões de viagens onde pessoas realizaram duas viagens e não trocaram de modo de transporte, utilizando o automóvel no primeiro caso para ida e volta ao trabalho, transporte coletivo no caso seguinte para ida e volta a escola e modo a pé no terceiro caso para viagens relacionadas a outras atividades, por exemplo.

Pitombo (2003) codificou 123 padrões de viagens segundo motivo e modo de transporte para que padrões com freqüência acima de 0,02\% da amostra da RMSP de 1987 fossem caracterizados e, neste trabalho, houve a necessidade de ampliar esta codificação para 172 padrões de viagens, com intuito de caracterizar também padrões de viagem com freqüência acima de 0,02\% das três amostras.

Observa-se que o padrão mais freqüente nas três amostras corresponde aos indivíduos que não viajam $(\mathrm{H})$, código 01 , no entanto, a partir daí os padrões divergem e a Figura 5.3. mostra a seqüência dos padrões de viagens mais freqüentes encontrados nas três amostras.

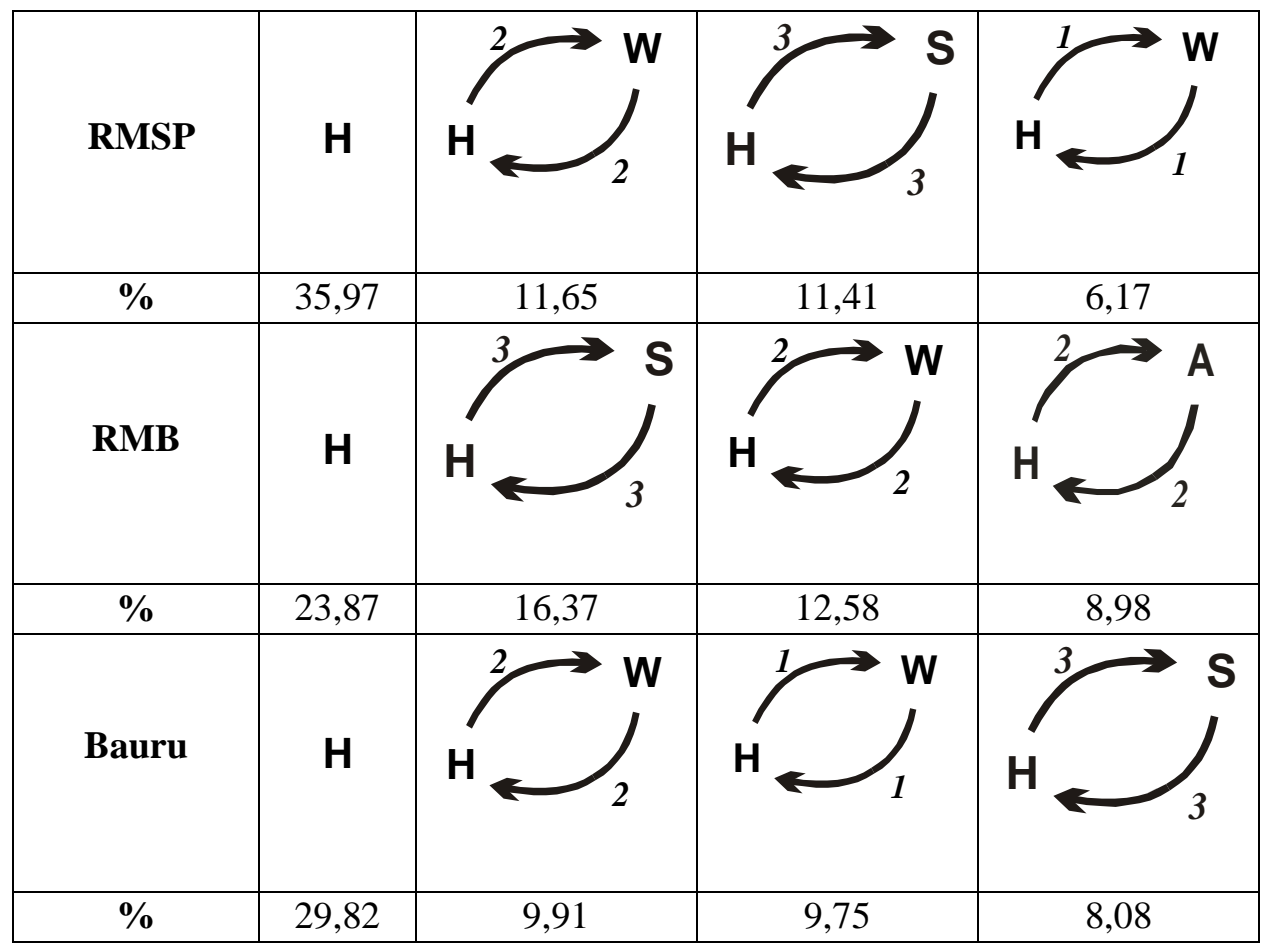

Figura 5.3: Quatro padrões mais freqüentes nas três amostras nesta etapa 
Analisando os padrões mais freqüentes mostrados na Figura 5.3, nota-se o maior percentual de indivíduos que utilizam o automóvel como modo de transporte na cidade de Bauru em relação às regiões metropolitanas. Isso se deve, provavelmente, ao maior índice de motorização da sua população.

Vale salientar que devido ao fato do S-Plus 6.1 analisar até 128 padrões de viagens encadeadas, foram eliminados aqueles indivíduos que realizam cinco ou mais viagens, contribuindo para o aumento do percentual dos indivíduos que fazem o padrão H (não viaja) nas três áreas urbanas.

\subsection{Etapa 2: Período do dia}

Nesta etapa, primeiramente agruparam-se os horários de chegada das viagens no destino onde as atividades seriam realizadas. A Figura 5.4 mostra o agrupamento proposto, considerando períodos de pico e entre-picos.

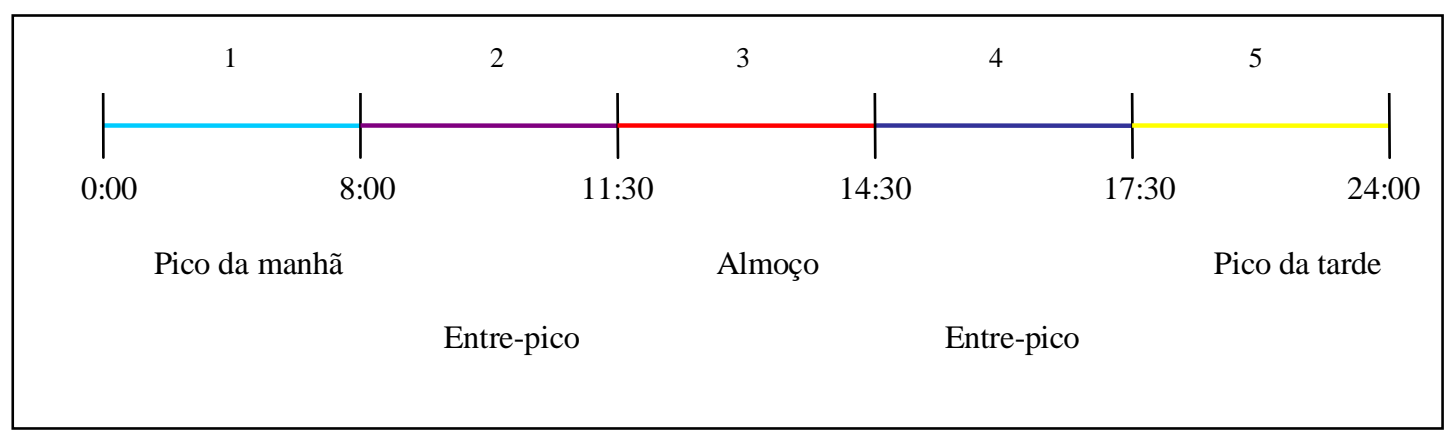

Figura 5.4: Agrupamento proposto para o período do dia

Os padrões de viagens referentes aos períodos do dia foram representados por números e possuíam a quantidade de algarismos de acordo com o número de viagens realizadas em um dia pelos indivíduos. Por exemplo, o padrão 1225 representa aqueles indivíduos que realizaram quatro viagens: a primeira no $1^{\circ}$ período $(0: 00-$ 8:00), a segunda e a terceira no $2^{\circ}$ período (8:00 - 11:30) e a última viagem de retorno ao domicílio no $5^{\circ}$ período (17:30 - 24:00). 
Os indivíduos que realizaram viagens que tiveram horário de saída no $5^{\circ}$ período e só retornaram no $1^{\circ}$ período foram eliminados das amostras. Portanto, nesta etapa houve um decréscimo das bases de dados que passaram a contabilizar os seguintes números de indivíduos: RMSP - 80.830, RMB - 28.092 e Bauru - 11.669.

A escolha de apenas cinco períodos para representar os horários se deve ao fato de que o aumento no número de períodos representados levaria conseqüentemente a um acréscimo no número de combinações e padrões resultantes, indo de encontro à limitação do Software disponível de apenas 128 padrões finais.

A Tabela 5.4 mostra todos padrões considerados, a sua freqüência e os seus respectivos códigos. O código 01 corresponde ao padrão H (zero viagens), 02 corresponde ao “ 15 ”, 03 representa “ 14 ” e assim sucessivamente.

Tabela 5.4: Padrões segundo período do dia com seus respectivos códigos e freqüências (\%)

\begin{tabular}{c|c|c|c|c|c|c|c|c|c}
\hline $\mathbf{C o ́ d}$ & $\begin{array}{c}\text { Padrões } \\
\text { Período }\end{array}$ & $\begin{array}{c}\text { RMSP } \\
\mathbf{( \% )}\end{array}$ & $\begin{array}{c}\text { RMB } \\
\mathbf{( \% )}\end{array}$ & $\begin{array}{c}\text { Bauru } \\
\mathbf{( \% )}\end{array}$ & Cód & $\begin{array}{c}\text { Padrões } \\
\text { Período }\end{array}$ & $\begin{array}{c}\text { RMSP } \\
\mathbf{( \% )}\end{array}$ & $\begin{array}{c}\text { RMB } \\
\mathbf{( \% )}\end{array}$ & $\begin{array}{c}\text { Bauru } \\
\mathbf{( \% )}\end{array}$ \\
\hline $\mathbf{0 1}$ & $\mathrm{H}$ & 36,21 & 24,01 & 30,49 & $\mathbf{6 2}$ & 1445 & 0,09 & 0,09 & 0,57 \\
$\mathbf{0 2}$ & 15 & 9,52 & 8,41 & 1,42 & $\mathbf{6 3}$ & 1244 & 0,05 & 0,06 & \\
$\mathbf{0 3}$ & 14 & 3,71 & 2,55 & 12,25 & $\mathbf{6 4}$ & 123 & 0,06 & 0,11 & \\
$\mathbf{0 4}$ & 13 & 6,65 & 11,26 & 1,00 & $\mathbf{6 5}$ & 2255 & 0,13 & 0,23 & \\
$\mathbf{0 5}$ & 34 & 2,38 & 1,83 & 8,31 & $\mathbf{6 6}$ & 3555 & 0,16 & 0,23 & 0,55 \\
$\mathbf{0 6}$ & 12 & 2,03 & 4,63 & 9,29 & $\mathbf{6 7}$ & 455 & 0,13 & 0,10 & \\
$\mathbf{0 7}$ & 24 & 2,68 & 2,58 & 3,25 & $\mathbf{6 8}$ & 444 & 0,07 & 0,01 & \\
$\mathbf{0 8}$ & 35 & 6,01 & 7,60 & 2,21 & $\mathbf{6 9}$ & 2233 & 0,08 & 0,05 & 0,11 \\
$\mathbf{0 9}$ & 45 & 2,54 & 4,21 & 2,49 & $\mathbf{7 0}$ & 3345 & 0,15 & 0,01 & 0,03 \\
$\mathbf{1 0}$ & 55 & 3,28 & 7,24 & 5,13 & $\mathbf{7 1}$ & 114 & 0,04 & 0,02 & \\
$\mathbf{1 1}$ & 25 & 5,96 & 3,56 & 2,91 & $\mathbf{7 2}$ & 133 & 0,13 & 0,05 & \\
$\mathbf{1 2}$ & 23 & 1,93 & 4,50 & 2,95 & $\mathbf{7 3}$ & 3355 & 0,27 & 0,06 & \\
$\mathbf{1 3}$ & 1455 & 0,49 & 0,30 & 0,31 & $\mathbf{7 4}$ & 2355 & 0,15 & 0,29 & \\
$\mathbf{1 4}$ & 22 & 1,11 & 4,56 & 2,59 & $\mathbf{7 5}$ & 555 & 0,11 & 0,07 & \\
$\mathbf{1 5}$ & 44 & 0,92 & 0,74 & 2,01 & $\mathbf{7 6}$ & 235 & 0,15 & 0,05 & \\
$\mathbf{1 6}$ & 1335 & 0,96 & 1,42 & 2,67 & $\mathbf{7 7}$ & 445 & 0,11 & 0,05 & \\
$\mathbf{1 7}$ & 155 & 0,59 & 0,26 & & $\mathbf{7 8}$ & 2245 & 0,10 & 0,19 & \\
$\mathbf{1 8}$ & 145 & 0,18 & 0,05 & & $\mathbf{7 9}$ & 3445 & 0,06 & 0,02 & 0,40 \\
$\mathbf{1 9}$ & 33 & 0,66 & 0,40 & 0,59 & $\mathbf{8 0}$ & 1223 & 0,03 & 0,08 & 0,07 \\
\hline
\end{tabular}




\begin{tabular}{|c|c|c|c|c|c|c|c|c|c|}
\hline Cód & $\begin{array}{l}\text { Padrões } \\
\text { Período }\end{array}$ & $\begin{array}{c}\text { RMSP } \\
(\%)\end{array}$ & $\begin{array}{c}\text { RMB } \\
(\%)\end{array}$ & $\begin{array}{c}\text { Bauru } \\
(\%)\end{array}$ & Cód & $\begin{array}{l}\text { Padrões } \\
\text { Período }\end{array}$ & $\begin{array}{c}\text { RMSP } \\
(\%)\end{array}$ & $\begin{array}{c}\text { RMB } \\
(\%)\end{array}$ & $\begin{array}{c}\text { Bauru } \\
(\%)\end{array}$ \\
\hline 20 & 1555 & 0,60 & 0,39 & 1,81 & 81 & 1123 & 0,04 & 0,07 & \\
\hline 21 & 1334 & 0,50 & 0,23 & 0,75 & 82 & 1224 & 0,01 & 0,01 & 0,05 \\
\hline 22 & 1234 & 0,11 & 0,08 & 0,08 & 83 & 4555 & 0,10 & 0,13 & 0,21 \\
\hline 23 & 3344 & 0,25 & 0,02 & 0,09 & 84 & 113 & 0,05 & 0,06 & \\
\hline 24 & 1345 & 0,36 & 1,10 & 0,19 & 85 & 1225 & 0,03 & 0,01 & 0,03 \\
\hline 25 & 1235 & 0,15 & 0,21 & 0,29 & 86 & 1155 & 0,12 & 0,05 & \\
\hline 26 & 1355 & 0,35 & 0,49 & & 87 & 1144 & 0,07 & 0,02 & \\
\hline 27 & 11 & 0,25 & 0,55 & 0,10 & 88 & 1145 & 0,06 & 0,02 & \\
\hline 28 & 1122 & 0,12 & 0,10 & 0,03 & 89 & 224 & 0,05 & 0,03 & \\
\hline 29 & 3455 & 0,18 & 0,11 & 0,22 & 90 & 2445 & 0,09 & 0,09 & 0,31 \\
\hline 30 & 255 & 0,50 & 0,11 & & 91 & 244 & 0,07 & 0,01 & \\
\hline 31 & 2335 & 0,73 & 0,61 & 1,26 & 92 & 335 & 0,08 & 0,01 & \\
\hline 32 & 2455 & 0,24 & 0,17 & 0,24 & 93 & 1222 & 0,02 & 0,02 & 0,03 \\
\hline 33 & 2234 & 0,08 & 0,06 & 0,09 & 94 & 1444 & 0,04 & 0,02 & 0,01 \\
\hline 34 & 134 & 0,13 & 0,05 & & 95 & 1333 & 0,03 & 0,02 & 0,01 \\
\hline 35 & 135 & 0,26 & 0,11 & & 96 & 225 & 0,09 & 0,02 & \\
\hline 36 & 344 & 0,14 & 0,02 & & 97 & 3444 & 0,03 & 0,01 & \\
\hline 37 & 345 & 0,15 & 0,04 & & 98 & 2223 & 0,03 & 0,07 & 0,15 \\
\hline 38 & 115 & 0,18 & 0,06 & & 99 & 333 & 0,04 & 0,004 & \\
\hline 39 & 1245 & 0,10 & 0,13 & & 100 & 2222 & 0,01 & 0,04 & 0,03 \\
\hline 40 & 1344 & 0,16 & 0,16 & 0,23 & 101 & 3335 & 0,02 & 0,004 & 0,01 \\
\hline 41 & 144 & 0,07 & 0,01 & & 102 & 112 & 0,01 & 0,02 & \\
\hline 42 & 1255 & 0,12 & 0,12 & & 103 & 1124 & 0,01 & 0,01 & 0,03 \\
\hline 43 & 2244 & 0,13 & 0,09 & & 104 & 1134 & 0,02 & 0,01 & \\
\hline 44 & 2555 & 0,42 & 0,10 & 0,68 & 105 & 2333 & 0,03 & 0,01 & \\
\hline 45 & 234 & 0,16 & 0,05 & & 106 & 5555 & 0,05 & 0,04 & 0,04 \\
\hline 46 & 223 & 0,17 & 0,22 & & 107 & 1125 & 0,07 & 0,01 & 0,03 \\
\hline 47 & 2345 & 0,28 & 0,64 & 0,16 & 108 & 2444 & 0,03 & 0,02 & \\
\hline 48 & 334 & 0,06 & 0,02 & & 109 & 4444 & 0,01 & 0,01 & 0,01 \\
\hline 49 & 245 & 0,14 & 0,04 & & 110 & 4445 & 0,02 & 0,01 & 0,06 \\
\hline 50 & 233 & 0,10 & 0,07 & & 111 & 1135 & 0,05 & 0,01 & \\
\hline 51 & 125 & 0,14 & 0,07 & & 112 & 3334 & 0,03 & 0,01 & 0,11 \\
\hline 52 & 4455 & 0,19 & 0,08 & 0,04 & 113 & 1114 & 0,01 & & 0,06 \\
\hline 53 & 1233 & 0,08 & 0,07 & 0,06 & 114 & 2224 & 0,01 & 0,01 & 0,01 \\
\hline 54 & 1133 & 0,20 & 0,10 & & 115 & 1115 & 0,04 & 0,02 & \\
\hline 55 & 2334 & 0,17 & 0,10 & 0,36 & 116 & 111 & 0,01 & 0,004 & \\
\hline 56 & 124 & 0,05 & 0,03 & & 117 & 1113 & 0,005 & 0,01 & 0,01 \\
\hline 57 & 122 & 0,04 & 0,08 & & 118 & 2225 & 0,02 & 0,004 & 0,02 \\
\hline 58 & 2235 & 0,14 & 0,17 & 0,11 & 119 & 1112 & 0,005 & 0,02 & 0,08 \\
\hline 59 & 355 & 0,18 & 0,11 & & 120 & 131 & & & \\
\hline 60 & 2344 & 0,11 & 0,06 & 0,15 & 121 & 3333 & 0,01 & & \\
\hline 61 & 222 & 0,05 & 0,09 & & 122 & 1111 & 0,002 & 0,004 & \\
\hline
\end{tabular}


Novamente foi seguida a codificação proposta por Pitombo (2003) e acrescentou-se somente o padrão “1111” (código 122) que corresponde aos indivíduos que realizam quatro viagens no período 1 (denominado pico da manhã, entre 0:00 - 8:00). A Figura 5.5 ilustra os quatro padrões de viagens mais freqüentes nesta etapa.

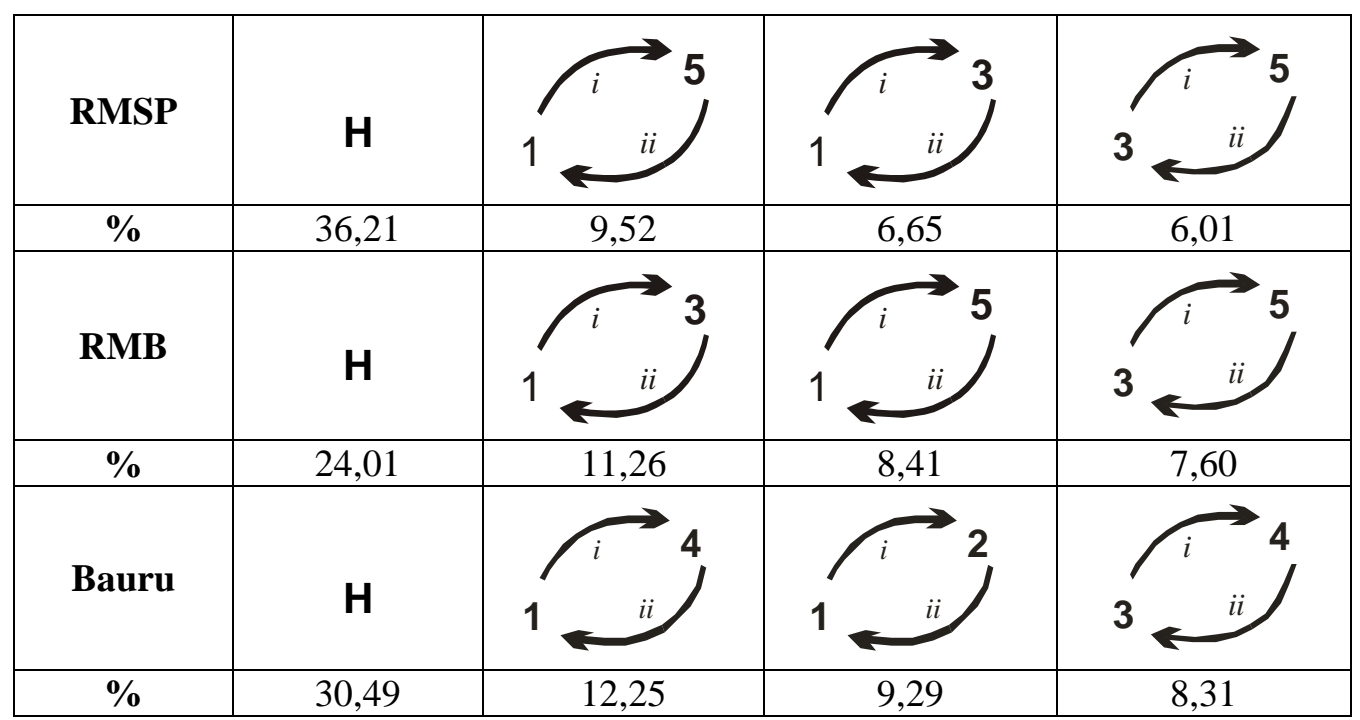

Figura 5.5: Quatro padrões mais freqüentes nas três amostras nesta etapa

\subsection{Padrões finais: combinação entre motivo, modo e período do dia}

Os padrões finais utilizados neste trabalho foram determinados a partir da combinação das etapas 1 (motivo e modo) e 2 (período do dia), ou seja, na sua maioria, os padrões foram representados por quatro algarismos, onde os dois primeiros se referem aos códigos atribuídos para os padrões segundo modo e motivo e os dois seguintes aos padrões de viagem segundo período do dia.

O padrão “0304”, por exemplo, corresponde aos indivíduos que realizaram os padrões “H2W2H” (código 03) e “13” (código 04), ou seja, realizaram duas viagens de transporte coletivo, uma viagem de casa ao trabalho e outra do trabalho para casa, em períodos distintos do dia ( $1^{\mathrm{a}}$ viagem entre 0:00-8:00, período 1 , e $2^{\mathrm{a}}$ viagem entre 11:30 e 14:30, período 2). 
O método para comparação entre as três regiões consiste em agrupar os três bancos de dados em um só e, a partir daí, determinar os 128 padrões de viagens finais para a análise. A Tabela 5.5 mostra o resultado da seleção dos 128 padrões finais utilizados para processamento da árvore de decisão neste banco de dados geral e as respectivas freqüências encontradas. Tal seleção constitui o Passo 5 da filtragem dos dados.

Salienta-se que a eliminação de padrões pouco freqüentes não seria a maneira ideal de proceder pois ocasiona eliminação de padrões complementares que ajudariam a compreender o comportamento de viajantes urbanos, porém, o número restrito de valores de variáveis resposta na árvore de decisão do S-Plus nos obrigar a trabalhar com um número máximo de 128 padrões de viagens.

Tabela 5.5: Padrões finais analisados e respectivas freqüências (\%)

\begin{tabular}{|c|c|c|c|c|c|c|c|c|c|}
\hline $\begin{array}{l}\text { Padrões } \\
\text { Finais }\end{array}$ & Motivo & Modo & Período & $\begin{array}{c}\text { Freqüência } \\
(\%)\end{array}$ & $\begin{array}{c}\text { Padrões } \\
\text { Finais }\end{array}$ & Motivo & Modo & Período & $\begin{array}{c}\text { Freqüência } \\
(\%)\end{array}$ \\
\hline 0101 & $\mathrm{H}$ & $\mathrm{H}$ & $\mathrm{H}$ & 37,83 & 0604 & HAH & 22 & 13 & 0,22 \\
\hline 0302 & HWH & 22 & 15 & 5,52 & 0709 & $\mathrm{HSH}$ & 22 & 45 & 0,20 \\
\hline 0204 & $\mathrm{HSH}$ & 33 & 13 & 3,57 & 1010 & $\mathrm{HSH}$ & 11 & 55 & 0,20 \\
\hline 0208 & $\mathrm{HSH}$ & 33 & 35 & 2,86 & 0312 & $\mathrm{HWH}$ & 22 & 23 & 0,19 \\
\hline 0311 & HWH & 22 & 25 & 2,71 & 0212 & HSH & 33 & 23 & 0,19 \\
\hline 0303 & HWH & 22 & 14 & 2,22 & 1121 & HWHWH & 3333 & 1334 & 0,19 \\
\hline 0402 & HWH & 11 & 15 & 2,10 & 0619 & НАH & 22 & 33 & 0,18 \\
\hline 0206 & $\mathrm{HSH}$ & 33 & 12 & 2,06 & 0919 & HAH & 33 & 33 & 0,16 \\
\hline 0210 & $\mathrm{HSH}$ & 33 & 55 & 1,86 & 2504 & HSH & 13 & 13 & 0,16 \\
\hline 0704 & $\mathrm{HSH}$ & 22 & 13 & 1,80 & 0602 & $\mathrm{HAH}$ & 22 & 15 & 0,16 \\
\hline 0411 & HWH & 11 & 25 & 1,60 & 1320 & HWHSH & 2233 & 1555 & 0,16 \\
\hline 0502 & HWH & 33 & 15 & 1,35 & 0702 & HSH & 22 & 15 & 0,16 \\
\hline 0612 & HAH & 22 & 23 & 1,26 & 0707 & HSH & 22 & 24 & 0,15 \\
\hline 0708 & $\mathrm{HSH}$ & 22 & 35 & 1,25 & 0412 & $\mathrm{HWH}$ & 11 & 23 & 0,14 \\
\hline 0914 & НАH & 33 & 22 & 1,15 & 0512 & $\mathrm{HWH}$ & 33 & 23 & 0,13 \\
\hline 0403 & $\mathrm{HWH}$ & 11 & 14 & 1,12 & 1417 & HWSH & 222 & 155 & 0,13 \\
\hline 0209 & $\mathrm{HSH}$ & 33 & 45 & 1,09 & 3716 & HWHWH & 2222 & 1335 & 0,13 \\
\hline 0503 & $\mathrm{HWH}$ & 33 & 14 & 1,07 & 0409 & HWH & 11 & 45 & 0,12 \\
\hline 0308 & $\mathrm{HWH}$ & 22 & 35 & 1,02 & 0509 & HWH & 33 & 45 & 0,12 \\
\hline 0205 & $\mathrm{HSH}$ & 33 & 34 & 1,02 & 1223 & HSHSH & 3333 & 3344 & 0,12 \\
\hline 0207 & $\mathrm{HSH}$ & 33 & 24 & 0,98 & 0214 & HSH & 33 & 22 & 0,11 \\
\hline 0710 & $\mathrm{HSH}$ & 22 & 55 & 0,93 & 0808 & $\mathrm{HAH}$ & 11 & 35 & 0,11 \\
\hline 0511 & $\mathrm{HWH}$ & 33 & 25 & 0,84 & 0806 & $\mathrm{HAH}$ & 11 & 12 & 0,11 \\
\hline 1004 & $\mathrm{HSH}$ & 11 & 13 & 0,82 & 0819 & $\mathrm{HAH}$ & 11 & 33 & 0,10 \\
\hline 0605 & $\mathrm{HAH}$ & 22 & 34 & 0,78 & 0603 & $\mathrm{HAH}$ & 22 & 14 & 0,10 \\
\hline 0910 & $\mathrm{HAH}$ & 33 & 55 & 0,71 & 0219 & $\mathrm{HSH}$ & 33 & 33 & 0,10 \\
\hline
\end{tabular}




\begin{tabular}{|c|c|c|c|c|c|c|c|c|c|}
\hline $\begin{array}{c}\text { Padrões } \\
\text { Finais }\end{array}$ & Motivo & Modo & Período & $\begin{array}{c}\text { Freqüência } \\
\text { (\%) }\end{array}$ & $\begin{array}{l}\text { Padrões } \\
\text { Finais }\end{array}$ & Motivo & Modo & Período & $\begin{array}{c}\text { Freqüência } \\
\text { (\%) }\end{array}$ \\
\hline 0609 & $\mathrm{HAH}$ & 22 & 45 & 0,68 & 0811 & $\mathrm{HAH}$ & 11 & 25 & 0,10 \\
\hline 0614 & HAH & 22 & 22 & 0,62 & 0908 & НАН & 33 & 35 & 0,09 \\
\hline 0307 & $\mathrm{HWH}$ & 22 & 24 & 0,57 & 0712 & $\mathrm{HSH}$ & 22 & 23 & 0,09 \\
\hline 0810 & $\mathrm{HAH}$ & 11 & 55 & 0,55 & 11931 & HWAWH & 2332 & 2335 & 0,09 \\
\hline 0304 & $\mathrm{HWH}$ & 22 & 13 & 0,54 & 0215 & HSH & 33 & 44 & 0,09 \\
\hline 0912 & НАH & 33 & 23 & 0,46 & 11916 & HWAWH & 2332 & 1335 & 0,09 \\
\hline 0607 & HAH & 22 & 24 & 0,41 & 0310 & HWH & 22 & 55 & 0,09 \\
\hline 0407 & $\mathrm{HWH}$ & 11 & 24 & 0,41 & 0703 & HSH & 22 & 14 & 0,09 \\
\hline 0909 & $\mathrm{HAH}$ & 33 & 45 & 0,41 & 0907 & $\mathrm{HAH}$ & 33 & 24 & 0,09 \\
\hline 1116 & HWHWH & 3333 & 1335 & 0,41 & 0927 & HAH & 33 & 11 & 0,08 \\
\hline 0812 & HAH & 11 & 23 & 0,40 & 1273 & HSHSH & 3333 & 3355 & 0,08 \\
\hline 0805 & НAH & 11 & 34 & 0,38 & 1430 & HWSH & 222 & 255 & 0,08 \\
\hline 0504 & $\mathrm{HWH}$ & 33 & 13 & 0,38 & 0807 & HAH & 11 & 24 & 0,08 \\
\hline 0706 & $\mathrm{HSH}$ & 22 & 12 & 0,38 & 2120 & HWHAH & 1111 & 1555 & 0,08 \\
\hline 0606 & HAH & 22 & 12 & 0,38 & 0227 & HSH & 33 & 11 & 0,07 \\
\hline 0610 & HAH & 22 & 55 & 0,38 & 1254 & HSHSH & 3333 & 1133 & 0,07 \\
\hline 1008 & HSH & 11 & 35 & 0,37 & 3238 & HSWH & 111 & 115 & 0,07 \\
\hline 0905 & HAH & 33 & 34 & 0,35 & 2802 & HWH & 12 & 15 & 0,07 \\
\hline 1006 & HSH & 11 & 12 & 0,35 & 1228 & HSHSH & 3333 & 1122 & 0,07 \\
\hline 0408 & $\mathrm{HWH}$ & 11 & 35 & 0,34 & 1019 & HSH & 11 & 33 & 0,07 \\
\hline 0608 & HAH & 22 & 35 & 0,34 & 2220 & HWHSH & 3333 & 1555 & 0,07 \\
\hline 0508 & $\mathrm{HWH}$ & 33 & 35 & 0,33 & 0203 & HSH & 33 & 14 & 0,07 \\
\hline 0915 & НАH & 33 & 44 & 0,33 & 0802 & HAH & 11 & 15 & 0,07 \\
\hline 1516 & HWHWH & 1111 & 1335 & 0,33 & 0202 & $\mathrm{HSH}$ & 33 & 15 & 0,07 \\
\hline 0615 & HAH & 22 & 44 & 0,32 & 1002 & $\mathrm{HSH}$ & 11 & 15 & 0,06 \\
\hline 0809 & HAH & 11 & 45 & 0,31 & 2411 & $\mathrm{HWH}$ & 21 & 25 & 0,06 \\
\hline 0507 & $\mathrm{HWH}$ & 33 & 24 & 0,31 & 3817 & HWSH & 111 & 155 & 0,06 \\
\hline 0814 & HAH & 11 & 22 & 0,30 & 1243 & HSHSH & 3333 & 2244 & 0,06 \\
\hline 0906 & HAH & 33 & 12 & 0,28 & 1124 & HWHWH & 3333 & 1345 & 0,06 \\
\hline 0309 & $\mathrm{HWH}$ & 22 & 45 & 0,27 & 1344 & HWHSH & 2233 & 2555 & 0,06 \\
\hline 0611 & HAH & 22 & 25 & 0,27 & 1313 & HWHSH & 2233 & 1455 & 0,06 \\
\hline 0815 & HAH & 11 & 44 & 0,26 & 1913 & HWHSH & 2222 & 1455 & 0,06 \\
\hline 1604 & $\mathrm{HSH}$ & 12 & 13 & 0,25 & 0904 & НАH & 33 & 13 & 0,05 \\
\hline 1005 & $\mathrm{HSH}$ & 11 & 34 & 0,25 & 3830 & HWSH & 111 & 255 & 0,05 \\
\hline 0404 & HWH & 11 & 13 & 0,25 & 0410 & HWH & 11 & 55 & 0,05 \\
\hline 1131 & HWHWH & 3333 & 2335 & 0,24 & 2213 & HWHSH & 3333 & 1455 & 0,05 \\
\hline 0705 & HSH & 22 & 34 & 0,24 & 2330 & HWAH & 111 & 255 & 0,05 \\
\hline 1531 & HWHWH & 1111 & 2335 & 0,22 & 3724 & HWHWH & 2222 & 1345 & 0,05 \\
\hline \multicolumn{10}{|c|}{ Amostra final de 104.594 indivíduos. Alguns padrões que ficaram fora são mostrados a seguir: } \\
\hline 0306 & $\mathrm{HWH}$ & 22 & 12 & 0,05 & 1147 & HWHWH & 3333 & 2345 & 0,05 \\
\hline 2402 & HWH & 21 & 15 & 0,05 & 0510 & HWH & 33 & 55 & 0,04 \\
\hline 1252 & HSHSH & 3333 & 4455 & 0,05 & 1155 & HWHWH & 3333 & 2334 & 0,04 \\
\hline 15931 & HWAWH & 1331 & 2335 & 0,05 & 2317 & HWAH & 111 & 155 & 0,04 \\
\hline 0902 & НАН & 33 & 15 & 0,05 & 2754 & HSHSH & 1111 & 1133 & 0,04 \\
\hline 3731 & HWHWH & 2222 & 2335 & 0,05 & 0911 & НАН & 33 & 25 & 0,04 \\
\hline 0405 & HWH & 11 & 34 & 0,05 & 3747 & HWHWH & 2222 & 2345 & 0,04 \\
\hline
\end{tabular}


Nota-se dentre alguns padrões que ficaram de fora da análise, existem aqueles do tipo HWAWH e HWAH, onde os indivíduos encadeiam as viagens por motivo “trabalho” e “outras atividades”, mais comuns na Região Metropolitana de São Paulo.

No banco de dados geral, a distribuição das amostras ficou da seguinte forma:

- RMSP: 69.569 indivíduos (66,51\%);

- RMB: 24.601 indivíduos (23,52\%);e

- Bauru: 10.424 indivíduos (9,97\%). 


\section{PROCESSAMENTO DA ÁRVORE DE DECISÃO E CLASSIFICAÇÃO E RESULTADOS}

Capítulo

O processamento da Árvore de Decisão e Classificação, contida no S-Plus 6.1., foi realizado utilizando como variável dependente, ou resposta, o "Padrão Final" (padrões de viagens segundo o motivo de viagens, modo de transporte e período do dia) e como variáveis preditoras, ou independentes, as seguintes características socioeconômicas: renda familiar, número de automóveis no domicílio, total de pessoas na família, grau de instrução, idade do indivíduo, sexo, identificador da base de dados, se o indivíduo estuda ou não e se ele trabalha ou não.

A ocupação principal do indivíduo se resumiu apenas em "trabalha ou não" e "estuda ou não" e o tipo de profissão exercida pelo indivíduo foi utilizado apenas para detalhamento e esclarecimento de resultados.

Salienta-se que não foram incluídas as características socioeconômicas individuais "salário médio" e "situação familiar" uma vez que o banco de dados da RMB não contemplar tais características.

As variáveis preditoras consideradas no processamento da árvore são descritas como:

> RFSM - Renda familiar em salários mínimos da época;

> Auto - Número de automóveis no domicílio;

$>$ TTPESF - Total de pessoas na família; 
> GI - Grau de instrução: (1) Analfabeto/4ª série incompleta; (2) $1^{\text {o }}$ grau incompleto/4 $4^{\mathrm{a}}$ série completa; (3) $1^{\circ}$ grau completo; (4) $2^{\circ}$ grau completo; (5) Superior completo

$>$ Idade - Idade do indivíduo;

$>$ Sexo - (1) Homem; (2) Mulher;

> Área Urbana - Identificador da base de dados: (1) RMSP; (2) RMB; (3) Bauru;

$>$ Estuda - Se o indivíduo estuda ou não;

$>$ Trabalha - Se o indivíduos trabalha ou não.

Nota-se que para o processamento da árvore foi criada uma variável preditora denominada “Área Urbana” com a função de identificar se e como as áreas urbanas interferem no comportamento de viajantes urbanos. Tal variável é de grande valia para a análise pois a partir dela se pode determinar os grupos socioeconômicos que apresentam diferenças ou similaridades dentre as três bases de dados.

Vale ressaltar que o algoritmo embutido na Árvore de Decisão e Classificação do SPlus 6.1, variante do algoritmo CART, estabelece uma relação entre variáveis preditoras e variáveis resposta. O algoritmo procura encontrar as variáveis preditoras mais importantes e que, portanto, forneçam a máxima segregação dos dados em relação as variáveis resposta.

O S-Plus gera resultados de forma gráfica (Árvore de Decisão e Classificação) e tabular (relatório). Tal relatório apresenta detalhadamente os resultados da árvore: número do nó, total de observações no nó, desvio, padrão predominante e as probabilidades de ocorrência de todos os padrões da análise.

\subsection{Processamento da Árvore de Decisão e Classificação}

A árvore foi gerada a partir dos dados filtrados e codificados da Pesquisa O/D da RMSP, realizada pelo METRÔ-SP, em 1997, da Pesquisa Domiciliar, realizada pela JICA e Governo do Estado do Pará na RMB, em 2000, e da Pesquisa O/D realizada 
pela EMDURB, em 1997. Os valores apresentados nos nós terminais (folhas) correspondem ao padrão predominante encontrado em cada classe de indivíduos.

Os critérios adotados para a geração da árvore no S-Plus foram: o mínimo de 20 observações por nó terminal e um desvio mínimo de 0,02 em relação ao nó principal. Ressalta-se que quanto menor o desvio, maior o número de classes e características distintas formadas e, conseqüentemente, a classificação se torna mais detalhada e complexa.

A variável mais importante foi “Trabalha”. A partir da raiz, a árvore se ramifica em dois grupos principais de indivíduos: “Não Trabalha” ou “Trabalha”. Salienta-se que os grupos principais foram formados a partir das variáveis socioeconômicas citadas no início deste capítulo.

Entre os indivíduos que não trabalham, formam-se duas classes principais:

$>$ Pessoas que não trabalham e não estudam;

$>$ Pessoas que não trabalham e estudam;

Já entre indivíduos que trabalham, primeiramente, eles são subdivididos de acordo com o número de automóveis no domicílio, formando então duas novas classes:

Pessoas que trabalham e não possuem automóvel no domicílio;

$>$ Pessoas que trabalham e possuem pelo menos um automóvel no domicílio.

Verifica-se que a participação das pessoas nas duas principais atividades (trabalho e estudo) e a posse de automóveis foram as variáveis mais importantes para a construção da árvore. A partir daí, a árvore segrega levando em consideração as outras variáveis socioeconômicas citadas anteriormente, inclusive, distinguindo as diferentes áreas urbanas. Ao final da segregação do banco de dados que inclui as três áreas urbanas, foram encontrados então 60 grupos "homogêneos” em relação aos padrões de viagens escolhidos. 
Dentre os 128 padrões finais contidos na análise, observa-se a predominância de apenas 10 deles. A Tabela 6.1 mostra os padrões finais predominantes encontrados na árvore gerada pelo S-Plus 6.1.

Tabela 6.1: Padrões predominantes encontrados nas classes finais de indivíduos

\begin{tabular}{|c|c|c|c|c|}
\hline $\begin{array}{c}\text { Padrões predominantes } \\
\text { (Cód. Motivo-Modo, Cód. Período do dia) }\end{array}$ & Viagem & Motivo & Modo & Período \\
\hline $0101(\mathrm{H})$ & \multicolumn{4}{|c|}{ Não viajou } \\
\hline \multirow{2}{*}{0302 (H2W2H, 15) } & $1^{a}$ & casa-trabalho & coletivo & 00:00-08:00 \\
\hline & $2^{a}$ & trabalho-casa & coletivo & 17:30-24:00 \\
\hline \multirow{2}{*}{0204 (H3S3H, 13) } & $1^{\mathrm{a}}$ & casa-escola & a pé & 00:00-08:00 \\
\hline & $2^{a}$ & escola-casa & a pé & 11:30-14:30 \\
\hline \multirow{2}{*}{0303 (H2W2H, 14) } & $1^{\mathrm{a}}$ & casa-trabalho & coletivo & 00:00-08:00 \\
\hline & $2^{a}$ & trabalho-casa & coletivo & 14:30-17:30 \\
\hline \multirow{2}{*}{0402 (H1W1H, 15) } & $1^{\mathrm{a}}$ & casa-trabalho & auto & 00:00-08:00 \\
\hline & $2^{\mathrm{a}}$ & trabalho-casa & auto & $17: 30-24: 00$ \\
\hline \multirow{2}{*}{0206 (H3S3H, 12) } & $1^{\mathrm{a}}$ & casa-escola & a pé & 00:00-08:00 \\
\hline & $2^{a}$ & escola-casa & a pé & 08:00-11:30 \\
\hline \multirow{2}{*}{0210 (H3S3H, 55) } & $1^{\mathrm{a}}$ & casa-escola & a pé & 17:30-24:00 \\
\hline & $2^{a}$ & escola-casa & a pé & $17: 30-24: 00$ \\
\hline \multirow{2}{*}{0704 (H2S2H,13) } & $1^{\mathrm{a}}$ & casa-escola & coletivo & 00:00-08:00 \\
\hline & $2^{\mathrm{a}}$ & escola-casa & coletivo & 11:30-14:30 \\
\hline \multirow{2}{*}{0403 (H1W1H, 14) } & $1^{\mathrm{a}}$ & casa-trabalho & auto & 00:00-08:00 \\
\hline & $2^{\mathrm{a}}$ & trabalho-casa & auto & $14: 30-17: 30$ \\
\hline \multirow{2}{*}{0710 (H2S2H, 55) } & $1^{\mathrm{a}}$ & casa-escola & coletivo & $17: 30-24: 00$ \\
\hline & $2^{\mathrm{a}}$ & escola-casa & coletivo & $17: 30-24: 00$ \\
\hline
\end{tabular}

A Figura 6.1 representa a árvore completa gerada pelo S-Plus com desvio mínimo de 0,02. Como já dito anteriormente, observam-se 60 folhas (nós terminais), ou seja, 60 grupos homogêneos.

O nó 17, por exemplo, corresponde ao grupo de pessoas que não trabalham, não estudam, fazem parte da base de dados da RMB e possuem automóvel no domicílio. Já o nó 25 compreende as pessoas que trabalham, não possuem automóvel no domicílio, não estudam e que fazem parte da base de dados de Bauru. Nestes exemplos, os respectivos padrões de viagens predominantes foram “0101”, ou seja, não viajaram, e “0303”, onde as pessoas foram da casa para o trabalho a pé no $1^{\circ}$ período (0:00-08:00) e retornaram para casa no $4^{\circ}$ período (14:30-17:30). 
A árvore ilustra com clareza as variáveis preditoras mais importantes para segregação dos dados, no entanto, somente através do relatório podem ser visualizados as probabilidades de ocorrência de todos os padrões utilizados para a análise em cada etapa da segregação dos dados.

\subsection{Resultados do relatório emitido pelo S-Plus}

No relatório constam todas as classes de indivíduos, com as respectivas características particulares, apresentadas através da árvore, seguidas de todos os padrões contidos na análise e a probabilidade de ocorrência de cada um deles. Além disso, o relatório também fornece o número de pessoas contidas em cada classe, assim como os desvios dos nós.

Considerando a ocupação do indivíduo (trabalho ou estudo), as 60 folhas encontradas no processamento da árvore com desvio mínimo de 0,02 dividem-se da seguinte maneira segundo as diferentes bases de dados utilizadas na análise:

Classes de pessoas que não trabalham e também não estudam: 8 classes na RMSP, 6 classes na RMB e 2 classes em Bauru;

> Classes de pessoas que não trabalham, mas estudam: 8 classes na RMSP, 5 classes na RMB e 1 classe em Bauru. Nesta divisão, foram encontrados 3 grupos similares entre a RMSP e a RMB;

> Classes de pessoas que trabalham e não estudam: 10 classes na RMSP, 6 classes na RMB e 1 classe em Bauru. Foram encontrados 7 grupos com características particulares semelhantes entre a RMSP e a RMB;

$>$ Classes de pessoas que trabalham e estudam: Formaram-se duas classes: 1 classe que engloba os três bancos de dados e outra que engloba a RMSP e a RMB.

Classes de indivíduos que trabalham e podem estudar ou não estudar: uma única classe constituída pelo banco de dados da cidade de Bauru. 
A partir da árvore podem ser identificados grupos que apresentam diferenças e similaridades entre as diferentes bases de dados da análise. Desta forma, no capítulo seguinte pretende-se discutir as possíveis causas para a formação destes grupos socioeconômicos.

A seguir, é mostrada uma síntese do relatório contendo todos os nós terminais encontrados, juntamente com as características socioeconômicas que os identificam, bem como os oito padrões predominantes para cada folha e as freqüências respectivas. Também é mostrado o total de pessoas classificados segundo as características particulares de cada nó.

Nos Anexos A e B é possível encontrar o relatório adaptado da árvore gerada pelo SPlus 6.1 com o desvio mínimo de 0,02. Através dele o leitor interessado pode identificar a probabilidade de ocorrência de um dado padrão em um determinado nó. Salienta-se que tais anexos serão de suma importância para a etapa de análise de resultados. 
Tabela 6.2: Padrões predominantes encontrados nos nós terminais da Árvore

\begin{tabular}{|c|c|c|c|c|c|c|c|c|c|}
\hline \multirow{2}{*}{$\begin{array}{c}\text { Características } \\
\text { Socioeconômicas } \\
\text { Nó } 64 \text { (Total de pessoas: 130) }\end{array}$} & \multicolumn{9}{|c|}{ Padrões Predominantes } \\
\hline & Código & 0101 & 0206 & 0204 & 0208 & 0914 & 0910 & 0704 & 0708 \\
\hline \multirow{4}{*}{$\begin{array}{c}\text { Não Trabalha e Não Estuda } \\
\text { Base:2 (RMB) } \\
\text { Sem Auto } \\
\text { Idade } \leq 12 \\
\end{array}$} & Motivo & $\mathrm{H}$ & $\mathrm{HSH}$ & $\mathrm{HSH}$ & $\mathrm{HSH}$ & $\mathrm{HAH}$ & $\mathrm{HAH}$ & $\mathrm{HSH}$ & $\mathrm{HSH}$ \\
\hline & Modo & $\mathrm{H}$ & 33 & 33 & 33 & 33 & 33 & 22 & 22 \\
\hline & Período & $\mathrm{H}$ & 12 & 13 & 35 & 22 & 55 & 13 & 35 \\
\hline & $\%$ & 70,77 & 9,23 & 5,39 & 4,62 & 1,54 & 1,54 & 0,77 & 0,77 \\
\hline \multirow{5}{*}{$\begin{array}{c}\text { Nó } 130 \text { (Total de pessoas: 2050) } \\
\text { Não Trabalha e Não Estuda } \\
\text { Base:2 (RMB) } \\
\text { Sem Auto } \\
12<\text { Idade } \leq 36 \text { e GI:1,2,3 } \\
\end{array}$} & Código & 0101 & 0914 & 0910 & 0612 & 0912 & 0909 & 0609 & 0607 \\
\hline & Motivo & $\mathrm{H}$ & $\mathrm{HAH}$ & $\mathrm{HAH}$ & $\mathrm{HAH}$ & HAH & $\mathrm{HAH}$ & $\mathrm{HAH}$ & $\mathrm{HAH}$ \\
\hline & Modo & $\mathrm{H}$ & 33 & 33 & 22 & 33 & 33 & 22 & 22 \\
\hline & Período & $\mathrm{H}$ & 22 & 55 & 23 & 23 & 45 & 45 & 24 \\
\hline & $\%$ & 52,10 & 9,02 & 4,68 & 3,37 & 2,73 & 2,39 & 2,10 & 1,81 \\
\hline \multirow{5}{*}{$\begin{array}{c}\text { Nó } 131 \text { (Total de pessoas: 897) } \\
\text { Não Trabalha e Não Estuda } \\
\text { Base:2 (RMB) } \\
\text { Sem Auto } \\
12<\text { Idade } \leq 36 \text { e GI:4,5 } \\
\end{array}$} & Código & 0101 & 0914 & 0612 & 0609 & 0910 & 0909 & 0610 & 0912 \\
\hline & Motivo & $\mathrm{H}$ & $\mathrm{HAH}$ & HAH & $\mathrm{HAH}$ & HAH & HAH & $\mathrm{HAH}$ & HAH \\
\hline & Modo & $\mathrm{H}$ & 33 & 22 & 22 & 33 & 33 & 22 & 33 \\
\hline & Período & $\mathrm{H}$ & 22 & 23 & 45 & 55 & 45 & 55 & 23 \\
\hline & $\%$ & 45,82 & 5,91 & 5,57 & 4,24 & 3,68 & 2,56 & 2,34 & 2,23 \\
\hline \multirow{5}{*}{$\begin{array}{c}\text { Nó } 66 \text { (Total de pessoas: 2777) } \\
\text { Não Trabalha e Não Estuda } \\
\text { Base:2 (RMB) } \\
\text { Sem Auto } \\
\text { 36<Idade } \leq 65 \\
\end{array}$} & Código & 0101 & 0914 & 0612 & 0614 & 0609 & 0910 & 0912 & 0906 \\
\hline & Motivo & $\mathrm{H}$ & $\mathrm{HAH}$ & $\mathrm{HAH}$ & $\mathrm{HAH}$ & $\mathrm{HAH}$ & $\mathrm{HAH}$ & $\mathrm{HAH}$ & $\mathrm{HAH}$ \\
\hline & Modo & $\mathrm{H}$ & 33 & 22 & 22 & 22 & 33 & 33 & 33 \\
\hline & Período & $\mathrm{H}$ & 22 & 23 & 22 & 45 & 55 & 23 & 12 \\
\hline & $\%$ & 47,35 & 9,76 & 6,81 & 3,53 & 3,31 & 3,03 & 2,70 & 2,49 \\
\hline \multirow{5}{*}{$\begin{array}{c}\text { Nó } 67 \text { (Total de pessoas: 1250) } \\
\text { Não Trabalha e Não Estuda } \\
\text { Base:2 (RMB) } \\
\text { Sem Auto } \\
\text { Idade > } 65 \\
\end{array}$} & Código & 0101 & 0914 & 0612 & 0614 & 0606 & 0609 & 0906 & 0604 \\
\hline & Motivo & $\mathrm{H}$ & $\mathrm{HAH}$ & $\mathrm{HAH}$ & $\mathrm{HAH}$ & $\mathrm{HAH}$ & $\mathrm{HAH}$ & $\mathrm{HAH}$ & $\mathrm{HAH}$ \\
\hline & Modo & $\mathrm{H}$ & 33 & 22 & 22 & 22 & 22 & 33 & 22 \\
\hline & Período & $\mathrm{H}$ & 22 & 23 & 22 & 12 & 45 & 12 & 13 \\
\hline & $\%$ & 64,24 & 7,36 & 4,64 & 3,12 & 2,88 & 2,32 & 2,16 & 1,60 \\
\hline \multirow{5}{*}{$\begin{array}{c}\text { Nó } 17 \text { (Total de pessoas: 1200) } \\
\text { Não Trabalha e Não Estuda } \\
\text { Base:2 (RMB) } \\
\text { Com Auto }\end{array}$} & Código & 0101 & 0612 & 0914 & 0812 & 0910 & 0609 & 0614 & 0610 \\
\hline & Motivo & $\mathrm{H}$ & HAH & HAH & HAH & HAH & HAH & HAH & HAH \\
\hline & Modo & $\mathrm{H}$ & 22 & 33 & 11 & 33 & 22 & 22 & 22 \\
\hline & Período & $\mathrm{H}$ & 23 & 22 & 23 & 55 & 45 & 22 & 55 \\
\hline & $\%$ & 54,42 & 5,67 & 4,75 & 2,75 & 2,58 & 2,42 & 1,92 & 1,92 \\
\hline \multirow{5}{*}{$\begin{array}{c}\text { Nó } 72 \text { (Total de pessoas: 3141) } \\
\text { Não Trabalha e Não Estuda } \\
\text { Base:1 (RMSP) } \\
\text { Sem Auto } \\
\text { TTPESF } \leq 2 \\
\end{array}$} & Código & 0101 & 0612 & 0605 & 0914 & 0614 & 0905 & 0608 & 0607 \\
\hline & Motivo & $\mathrm{H}$ & $\mathrm{HAH}$ & $\mathrm{HAH}$ & $\mathrm{HAH}$ & $\mathrm{HAH}$ & $\mathrm{HAH}$ & $\mathrm{HAH}$ & HAH \\
\hline & Modo & $\mathrm{H}$ & 22 & 22 & 33 & 22 & 33 & 22 & 22 \\
\hline & Período & $\mathrm{H}$ & 23 & 34 & 22 & 22 & 34 & 35 & 24 \\
\hline & $\%$ & 75,61 & 2,96 & 2,74 & 1,47 & 1,40 & 1,40 & 1,11 & 1,02 \\
\hline \multirow{5}{*}{$\begin{array}{c}\text { Nó } 146 \text { (Total de pessoas: 2751) } \\
\text { Não Trabalha e Não Estuda } \\
\text { Base:1 (RMSP) } \\
\text { Sem Auto } \\
\text { TTPESF>2 e Homem }\end{array}$} & Código & 0101 & 0612 & 0605 & 0607 & 0910 & 0914 & 0912 & 0614 \\
\hline & Motivo & $\mathrm{H}$ & $\mathrm{HAH}$ & $\mathrm{HAH}$ & $\mathrm{HAH}$ & HAH & $\mathrm{HAH}$ & $\mathrm{HAH}$ & HAH \\
\hline & Modo & $\mathrm{H}$ & 22 & 22 & 22 & 33 & 33 & 33 & 22 \\
\hline & Período & $\mathrm{H}$ & 23 & 34 & 24 & 55 & 22 & 23 & 22 \\
\hline & $\%$ & 82,48 & 2,00 & 1,31 & 0,98 & 0,91 & 0,84 & 0,76 & 0,73 \\
\hline \multirow{5}{*}{$\begin{array}{c}\text { Nó } 294 \text { (Total de pessoas: 4979) } \\
\text { Não Trabalha e Não Estuda } \\
\text { Base:1 (RMSP) } \\
\text { Sem Auto } \\
\text { TTPESF>2, Mulher e GI:1,2 }\end{array}$} & Código & 0101 & 0612 & 0605 & 0910 & 0905 & 0609 & 0614 & 0607 \\
\hline & Motivo & $\mathrm{H}$ & $\mathrm{HAH}$ & $\mathrm{HAH}$ & $\mathrm{HAH}$ & HAH & $\mathrm{HAH}$ & HAH & HAH \\
\hline & Modo & $\mathrm{H}$ & 22 & 22 & 33 & 33 & 22 & 22 & 22 \\
\hline & Período & $\mathrm{H}$ & 23 & 34 & 55 & 34 & 45 & 22 & 24 \\
\hline & $\%$ & 80,82 & 1,53 & 1,49 & 1,13 & 0,88 & 0,74 & 0,70 & 0,70 \\
\hline
\end{tabular}

Codificação: Motivos: H (Residência); W (Trabalho); S (Escola); e A (Outras Atividades). Modos: 1 (Auto); 2 (Coletivo); e 3

(A pé). Períodos: 1 (0:00 - 08:00); 2 (08:00 - 11:30); 3 (11:30 - 14:30); 4 (14:30 - 17:30) e 5 (17:30 - 24:00). 


\begin{tabular}{|c|c|c|c|c|c|c|c|c|c|}
\hline \multirow{2}{*}{$\begin{array}{c}\text { Características } \\
\text { Socioeconômicas } \\
\text { Nó } 295 \text { (Total de pessoas: 1607) }\end{array}$} & \multicolumn{9}{|c|}{ Padrões Predominantes } \\
\hline & Código & 0101 & 0612 & 0605 & 0609 & 0910 & 0607 & 0606 & 0608 \\
\hline \multirow{4}{*}{$\begin{array}{c}\text { Não Trabalha e Não Estuda } \\
\text { Base:1 (RMSP) } \\
\text { Sem Auto } \\
\text { TTPESF>2, Mulher e GI:3,4,5 } \\
\end{array}$} & Motivo & $\mathrm{H}$ & $\mathrm{HAH}$ & $\mathrm{HAH}$ & $\mathrm{HAH}$ & $\mathrm{HAH}$ & $\mathrm{HAH}$ & $\mathrm{HAH}$ & $\mathrm{HAH}$ \\
\hline & Modo & $\mathrm{H}$ & 22 & 22 & 22 & 33 & 22 & 22 & 22 \\
\hline & Período & $\mathrm{H}$ & 23 & 34 & 45 & 55 & 24 & 12 & 35 \\
\hline & $\%$ & 75,54 & 2,61 & 1,81 & 1,62 & 1,06 & 1,00 & 1,00 & 0,93 \\
\hline \multirow{5}{*}{$\begin{array}{c}\text { Nó } 37 \text { (Total de pessoas: 2263) } \\
\text { Não Trabalha e Não Estuda } \\
\text { Base:3 (Bauru) } \\
\text { Sem Auto }\end{array}$} & Código & 0101 & 0605 & 0614 & 0612 & 0914 & 0905 & 0912 & 0910 \\
\hline & Motivo & $\mathrm{H}$ & $\mathrm{HAH}$ & $\mathrm{HAH}$ & $\mathrm{HAH}$ & $\mathrm{HAH}$ & $\mathrm{HAH}$ & $\mathrm{HAH}$ & $\mathrm{HAH}$ \\
\hline & Modo & $\mathrm{H}$ & 22 & 22 & 22 & 33 & 33 & 33 & 33 \\
\hline & Período & $\mathrm{H}$ & 34 & 22 & 23 & 22 & 34 & 23 & 55 \\
\hline & $\%$ & 66,77 & 4,51 & 3,09 & 2,83 & 2,61 & 2,25 & 2,21 & 2,08 \\
\hline \multirow{5}{*}{$\begin{array}{c}\text { Nó } 76 \text { (Total de pessoas: 2685) } \\
\text { Não Trabalha e Não Estuda } \\
\text { Base:1(RMSP) } \\
\text { Com Auto } \\
\text { Homem }\end{array}$} & Código & 0101 & 0612 & 0812 & 0810 & 0814 & 0809 & 0805 & 0614 \\
\hline & Motivo & $\mathrm{H}$ & $\mathrm{HAH}$ & $\mathrm{HAH}$ & $\mathrm{HAH}$ & $\mathrm{HAH}$ & $\mathrm{HAH}$ & $\mathrm{HAH}$ & $\mathrm{HAH}$ \\
\hline & Modo & $\mathrm{H}$ & 22 & 11 & 11 & 11 & 11 & 11 & 22 \\
\hline & Período & $\mathrm{H}$ & 23 & 23 & 55 & 22 & 45 & 34 & 22 \\
\hline & $\%$ & 73,48 & 2,53 & 1,90 & 1,64 & 1,60 & 1,56 & 1,42 & 1,23 \\
\hline \multirow{2}{*}{$\begin{array}{l}\text { Nó } 308 \text { (Total de pessoas: 2207) } \\
\text { Não Trabalha e Não Estuda }\end{array}$} & Código & 0101 & 0810 & 0612 & 0805 & 0605 & 0809 & 0815 & 0812 \\
\hline & Motivo & $\mathrm{H}$ & HAH & HAH & HAH & $\mathrm{HAH}$ & HAH & HAH & $\mathrm{HAH}$ \\
\hline \multirow{3}{*}{$\begin{array}{c}\text { Não Trabalha e Não Estuda } \\
\text { Base:1(RMSP) } \\
1 \text { Auto } \\
\text { Mulher e TTPESF } \leq 3 \\
\end{array}$} & Modo & $\mathrm{H}$ & 11 & 22 & 11 & 22 & 11 & 11 & 11 \\
\hline & Período & $\mathrm{H}$ & 55 & 23 & 34 & 34 & 45 & 44 & 23 \\
\hline & $\%$ & 74,44 & 1,99 & 1,90 & 1,68 & 1,50 & 1,36 & 1,18 & 1,13 \\
\hline \multirow{5}{*}{$\begin{array}{c}\text { Nó } 309 \text { (Total de pessoas: 3498) } \\
\text { Não Trabalha e Não Estuda } \\
\text { Base:1 (RMSP) } \\
1 \text { Auto } \\
\text { Mulher e TTPESF>3 }\end{array}$} & Código & 0101 & 0810 & 0605 & 0612 & 0609 & 1223 & 0614 & 0219 \\
\hline & Motivo & $\mathrm{H}$ & HAH & HAH & $\mathrm{HAH}$ & HAH & HSHSH & HAH & $\mathrm{HSH}$ \\
\hline & Modo & $\mathrm{H}$ & 11 & 22 & 22 & 22 & 3333 & 22 & 33 \\
\hline & Período & $\mathrm{H}$ & 55 & 34 & 23 & 45 & 3344 & 22 & 33 \\
\hline & $\%$ & 76,36 & 1,80 & 1,72 & 1,26 & 1,09 & 0,97 & 0,86 & 0,77 \\
\hline \multirow{5}{*}{$\begin{array}{c}\text { Nó } 155 \text { (Total de pessoas: 2071) } \\
\text { Não Trabalha e Não Estuda } \\
\text { Base:1 (RMSP) } \\
2 \text { ou mais Auto } \\
\text { Mulher }\end{array}$} & Código & 0101 & 0810 & 0805 & 0809 & 0815 & 0812 & 1019 & 0612 \\
\hline & Motivo & $\mathrm{H}$ & HAH & $\mathrm{HAH}$ & $\mathrm{HAH}$ & HAH & $\mathrm{HAH}$ & $\mathrm{HSH}$ & $\mathrm{HAH}$ \\
\hline & Modo & $\mathrm{H}$ & 11 & 11 & 11 & 11 & 11 & 11 & 22 \\
\hline & Período & $\mathrm{H}$ & 55 & 34 & 45 & 44 & 23 & 33 & 23 \\
\hline & $\%$ & 74,89 & 2,85 & 2,22 & 2,03 & 1,59 & 1,55 & 1,30 & 1,16 \\
\hline \multirow{5}{*}{$\begin{array}{c}\text { Nó } 39 \text { (Total de pessoas: 3126) } \\
\text { Não Trabalha e Não Estuda } \\
\text { Base:3 (Bauru) } \\
\text { Com Auto }\end{array}$} & Código & 0101 & 0805 & 0810 & 0605 & 0814 & 0812 & 0815 & 0809 \\
\hline & Motivo & $\mathrm{H}$ & $\mathrm{HAH}$ & $\mathrm{HAH}$ & $\mathrm{HAH}$ & $\mathrm{HAH}$ & $\mathrm{HAH}$ & $\mathrm{HAH}$ & $\mathrm{HAH}$ \\
\hline & Modo & $\mathrm{H}$ & 11 & 11 & 22 & 11 & 11 & 11 & 11 \\
\hline & Período & $\mathrm{H}$ & 34 & 55 & 34 & 22 & 23 & 44 & 45 \\
\hline & $\%$ & 65,23 & 4,29 & 3,52 & 2,91 & 2,62 & 2,53 & 2,46 & 1,98 \\
\hline \multirow{5}{*}{$\begin{array}{c}\text { Nó } 160 \text { (Total de pessoas: 1043) } \\
\text { Não Trabalha e Estuda } \\
\text { Base:1 (RMB) } \\
\text { GI:1 } \\
\text { RFSM } \leq 14.95\end{array}$} & Código & 0101 & 0205 & 0206 & 0204 & 0209 & 0207 & 0208 & 0212 \\
\hline & Motivo & $\mathrm{H}$ & $\mathrm{HSH}$ & $\mathrm{HSH}$ & $\mathrm{HSH}$ & $\mathrm{HSH}$ & $\mathrm{HSH}$ & $\mathrm{HSH}$ & $\mathrm{HSH}$ \\
\hline & Modo & $\mathrm{H}$ & 33 & 33 & 33 & 33 & 33 & 33 & 33 \\
\hline & Período & $\mathrm{H}$ & 34 & 12 & 13 & 45 & 24 & 35 & 23 \\
\hline & $\%$ & 27,80 & 11,60 & 10,07 & 9,49 & 5,85 & 5,18 & 4,41 & 2,88 \\
\hline \multirow{5}{*}{$\begin{array}{c}\text { Nó } 1288 \text { (Total de pessoas: 1509) } \\
\text { Não Trabalha e Estuda } \\
\text { Base:1 (RMSP) } \\
\text { GI:2 } \\
\text { Sem Auto e RFSM } \leq 2.95\end{array}$} & Código & 0101 & 0204 & 0208 & 0206 & 0207 & 0209 & 0210 & 0205 \\
\hline & Motivo & $\mathrm{H}$ & $\mathrm{HSH}$ & HSH & $\mathrm{HSH}$ & HSH & HSH & $\mathrm{HSH}$ & $\mathrm{HSH}$ \\
\hline & Modo & $\mathrm{H}$ & 33 & 33 & 33 & 33 & 33 & 33 & 33 \\
\hline & Período & $\mathrm{H}$ & 13 & 35 & 12 & 24 & 45 & 55 & 34 \\
\hline & $\%$ & 25,12 & 17,56 & 14,71 & 8,68 & 6,89 & 6,83 & 4,57 & 3,91 \\
\hline
\end{tabular}




\begin{tabular}{|c|c|c|c|c|c|c|c|c|c|}
\hline Características & \multicolumn{9}{|c|}{ Padrões Predominantes } \\
\hline \multirow{5}{*}{$\begin{array}{c}\text { Nó } 2578 \text { (Total de pessoas: 1455) } \\
\text { Não Trabalha e Estuda } \\
\text { Base:1 (RMSP) } \\
\text { GI:2 e Sem Auto } \\
2.95<\text { RFSM } \leq 9.25 \text { e TTPESF } \leq 4\end{array}$} & Código & 0101 & 0208 & 0204 & 0206 & 0207 & 0209 & 0210 & 0704 \\
\hline & Motivo & $\mathrm{H}$ & $\mathrm{HSH}$ & $\mathrm{HSH}$ & $\mathrm{HSH}$ & $\mathrm{HSH}$ & $\mathrm{HSH}$ & $\mathrm{HSH}$ & $\mathrm{HSH}$ \\
\hline & Modo & $\mathrm{H}$ & 33 & 33 & 33 & 33 & 33 & 33 & 22 \\
\hline & Período & $\mathrm{H}$ & 35 & 13 & 12 & 24 & 45 & 55 & 13 \\
\hline & $\%$ & 23,02 & 16,49 & 15,53 & 7,97 & 6,80 & 6,39 & 4,61 & 3,16 \\
\hline \multirow{5}{*}{$\begin{array}{c}\text { Nó } 2579 \text { (Total de pessoas: 2642) } \\
\text { Não Trabalha e Estuda } \\
\text { Base:1 (RMSP) } \\
\text { GI:2 e Sem Auto } \\
2.95<\text { RFSM } \leq 9.25 \text { e TTPESF }>4\end{array}$} & Código & 0101 & 0204 & 0208 & 0206 & 0207 & 0209 & 0210 & 0205 \\
\hline & Motivo & $\mathrm{H}$ & $\mathrm{HSH}$ & $\mathrm{HSH}$ & $\mathrm{HSH}$ & $\mathrm{HSH}$ & $\mathrm{HSH}$ & $\mathrm{HSH}$ & $\mathrm{HSH}$ \\
\hline & Modo & $\mathrm{H}$ & 33 & 33 & 33 & 33 & 33 & 33 & 33 \\
\hline & Período & $\mathrm{H}$ & 13 & 35 & 12 & 24 & 45 & 55 & 34 \\
\hline & $\%$ & 26,46 & 17,07 & 14,80 & 8,74 & 7,15 & 6,13 & 5,60 & 2,91 \\
\hline \multirow{5}{*}{$\begin{array}{c}\text { Nó } 645 \text { (Total de pessoas: 931) } \\
\text { Não Trabalha e Estuda } \\
\text { Base:1 (RMSP) } \\
\text { GI:2 e Sem Auto } \\
9.25<\text { RFSM } \leq 14.95\end{array}$} & Código & 0101 & 0204 & 0208 & 0206 & 0704 & 0210 & 0207 & 0209 \\
\hline & Motivo & $\mathrm{H}$ & $\mathrm{HSH}$ & $\mathrm{HSH}$ & $\mathrm{HSH}$ & $\mathrm{HSH}$ & $\mathrm{HSH}$ & $\mathrm{HSH}$ & $\mathrm{HSH}$ \\
\hline & Modo & $\mathrm{H}$ & 33 & 33 & 33 & 22 & 33 & 33 & 33 \\
\hline & Período & $\mathrm{H}$ & 13 & 35 & 12 & 13 & 55 & 24 & 45 \\
\hline & $\%$ & 22,23 & 17,08 & 15,79 & 6,55 & 5,69 & 5,59 & 5,16 & 4,51 \\
\hline \multirow{5}{*}{$\begin{array}{c}\text { Nó } 646 \text { (Total de pessoas: 2415) } \\
\text { Não Trabalha e Estuda } \\
\text { Base:1 (RMSP) } \\
\text { RFSM } \leq 14.95 \\
\text { GI:2, Com Auto e TTPESF } \leq 5 \\
\end{array}$} & Código & 0101 & 0204 & 0208 & 0209 & 0206 & 0704 & 0207 & 0708 \\
\hline & Motivo & $\mathrm{H}$ & $\mathrm{HSH}$ & $\mathrm{HSH}$ & $\mathrm{HSH}$ & $\mathrm{HSH}$ & $\mathrm{HSH}$ & $\mathrm{HSH}$ & $\mathrm{HSH}$ \\
\hline & Modo & $\mathrm{H}$ & 33 & 33 & 33 & 33 & 22 & 33 & 22 \\
\hline & Período & $\mathrm{H}$ & 13 & 35 & 45 & 12 & 13 & 24 & 35 \\
\hline & $\%$ & 22,24 & 15,53 & 13,50 & 5,96 & 5,76 & 5,34 & 5,05 & 3,77 \\
\hline \multirow{5}{*}{$\begin{array}{c}\text { Nó } 647 \text { (Total de pessoas: 1029) } \\
\text { Não Trabalha e Estuda } \\
\text { Base:1 (RMSP) } \\
\text { RFSM } \leq 14.95 \\
\text { GI:2, Com Auto e TTPESF>5 }\end{array}$} & Código & 0101 & 0208 & 0204 & 0206 & 0209 & 0210 & 0207 & 0704 \\
\hline & Motivo & $\mathrm{H}$ & $\mathrm{HSH}$ & $\mathrm{HSH}$ & $\mathrm{HSH}$ & $\mathrm{HSH}$ & $\mathrm{HSH}$ & $\mathrm{HSH}$ & $\mathrm{HSH}$ \\
\hline & Modo & $\mathrm{H}$ & 33 & 33 & 33 & 33 & 33 & 33 & 22 \\
\hline & Período & $\mathrm{H}$ & 35 & 13 & 12 & 45 & 55 & 24 & 13 \\
\hline & $\%$ & 25,27 & 17,10 & 15,26 & 6,41 & 5,83 & 5,73 & 5,73 & 3,01 \\
\hline \multirow{5}{*}{$\begin{array}{c}\text { Nó } 324 \text { (Total de pessoas: 2529) } \\
\text { Não Trabalha e Estuda } \\
\text { Base:2 (RMB) } \\
\text { RFSM } \leq 14.95\end{array}$} & Código & 0204 & 0206 & 0101 & 0208 & 0207 & 0209 & 0205 & 0704 \\
\hline & Motivo & $\mathrm{HSH}$ & $\mathrm{HSH}$ & $\mathrm{H}$ & $\mathrm{HSH}$ & $\mathrm{HSH}$ & $\mathrm{HSH}$ & $\mathrm{HSH}$ & $\mathrm{HSH}$ \\
\hline & Modo & 33 & 33 & $\mathrm{H}$ & 33 & 33 & 33 & 33 & 22 \\
\hline & Período & 13 & 12 & $\mathrm{H}$ & 35 & 24 & 45 & 34 & 13 \\
\hline & $\%$ & 23,65 & 18,19 & 13,80 & 12,85 & 5,73 & 5,14 & 4,86 & 3,64 \\
\hline \multirow{5}{*}{$\begin{array}{c}\text { Nó } 325 \text { (Total de pessoas: 439) } \\
\text { Não Trabalha e Estuda } \\
\text { Base:2 (RMB) }\end{array}$} & Código & 0204 & 0208 & 0704 & 0101 & 0206 & 0708 & 0207 & 0209 \\
\hline & Motivo & $\mathrm{HSH}$ & $\mathrm{HSH}$ & $\mathrm{HSH}$ & $\mathrm{H}$ & $\mathrm{HSH}$ & $\mathrm{HSH}$ & $\mathrm{HSH}$ & $\mathrm{HSH}$ \\
\hline & Modo & 33 & 33 & 22 & $\mathrm{H}$ & 33 & 22 & 33 & 33 \\
\hline & Período & 13 & 35 & 13 & $\mathrm{H}$ & 12 & 35 & 24 & 45 \\
\hline & $\%$ & 22,72 & 16,47 & 12,93 & 9,52 & 6,53 & 5,84 & 5,21 & 5,14 \\
\hline \multirow{5}{*}{$\begin{array}{c}\text { Nó } 163 \text { (Total de pessoas: 1281) } \\
\text { Não Trabalha e Estuda } \\
\text { Base:2 (RMB) } \\
\text { GI:1,2 } \\
\text { RFSM } \leq 14.95 \text { e Idade }>14 \\
\end{array}$} & Código & 0210 & 0208 & 0101 & 0204 & 0710 & 0704 & 0708 & 0206 \\
\hline & Motivo & $\mathrm{HSH}$ & $\mathrm{HSH}$ & $\mathrm{H}$ & $\mathrm{HSH}$ & $\mathrm{HSH}$ & $\mathrm{HSH}$ & $\mathrm{HSH}$ & $\mathrm{HSH}$ \\
\hline & Modo & 33 & 33 & $\mathrm{H}$ & 33 & 22 & 22 & 22 & 33 \\
\hline & Período & 55 & 35 & $\mathrm{H}$ & 13 & 55 & 13 & 35 & 12 \\
\hline & $\%$ & 22,56 & 15,14 & 12,33 & 7,81 & 6,79 & 4,84 & 4,84 & 3,90 \\
\hline \multirow{5}{*}{$\begin{array}{c}\text { Nó } 82 \text { (Total de pessoas: 2202) } \\
\text { Não Trabalha e Estuda } \\
\text { Base:1,2 (RMSP e RMB) } \\
\text { GI:1,2 } \\
\text { RFSM>14.95 e } 1 \text { Auto }\end{array}$} & Código & 0101 & 0204 & 0208 & 0704 & 0708 & 1004 & 1008 & 0206 \\
\hline & Motivo & $\mathrm{H}$ & $\mathrm{HSH}$ & $\mathrm{HSH}$ & $\mathrm{HSH}$ & $\mathrm{HSH}$ & $\mathrm{HSH}$ & $\mathrm{HSH}$ & $\mathrm{HSH}$ \\
\hline & Modo & $\mathrm{H}$ & 33 & 33 & 22 & 22 & 11 & 11 & 33 \\
\hline & Período & $\mathrm{H}$ & 13 & 35 & 13 & 35 & 13 & 35 & 12 \\
\hline & $\%$ & 20,98 & 14,17 & 11,40 & 8,13 & 6,90 & 6,40 & 4,09 & 3,91 \\
\hline
\end{tabular}

Codificação: Motivos: H (Residência); W (Trabalho); S (Escola); e A (Outras Atividades). Modos: 1 (Auto); 2 (Coletivo); e 3 (A pé). Períodos: 1 (0:00 - 08:00); 2 (08:00 - 11:30); 3 (11:30 - 14:30); 4 (14:30 - 17:30) e 5 (17:30 - 24:00). 
Características

Socioeconômicas

\section{Padrões Predominantes}

\begin{tabular}{|c|c|c|c|c|c|c|c|c|c|}
\hline \multirow{5}{*}{$\begin{array}{c}\text { Nó } 83 \text { (Total de pessoas: 1315) } \\
\text { Não Trabalha e Estuda } \\
\text { Base:1,2 (RMSP e RMB) } \\
\text { GI:1,2 } \\
\text { RFSM>14.95 e } 2 \text { ou mais Auto }\end{array}$} & Código & 0101 & 1004 & 1008 & 0204 & 0708 & 0704 & 0208 & 1604 \\
\hline & Motivo & $\mathrm{H}$ & $\mathrm{HSH}$ & $\mathrm{HSH}$ & $\mathrm{HSH}$ & $\mathrm{HSH}$ & $\mathrm{HSH}$ & $\mathrm{HSH}$ & $\mathrm{HSH}$ \\
\hline & Modo & $\mathrm{H}$ & 11 & 11 & 33 & 22 & 22 & 33 & 12 \\
\hline & Período & $\mathrm{H}$ & 13 & 35 & 13 & 35 & 13 & 35 & 13 \\
\hline & $\%$ & 20,23 & 19,01 & 10,27 & 7,45 & 6,92 & 6,62 & 5,40 & 4,03 \\
\hline \multirow{5}{*}{$\begin{array}{c}\text { Nó } 84 \text { (Total de pessoas: 2148) } \\
\text { Não Trabalha e Estuda } \\
\text { Base:1 (RMSP) } \\
\text { GI:3,4,5 } \\
\text { RFSM } \leq 17.85 \\
\end{array}$} & Código & 0101 & 0210 & 0704 & 0204 & 0710 & 0208 & 0708 & 0206 \\
\hline & Motivo & $\mathrm{H}$ & $\mathrm{HSH}$ & $\mathrm{HSH}$ & $\mathrm{HSH}$ & $\mathrm{HSH}$ & $\mathrm{HSH}$ & $\mathrm{HSH}$ & $\mathrm{HSH}$ \\
\hline & Modo & $\mathrm{H}$ & 33 & 22 & 33 & 22 & 33 & 22 & 33 \\
\hline & Período & $\mathrm{H}$ & 55 & 13 & 13 & 55 & 35 & 35 & 12 \\
\hline & $\%$ & 25,84 & 16,62 & 9,17 & 9,03 & 8,24 & 4,52 & 4,10 & 2,79 \\
\hline \multirow{5}{*}{$\begin{array}{c}\text { Nó } \mathbf{1 7 0} \text { (Total de pessoas: 921) } \\
\text { Não Trabalha e Estuda } \\
\text { Base:2 (RMB) } \\
\text { GI:3,4,5 } \\
\text { RFSM } \leq 17.85 \text { e Idade } \leq 17 \\
\end{array}$} & Código & 0704 & 0708 & 0208 & 0204 & 0101 & 0210 & 0710 & 0209 \\
\hline & Motivo & $\mathrm{HSH}$ & $\mathrm{HSH}$ & HSH & $\mathrm{HSH}$ & $\mathrm{H}$ & $\mathrm{HSH}$ & $\mathrm{HSH}$ & $\mathrm{HSH}$ \\
\hline & Modo & 22 & 22 & 33 & 33 & $\mathrm{H}$ & 33 & 22 & 33 \\
\hline & Período & 13 & 35 & 35 & 13 & $\mathrm{H}$ & 55 & 55 & 45 \\
\hline & $\%$ & 24,54 & 16,40 & 10,97 & 10,75 & 7,49 & 6,19 & 5,21 & 2,71 \\
\hline \multirow{5}{*}{$\begin{array}{c}\text { Nó } 171 \text { (Total de pessoas: 1644) } \\
\text { Não Trabalha e Estuda } \\
\text { Base:2 (RMB) } \\
\text { GI:3,4,5 } \\
\text { RFSM } \leq 17.85 \text { e Idade } \leq 17\end{array}$} & Código & 0710 & 0210 & 0708 & 0704 & 0101 & 0208 & 0204 & 0709 \\
\hline & Motivo & $\mathrm{HSH}$ & $\mathrm{HSH}$ & $\mathrm{HSH}$ & $\mathrm{HSH}$ & $\mathrm{H}$ & $\mathrm{HSH}$ & $\mathrm{HSH}$ & $\mathrm{HSH}$ \\
\hline & Modo & 22 & 33 & 22 & 22 & $\mathrm{H}$ & 33 & 33 & 22 \\
\hline & Período & 55 & 55 & 35 & 13 & $\mathrm{H}$ & 35 & 13 & 45 \\
\hline & $\%$ & 18,49 & 17,15 & 12,10 & 12,04 & 10,89 & 3,95 & 3,35 & 2,01 \\
\hline \multirow{5}{*}{$\begin{array}{c}\text { Nó } 43 \text { (Total de pessoas: 1659) } \\
\text { Não Trabalha e Estuda } \\
\text { Base:1,2 (RMSP e RMB) } \\
\text { GI:3,4,5 } \\
\text { RFSM }>17.85 \\
\end{array}$} & Código & 0101 & 1004 & 0704 & 0204 & 1604 & 0710 & 1010 & 0210 \\
\hline & Motivo & $\mathrm{H}$ & $\mathrm{HSH}$ & $\mathrm{HSH}$ & $\mathrm{HSH}$ & $\mathrm{HSH}$ & $\mathrm{HSH}$ & $\mathrm{HSH}$ & $\mathrm{HSH}$ \\
\hline & Modo & $\mathrm{H}$ & 11 & 22 & 33 & 12 & 22 & 11 & 33 \\
\hline & Período & $\mathrm{H}$ & 13 & 13 & 13 & 13 & 55 & 55 & 55 \\
\hline & $\%$ & 25,62 & 13,02 & 11,33 & 7,11 & 4,70 & 4,34 & 3,86 & 3,62 \\
\hline \multirow{5}{*}{$\begin{array}{c}\text { Nó } 11 \text { (Total de pessoas: 1893) } \\
\text { Não Trabalha e Estuda } \\
\text { Base:3 (Bauru) }\end{array}$} & Código & 0206 & 1006 & 0205 & 1005 & 0706 & 0210 & 0710 & 0705 \\
\hline & Motivo & $\mathrm{HSH}$ & $\mathrm{HSH}$ & $\mathrm{HSH}$ & $\mathrm{HSH}$ & $\mathrm{HSH}$ & $\mathrm{HSH}$ & $\mathrm{HSH}$ & $\mathrm{HSH}$ \\
\hline & Modo & 33 & 11 & 33 & 11 & 22 & 33 & 22 & 22 \\
\hline & Período & 12 & 12 & 34 & 34 & 12 & 55 & 55 & 34 \\
\hline & $\%$ & 24,41 & 16,43 & 15,58 & 8,61 & 8,45 & 6,45 & 4,70 & 3,75 \\
\hline \multirow{5}{*}{$\begin{array}{c}\text { Nó } \mathbf{3 8 4} \text { (Total de pessoas: 320) } \\
\text { Trabalha, Sem Auto e Não Estuda } \\
\text { Base:1 (RMSP) } \\
\text { Homem } \\
\text { GI:1,2 e RFSM } \leq 2.15\end{array}$} & Código & 0101 & 0302 & 0502 & 0303 & 0503 & 0311 & 0507 & 1116 \\
\hline & Motivo & $\mathrm{H}$ & $\mathrm{HWH}$ & $\mathrm{HWH}$ & HWH & $\mathrm{HWH}$ & $\mathrm{HWH}$ & HWH & HWHWH \\
\hline & Modo & $\mathrm{H}$ & 22 & 33 & 22 & 33 & 22 & 33 & 3333 \\
\hline & Período & $\mathrm{H}$ & 15 & 15 & 14 & 14 & 25 & 24 & 1335 \\
\hline & $\%$ & 47,81 & 9,69 & 9,38 & 3,75 & 3,44 & 3,13 & 2,19 & 1,88 \\
\hline \multirow{5}{*}{$\begin{array}{c}\text { Nó } 1540 \text { (Total de pessoas: 1959) } \\
\text { Trabalha, Sem Auto e Não Estuda } \\
\text { Base:1 (RMSP) } \\
\text { Homem e GI:1,2 } \\
2.15<\text { RFSM } \leq 7.65 \text { e TTPESF } \leq 4\end{array}$} & Código & 0302 & 0101 & 0303 & 0502 & 0311 & 0503 & 0308 & 0511 \\
\hline & Motivo & $\mathrm{HWH}$ & $\mathrm{H}$ & $\mathrm{HWH}$ & $\mathrm{HWH}$ & $\mathrm{HWH}$ & $\mathrm{HWH}$ & $\mathrm{HWH}$ & $\mathrm{HWH}$ \\
\hline & Modo & 22 & $\mathrm{H}$ & 22 & 33 & 22 & 33 & 22 & 33 \\
\hline & Período & 15 & $\mathrm{H}$ & 14 & 15 & 25 & 14 & 35 & 25 \\
\hline & $\%$ & 26,19 & 24,91 & 7,76 & 6,94 & 6,18 & 4,95 & 2,60 & 2,60 \\
\hline \multirow{5}{*}{$\begin{array}{c}\text { Nó } 1541 \text { (Total de pessoas: } 1125 \text { ) } \\
\text { Trabalha, Sem Auto e Não Estuda } \\
\text { Base:1 (RMSP) } \\
\text { Homem e GI:1,2 } \\
2.15<\text { RFSM } \leq 7.65 \text { e TTPESF }>4\end{array}$} & Código & 0101 & 0302 & 0502 & 0303 & 0503 & 0311 & 0511 & 0308 \\
\hline & Motivo & $\mathrm{H}$ & $\mathrm{HWH}$ & $\mathrm{HWH}$ & $\mathrm{HWH}$ & $\mathrm{HWH}$ & $\mathrm{HWH}$ & $\mathrm{HWH}$ & $\mathrm{HWH}$ \\
\hline & Modo & $\mathrm{H}$ & 22 & 33 & 22 & 33 & 22 & 33 & 22 \\
\hline & Período & $\mathrm{H}$ & 15 & 15 & 14 & 14 & 25 & 25 & 35 \\
\hline & $\%$ & 28,71 & 25,33 & 7,91 & 7,11 & 5,42 & 4,80 & 2,40 & 2,31 \\
\hline
\end{tabular}

Codificação: Motivos: H (Residência); W (Trabalho); S (Escola); e A (Outras Atividades). Modos: 1 (Auto); 2 (Coletivo); e 3

(A pé). Períodos: 1 (0:00 - 08:00); 2 (08:00 - 11:30); 3 (11:30 - 14:30); 4 (14:30 - 17:30) e 5 (17:30 - 24:00). 


\begin{tabular}{|c|c|c|c|c|c|c|c|c|c|}
\hline \multirow{2}{*}{$\begin{array}{c}\text { Características } \\
\text { Socioeconômicas } \\
\text { Nó } 771 \text { (Total de pessoas: 1383) }\end{array}$} & \multicolumn{9}{|c|}{ Padrões Predominantes } \\
\hline & Código & 0101 & 0302 & 0502 & 0303 & 0311 & 0503 & 0402 & 0308 \\
\hline \multirow{4}{*}{$\begin{array}{c}\text { Trabalha, Sem Auto e Não Estuda } \\
\text { Base:1 (RMSP) } \\
\text { Homem } \\
\text { GI:1,2 e RFSM>7.65 }\end{array}$} & Motivo & $\mathrm{H}$ & HWH & $\mathrm{HWH}$ & HWH & HWH & HWH & HWH & HWH \\
\hline & Modo & $\mathrm{H}$ & 22 & 33 & 22 & 22 & 33 & 11 & 22 \\
\hline & Período & $\mathrm{H}$ & 15 & 15 & 14 & 25 & 14 & 15 & 35 \\
\hline & $\%$ & 25,45 & 21,91 & 7,59 & 6,87 & 6,00 & 4,19 & 3,18 & 2,82 \\
\hline \multirow{5}{*}{$\begin{array}{c}\text { Nó } 193 \text { (Total de pessoas: 2377) } \\
\text { Trabalha, Sem Auto e Não Estuda } \\
\text { Base:1 (RMSP) } \\
\text { Homem } \\
\text { GI:3,4 e } 5\end{array}$} & Código & 0302 & 0101 & 0311 & 0303 & 0502 & 0308 & 0402 & 0511 \\
\hline & Motivo & $\mathrm{HWH}$ & $\mathrm{H}$ & $\mathrm{HWH}$ & HWH & $\mathrm{HWH}$ & HWH & HWH & HWH \\
\hline & Modo & 22 & $\mathrm{H}$ & 22 & 22 & 33 & 22 & 11 & 33 \\
\hline & Período & 15 & $\mathrm{H}$ & 25 & 14 & 15 & 35 & 15 & 25 \\
\hline & $\%$ & 24,02 & 22,68 & 10,14 & 6,86 & 4,08 & 3,49 & 3,45 & 3,20 \\
\hline \multirow{5}{*}{$\begin{array}{c}\text { Nó } 388 \text { (Total de pessoas: 1998) } \\
\text { Trabalha, Sem Auto e Não Estuda } \\
\text { Base:1 (RMSP) } \\
\text { Mulher } \\
\text { GI:1,2 e Idade } \leq 59\end{array}$} & Código & 0101 & 0302 & 0311 & 0303 & 0503 & 0502 & 0511 & 0307 \\
\hline & Motivo & $\mathrm{H}$ & $\mathrm{HWH}$ & $\mathrm{HWH}$ & HWH & HWH & HWH & HWH & HWH \\
\hline & Modo & $\mathrm{H}$ & 22 & 22 & 22 & 33 & 33 & 33 & 22 \\
\hline & $\begin{array}{l}\text { Período } \\
\end{array}$ & $\mathrm{H}$ & 15 & 25 & 14 & 14 & 15 & 25 & 24 \\
\hline & $\%$ & 25,23 & 15,72 & 11,21 & 9,16 & 5,71 & 4,25 & 3,60 & 3,00 \\
\hline \multirow{5}{*}{$\begin{array}{c}\text { Nó } 389 \text { (Total de pessoas: 835) } \\
\text { Trabalha, Sem Auto e Não Estuda } \\
\text { Base:1 (RMSP) } \\
\text { Mulher } \\
\text { GI:1,2 e Idade>59 }\end{array}$} & Código & 0101 & 0302 & 0303 & 0311 & 0503 & 0511 & 0502 & 0308 \\
\hline & Motivo & $\mathrm{H}$ & HWH & $\mathrm{HWH}$ & HWH & HWH & HWH & HWH & HWH \\
\hline & Modo & $\mathrm{H}$ & 22 & 22 & 22 & 33 & 33 & 33 & 22 \\
\hline & $\begin{array}{l}\text { Período } \\
\end{array}$ & $\mathrm{H}$ & 15 & 14 & 25 & 14 & 25 & 15 & 35 \\
\hline & $\%$ & 25,63 & 15,45 & 11,02 & 10,30 & 4,07 & 3,47 & 3,35 & 2,64 \\
\hline \multirow{5}{*}{$\begin{array}{c}\text { Nó } 195 \text { (Total de pessoas: 2129) } \\
\text { Trabalha, Sem Auto e Não Estuda } \\
\text { Base:1 (RMSP) } \\
\text { Mulher } \\
\text { GI:3,4,5 }\end{array}$} & Código & 0101 & 0302 & 0311 & 0303 & 0308 & 0511 & 0502 & 0503 \\
\hline & Motivo & $\mathrm{H}$ & HWH & HWH & HWH & HWH & HWH & HWH & HWH \\
\hline & Modo & $\mathrm{H}$ & 22 & 22 & 22 & 22 & 33 & 33 & 33 \\
\hline & Período & $\mathrm{H}$ & 15 & 25 & 14 & 35 & 25 & 15 & 14 \\
\hline & $\%$ & 18,27 & 17,61 & 15,45 & 6,62 & 6,20 & 4,13 & 4,09 & 3,01 \\
\hline \multirow{5}{*}{$\begin{array}{c}\text { Nó } 196 \text { (Total de pessoas: 1607) } \\
\text { Trabalha, Sem Auto e Não Estuda } \\
\text { Base:2 (RMB) } \\
\text { GI:1,2 } \\
\text { Homem }\end{array}$} & Código & 0302 & 0101 & 0502 & 0303 & 0311 & 0503 & 0504 & 1116 \\
\hline & Motivo & HWH & $\mathrm{H}$ & $\mathrm{HWH}$ & HWH & HWH & HWH & HWH & HWHWH \\
\hline & Modo & 22 & $\mathrm{H}$ & 33 & 22 & 22 & 33 & 33 & 3333 \\
\hline & Período & 15 & $\mathrm{H}$ & 15 & 14 & 25 & 14 & 13 & 1335 \\
\hline & $\%$ & 20,91 & 17,61 & 9,58 & 4,11 & 3,92 & 3,86 & 3,61 & 3,11 \\
\hline \multirow{5}{*}{$\begin{array}{c}\text { Nó } 197 \text { (Total de pessoas: 840) } \\
\text { Trabalha, Sem Auto e Não Estuda } \\
\text { Base:2 (RMB) } \\
\text { GI:1,2 } \\
\text { Mulher }\end{array}$} & Código & 0101 & 0302 & 0311 & 0303 & 0502 & 0914 & 0304 & 0612 \\
\hline & Motivo & $\mathrm{H}$ & $\mathrm{HWH}$ & $\mathrm{HWH}$ & $\mathrm{HWH}$ & $\mathrm{HWH}$ & HAH & $\mathrm{HWH}$ & HAH \\
\hline & Modo & $\mathrm{H}$ & 22 & 22 & 22 & 33 & 33 & 22 & 22 \\
\hline & Período & $\mathrm{H}$ & 15 & 25 & 14 & 15 & 22 & 13 & 23 \\
\hline & $\%$ & 19,88 & 18,21 & 6,31 & 6,31 & 5,00 & 3,45 & 3,21 & 3,10 \\
\hline \multirow{5}{*}{$\begin{array}{c}\text { Nó } 396 \text { (Total de pessoas: 1246) } \\
\text { Trabalha, Sem Auto e Não Estuda } \\
\text { Base:2 (RMB) } \\
\text { GI:3,4,5 } \\
\text { Homem e Idade } \leq 36 \\
\end{array}$} & Código & 0302 & 0101 & 0311 & 0303 & 0502 & 0304 & 0308 & 0503 \\
\hline & Motivo & HWH & $\mathrm{H}$ & $\mathrm{HWH}$ & HWH & HWH & $\mathrm{HWH}$ & HWH & HWH \\
\hline & Modo & 22 & $\mathrm{H}$ & 22 & 22 & 33 & 22 & 22 & 33 \\
\hline & $\begin{array}{l}\text { Período } \\
\end{array}$ & 15 & $\mathrm{H}$ & 25 & 14 & 15 & 13 & 35 & 14 \\
\hline & $\%$ & 24,40 & 13,24 & 7,87 & 6,10 & 4,25 & 4,25 & 3,45 & 2,41 \\
\hline \multirow{5}{*}{$\begin{array}{c}\text { Nó } 397 \text { (Total de pessoas: 943) } \\
\text { Trabalha, Sem Auto e Não Estuda } \\
\text { Base:2 (RMB) } \\
\text { GI:3,4,5 } \\
\text { Homem e Idade>36 }\end{array}$} & Código & 0302 & 0101 & 0311 & 0303 & 0304 & 0502 & 0612 & 0308 \\
\hline & Motivo & HWH & $\mathrm{H}$ & $\mathrm{HWH}$ & HWH & HWH & HWH & HAH & HWH \\
\hline & Modo & 22 & $\mathrm{H}$ & 22 & 22 & 22 & 33 & 22 & 22 \\
\hline & Período & 15 & $\mathrm{H}$ & 25 & 14 & 13 & 15 & 23 & 35 \\
\hline & $\%$ & 21,21 & 19,09 & 7,11 & 5,09 & 4,98 & 3,92 & 2,44 & 2,33 \\
\hline \multirow{5}{*}{$\begin{array}{c}\text { Nó } 199 \text { (Total de pessoas: 1790) } \\
\text { Trabalha, Sem Auto e Não Estuda } \\
\text { Base:2 (RMB) } \\
\text { GI:3,4,5 } \\
\text { Mulher }\end{array}$} & Código & 0302 & 0101 & 0311 & 0304 & 0303 & 0308 & 0504 & 0612 \\
\hline & Motivo & HWH & $\mathrm{H}$ & HWH & HWH & HWH & HWH & $\mathrm{HWH}$ & HAH \\
\hline & Modo & 22 & $\mathrm{H}$ & 22 & 22 & 22 & 22 & 33 & 22 \\
\hline & Período & 15 & $\mathrm{H}$ & 25 & 13 & 14 & 35 & 13 & 23 \\
\hline & $\%$ & 17,82 & 17,43 & 9,44 & 4,58 & 4,47 & 4,25 & 3,02 & 2,68 \\
\hline
\end{tabular}

Codificação: Motivos: H (Residência); W (Trabalho); S (Escola); e A (Outras Atividades). Modos: 1 (Auto); 2 (Coletivo); e 3 (A pé). Períodos: 1 (0:00 - 08:00); 2 (08:00 - 11:30); 3 (11:30 - 14:30); 4 (14:30 - 17:30) e 5 (17:30 - 24:00). 


\begin{tabular}{|c|c|c|c|c|c|c|c|c|c|}
\hline \multirow{2}{*}{$\begin{array}{c}\text { Características } \\
\text { Socioeconômicas }\end{array}$} & \multicolumn{9}{|c|}{ Padrões Predominantes } \\
\hline & Código & 0303 & 0503 & 0302 & 0311 & 0403 & 0307 & 0308 & 0310 \\
\hline \multirow{4}{*}{$\begin{array}{c}\text { Trabalha, Sem Auto e Não Estuda } \\
\text { Base:3 (Bauru) }\end{array}$} & Motivo & $\mathrm{HWH}$ & HWH & $\mathrm{HWH}$ & $\mathrm{HWH}$ & $\mathrm{HWH}$ & $\mathrm{HWH}$ & $\mathrm{HWH}$ & $\mathrm{HWH}$ \\
\hline & Modo & 22 & 33 & 22 & 22 & 11 & 22 & 22 & 22 \\
\hline & Período & 14 & 14 & 15 & 25 & 14 & 24 & 35 & 55 \\
\hline & $\%$ & 30,93 & 12,62 & 8,09 & 7,20 & 7,11 & 5,60 & 4,09 & 3,11 \\
\hline \multirow{5}{*}{$\begin{array}{r}\text { Nó } 13 \text { (Total de pess } \\
\text { Trabalha } \\
\text { Sem Auto } \\
\text { Estuda }\end{array}$} & Código & 0101 & 0302 & 1320 & 0311 & 0210 & 1417 & 2220 & 2213 \\
\hline & Motivo & $\mathrm{H}$ & $\mathrm{HWH}$ & HWHSH & HWH & $\mathrm{HSH}$ & HWSH & HWHSH & HWHSH \\
\hline & Modo & $\mathrm{H}$ & 22 & 2233 & 22 & 33 & 222 & 3333 & 3333 \\
\hline & Período & $\mathrm{H}$ & 15 & 1555 & 25 & 55 & 155 & 1555 & 1455 \\
\hline & $\%$ & 11,34 & 9,32 & 8,44 & 7,12 & 6,33 & 5,62 & 4,48 & 3,60 \\
\hline \multirow{5}{*}{$\begin{array}{c}\text { Nó } 448 \text { (Total de pessoas: 1318) } \\
\text { Trabalha, Com Auto e Não Estuda } \\
\text { Base:1,2 (RMSP e RMB) } \\
\text { RFSM } \leq 8.55 \\
\text { Homem e GI:1,2 } \\
\end{array}$} & Código & 0101 & 0302 & 0402 & 0502 & 0311 & 0303 & 0403 & 0411 \\
\hline & Motivo & $\mathrm{H}$ & HWH & $\mathrm{HWH}$ & HWH & HWH & HWH & HWH & HWH \\
\hline & Modo & $\mathrm{H}$ & 22 & 11 & \begin{tabular}{|l|}
33 \\
\end{tabular} & 22 & 22 & 11 & 11 \\
\hline & Período & $\mathrm{H}$ & 15 & 15 & 15 & 25 & 14 & 14 & 25 \\
\hline & $\%$ & 26,33 & 15,93 & 10,85 & 4,55 & 4,33 & 4,33 & 4,10 & 2,58 \\
\hline \multirow{5}{*}{$\begin{array}{c}\text { Nó } 449 \text { (Total de pessoas: 1388) } \\
\text { Trabalha, Com Auto e Não Estuda } \\
\text { Base:1,2 (RMSP e RMB) } \\
\text { 8.55<RFSM } \leq 24.65 \\
\text { Homem e GI:1,2 }\end{array}$} & Código & 0101 & 0402 & 0302 & 0411 & 0403 & 0303 & 0502 & 0311 \\
\hline & Motivo & $\mathrm{H}$ & HWH & HWH & HWH & $\mathrm{HWH}$ & HWH & HWH & $\mathrm{HWH}$ \\
\hline & Modo & $\mathrm{H}$ & 11 & 22 & \begin{tabular}{|l|}
11 \\
\end{tabular} & 11 & 22 & 33 & 22 \\
\hline & Período & $\mathrm{H}$ & 15 & 15 & 25 & 14 & 14 & 15 & 25 \\
\hline & $\%$ & 26,51 & 14,91 & 13,04 & 5,98 & 4,11 & 3,60 & 3,39 & 3,31 \\
\hline \multirow{5}{*}{$\begin{array}{c}\text { Nó } 900 \text { (Total de pessoas: 1909) } \\
\text { Trabalha, Com Auto e Não Estuda } \\
\text { Base:1 (RMSP) } \\
\text { RFSM } \leq 15.15 \\
\text { Homem e GI:3,4,5 }\end{array}$} & Código & 0101 & 0402 & 0302 & 0411 & 0311 & 0303 & 0403 & 0308 \\
\hline & Motivo & $\mathrm{H}$ & HWH & $\mathrm{HWH}$ & HWH & HWH & HWH & HWH & $\mathrm{HWH}$ \\
\hline & Modo & $\mathrm{H}$ & 11 & 22 & \begin{tabular}{|l|}
11 \\
\end{tabular} & 22 & 22 & 11 & 22 \\
\hline & Período & $\mathrm{H}$ & 15 & 15 & 25 & 25 & 14 & 14 & 35 \\
\hline & $\%$ & 19,38 & 14,82 & 13,88 & 7,39 & 5,97 & 4,35 & 4,03 & 2,99 \\
\hline \multirow{5}{*}{$\begin{array}{c}\text { Nó } 901 \text { (Total de pessoas: 1363) } \\
\text { Trabalha, Com Auto e Não Estuda } \\
\text { Base:1 (RMSP) } \\
15.15<\text { RFSM } \leq 24.65 \\
\text { Homem e GI:3,4,5 }\end{array}$} & Código & 0101 & 0402 & 0411 & 0302 & 0311 & 0403 & 0303 & 0502 \\
\hline & Motivo & $\mathrm{H}$ & HWH & HWH & HWH & HWH & HWH & HWH & $\mathrm{HWH}$ \\
\hline & Modo & $\mathrm{H}$ & 11 & 11 & 22 & 22 & 11 & 22 & 33 \\
\hline & $\begin{array}{l}\text { Período } \\
\end{array}$ & $\mathrm{H}$ & 15 & 25 & 15 & 25 & 14 & 14 & 15 \\
\hline & $\%$ & 20,98 & 19,52 & 11,37 & 7,63 & 5,80 & 4,40 & 2,35 & 2,05 \\
\hline \multirow{5}{*}{$\begin{array}{c}\text { Nó } 451 \text { (Total de pessoas: 593) } \\
\text { Trabalha, Com Auto e Não Estuda } \\
\text { Base:2 (RMB) } \\
\text { RFSM } \leq 24.65 \\
\text { Homem e GI:3,4,5 } \\
\end{array}$} & Código & 0101 & 0402 & 0302 & 0311 & 0411 & 1516 & 0404 & 0304 \\
\hline & Motivo & $\mathrm{H}$ & $\mathrm{HWH}$ & HWH & HWH & HWH & HWHWH & HWH & $\mathrm{HWH}$ \\
\hline & Modo & $\mathrm{H}$ & 11 & 22 & 22 & 11 & 1111 & 11 & 22 \\
\hline & Período & $\mathrm{H}$ & 15 & 15 & 25 & 25 & 1335 & 13 & 13 \\
\hline & $\%$ & 19,22 & 11,47 & 11,30 & 5,40 & 5,40 & 5,06 & 3,54 & 2,36 \\
\hline \multirow{5}{*}{$\begin{array}{c}\text { Nó } 226 \text { (Total de pessoas: 2049) } \\
\text { Trabalha, Com Auto e Não Estuda } \\
\text { Base:1,2 (RMSP e RMB) } \\
\text { RFSM } \leq 24.65 \\
\text { Mulher e GI:1,2,3 }\end{array}$} & Código & 0101 & 0302 & 0311 & 0303 & 0402 & 0308 & 0511 & 0503 \\
\hline & Motivo & $\mathrm{H}$ & HWH & $\mathrm{HWH}$ & HWH & HWH & HWH & HWH & HWH \\
\hline & Modo & $\mathrm{H}$ & 22 & 22 & 22 & 11 & 22 & 33 & 33 \\
\hline & Período & $\mathrm{H}$ & 15 & 25 & 14 & 15 & 35 & 25 & 14 \\
\hline & $\%$ & 34,75 & 10,79 & 7,42 & 5,95 & 2,83 & 2,83 & 2,78 & 2,44 \\
\hline \multirow{5}{*}{$\begin{array}{c}\text { Nó } 227 \text { (Total de pessoas: 1919) } \\
\text { Trabalha, Com Auto e Não Estuda } \\
\text { Base:1,2 (RMSP e RMB) } \\
\text { RFSM } 24.65 \\
\text { Mulher e GI:4,5 }\end{array}$} & Código & 0101 & 0302 & 0311 & 0402 & 0411 & 0308 & 0303 & 0307 \\
\hline & Motivo & $\mathrm{H}$ & $\mathrm{HWH}$ & $\mathrm{HWH}$ & HWH & $\mathrm{HWH}$ & $\mathrm{HWH}$ & $\mathrm{HWH}$ & $\mathrm{HWH}$ \\
\hline & Modo & $\mathrm{H}$ & 22 & 22 & \begin{tabular}{|l|}
11 \\
\end{tabular} & 11 & 22 & 22 & 22 \\
\hline & Período & $\mathrm{H}$ & 15 & 25 & 15 & 25 & 35 & 14 & 24 \\
\hline & $\%$ & 20,11 & 13,08 & 10,42 & 5,73 & 5,11 & 4,38 & 3,23 & 2,55 \\
\hline
\end{tabular}




\section{Características \\ Socioeconômicas}

\section{Padrões Predominantes}

\begin{tabular}{|c|c|c|c|c|c|c|c|c|c|}
\hline \multirow{3}{*}{$\begin{array}{c}\text { Nó } 114 \text { (Total de pessoas: 1394) } \\
\text { Trabalha, Com Auto e Não Estuda } \\
\text { Base:1,2 (RMSP e RMB) } \\
\text { RFSM>24.65 } \\
\text { GI:1,2,3 }\end{array}$} & Código & 0101 & 0402 & 0411 & 0302 & 0311 & 0502 & 0511 & 0403 \\
\hline & Modo & $\mathrm{H}$ & 11 & 11 & 22 & 22 & 33 & 33 & 11 \\
\hline & $\%$ & 55,81 & 8,18 & 5,52 & 3,66 & 2,08 & 1,51 & 1,36 & 1,29 \\
\hline \multirow{4}{*}{$\begin{array}{c}\text { Nó } 230 \text { (Total de pessoas: 2191) } \\
\text { Trabalha, Com Auto e Não Estuda } \\
\text { Base:1,2 (RMSP e RMB) } \\
\text { RFSM>24.65 } \\
\text { GI:4,5 e Homem }\end{array}$} & Código & 0402 & 0101 & 0411 & 0311 & 0302 & 0403 & 0407 & 1531 \\
\hline & Modo & 11 & $\mathrm{H}$ & 11 & 22 & 22 & 11 & 11 & 1111 \\
\hline & Período & 15 & $\mathrm{H}$ & 25 & 25 & 15 & 14 & 24 & 2335 \\
\hline & $\%$ & 21,77 & 21,22 & 20,90 & 4,25 & 3,65 & 2,60 & 2,10 & 1,92 \\
\hline \multirow{2}{*}{$\begin{array}{c}\text { Nó } 231 \text { (Total de pessoas: 1490) } \\
\text { Trabalha, Com Auto e Não Estuda } \\
\text { Base:1,2 (RMSP e RMB) } \\
\text { RFSM>24.65 } \\
\text { GI:4,5 e Mulher }\end{array}$} & Código & 0101 & 0411 & 0402 & 0311 & 0408 & 0302 & 0403 & 0404 \\
\hline & $\%$ & 23,62 & 15,17 & 8,93 & 6,64 & 4,03 & 3,89 & 2,55 & 2,28 \\
\hline \multirow{5}{*}{$\begin{array}{c}\text { Nó } 29 \text { (Total de pessoas: 1478) } \\
\text { Trabalha, Com Auto e Estuda } \\
\text { Base:1,2 (RMSP e RMB) }\end{array}$} & Código & 0101 & 0302 & 0210 & 0311 & 0402 & 1417 & 1320 & 0411 \\
\hline & Motivo & $\mathrm{H}$ & HWH & $\mathrm{HSH}$ & HWH & HWH & HWSH & HWHSH & $\mathrm{HWH}$ \\
\hline & Modo & $\mathrm{H}$ & 22 & 33 & 22 & 11 & 222 & 2233 & 11 \\
\hline & Período & $\mathrm{H}$ & 15 & 55 & 25 & 15 & 155 & 1555 & 25 \\
\hline & $\%$ & 17,66 & 6,77 & 4,80 & 4,74 & 4,33 & 4,20 & 3,72 & 3,52 \\
\hline \multirow{2}{*}{$\begin{array}{c}\text { Nó } 15 \text { (Total de pessoas: 2000) } \\
\text { Trabalha } \\
\text { Com Auto } \\
\text { Base:3 (Bauru) }\end{array}$} & Código & 0403 & 0303 & 0407 & 1516 & 0411 & 0503 & 0408 & 1531 \\
\hline & Motivo & HWH & HWH & $\mathrm{HWH}$ & HWHWH & $\mathrm{HWH}$ & HWH & HWH & HWHWH \\
\hline
\end{tabular}

Codificação: Motivos: H (Residência); W (Trabalho); S (Escola); e A (Outras Atividades). Modos: 1 (Auto); 2 (Coletivo); e 3

(A pé). Períodos: 1 (0:00 - 08:00); 2 (08:00 - 11:30); 3 (11:30 - 14:30); 4 (14:30 - 17:30) e 5 (17:30 - 24:00). 


\section{ANÁLISE DE RESULTADOS}

\section{Capítulo}

O principal objetivo deste capítulo é discutir, de uma maneira geral, as similaridades e diferenças encontradas no comportamento referente ao encadeamento de viagens entre os principais grupos socioeconômicos identificados pela árvore. A Figura 7.1 ilustra nós terminais da árvore que apresentaram similaridades entre as bases de dados em questão.

Na árvore gerada pelo software S-Plus foram identificados 60 grupos de indivíduos caracterizados de forma "homogênea" em relação à distribuição dos padrões de encadeamento de viagens escolhidos. Foi possível notar que, na maioria dos casos, a árvore separou as três áreas urbanas em análise formando grupos socioeconômicos intrínsecos de cada região. Entretanto, em alguns casos, também houve a formação de grupos similares dentre as amostras das regiões que se comportam homogeneamente em relação aos padrões de viagens.

Salienta-se que a segregação dos dados promovida pela árvore de decisão está intimamente ligada ao desvio mínimo adotado de 0,02 para o processamento da árvore. Quanto menor o desvio, maior o número de classes de indivíduos formados e, conseqüentemente, mais detalhada e complexa se torna a classificação.

Dadas as condições para o processamento da árvore de decisão de decisão e classificação (desvio mínimo de 0,02 e número mínimo de observações por nó terminal igual a 20), verifica-se que as variáveis mais importantes para a segregação dos dados foram “Trabalha”, "Estuda” e “Auto”, ou seja, se o indivíduo trabalha ou 
não, estuda ou não e possui ou não automóvel. Nota-se que, em geral, as populações das três áreas urbanas classificadas segundo estas variáveis não se comportam de maneira homogênea.

A análise dos resultados será feita em quatro partes, de acordo com discussões acerca dos principais grupos socioeconômicos descritos abaixo:

Parte 1: Indivíduos que não trabalham e não estudam;

> Parte 2: Indivíduos que não trabalham e estudam;

$>$ Parte 3: Indivíduos que trabalham e não estudam;

$>$ Parte 4: Indivíduos que trabalham e estudam. 


\subsection{Parte 1: Indivíduos que não trabalham e não estudam}

Neste grupo, nota-se que as características mais importantes para segregação dos dados variam bastante entre as bases de dados. De início, dois grandes sub-grupos foram formados: um sub-grupo constituído pela base de dados da RMB e outro formado pela RMSP e a cidade de Bauru. A partir daí, a variável mais importante para os dois grupos foi a presença ou não de automóvel no domicílio. O segmento abaixo ilustra as características mais importantes determinadas pela árvore de decisão e classificação.

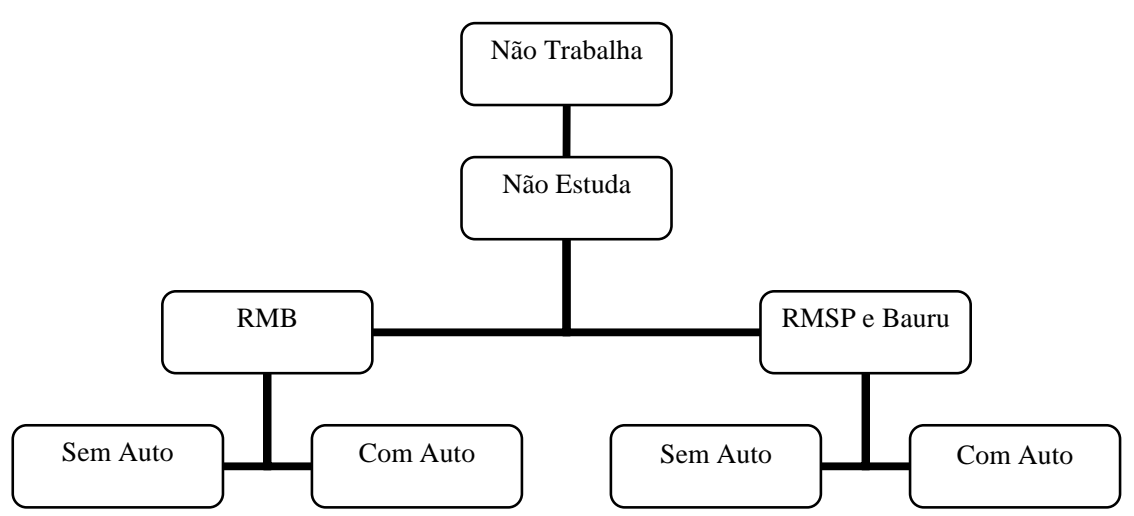

Figura 7.2: Características importantes para segregação dos dados na Parte 1

Desta forma, a partir de informações obtidas através do relatório, optou-se por analisar o comportamento dos viajantes urbanos presentes nestas três amostras somente através das características ilustradas na Figura 7.2.

\section{a) Grupo das pessoas que não trabalham, não estudam e não possuem automóvel}

Percebe-se que estas características constituíram um grupo homogêneo na base de dados da cidade de Bauru, representado pelo nó terminal 37. Já nas regiões metropolitanas, são influenciados por outras variáveis, tais como: idade, total de pessoas na família, sexo e grau de instrução. 
A Tabela 7.1 mostra os padrões de viagens mais freqüentes, com respectivas freqüências, encontrados sob essas características nas três bases de dados.

Tabela 7.1: Padrões predominantes encontrados para pessoas que não trabalham, não estudam e não possuem auto nas três amostras

\begin{tabular}{|c|c|c|c|c|c|c|c|c|c|}
\hline $\begin{array}{l}\text { Base de dados } \\
\text { (Total de nessoas) }\end{array}$ & Códigos & & & Padr & ões Pre & domin & antes & & \\
\hline \multirow{4}{*}{$\begin{array}{c}\text { RMSP } \\
(12.478)\end{array}$} & Motivo & $\mathrm{H}$ & $\mathrm{HAH}$ & HAH & $\mathrm{HAH}$ & HАН & $\mathrm{HAH}$ & HAH & $\mathrm{HAH}$ \\
\hline & Modo & & 22 & 22 & 33 & 33 & 22 & 33 & 22 \\
\hline & Período & & 23 & 34 & 55 & 22 & 24 & 34 & 45 \\
\hline & $\%$ & 79,20 & 2,13 & 1,80 & 0,95 & 0,91 & 0,88 & 0,88 & 0,87 \\
\hline \multirow{4}{*}{$\begin{array}{c}\text { RMB } \\
(7.104)\end{array}$} & Motivo & $\mathrm{H}$ & НАН & HAH & HAH & HAH & HAH & HAH & $\mathrm{HAH}$ \\
\hline & Modo & & 33 & 22 & 33 & 22 & 22 & 33 & 33 \\
\hline & Período & & 22 & 23 & 55 & 45 & 22 & 23 & 12 \\
\hline & $\%$ & 51,93 & 8,49 & 5,15 & 3,28 & 2,84 & 2,45 & 2,27 & 1,97 \\
\hline \multirow{4}{*}{$\begin{array}{c}\text { BAURU } \\
(2.263)\end{array}$} & Motivo & $\mathrm{H}$ & $\mathrm{HAH}$ & HAH & $\mathrm{HAH}$ & HАH & HAH & HAH & $\mathrm{HAH}$ \\
\hline & Modo & & 22 & 22 & 22 & 33 & 33 & 33 & 33 \\
\hline & Período & & 34 & 22 & 23 & 22 & 34 & 23 & 55 \\
\hline & $\%$ & 66,77 & 4,51 & 3,09 & 2,83 & 2,61 & 2,25 & 2,21 & 2,08 \\
\hline
\end{tabular}

Codificação: Motivos: H (Residência); W (Trabalho); S (Escola); e A (Outras Atividades). Modos: 1 (Auto); 2 (Coletivo); e 3 (A pé). Períodos: 1 (0:00 - 08:00); 2 (08:00 - 11:30); 3 (11:30 - 14:30); 4 (14:30 - 17:30) e 5 (17:30 - 24:00).

Nota-se que na RMB as pessoas saem mais para realizar outras atividades (negócios, compras, saúde etc.) do que em São Paulo e Bauru. Tal diferença pode estar relacionada à forma da coleta dos dados referentes aos deslocamentos dos indivíduos no dia anterior à pesquisa. Sabe-se que na RMB todos os deslocamentos foram coletados independentemente da distância percorrida até o destino da atividade. $\mathrm{Na}$ RMSP, os deslocamentos por motivo “Outras Atividades” foram catalogados a partir de 500 metros quando realizados a pé, e não estavam encadeados aos motivos “estudo” e “trabalho”. Já a cidade de Bauru catalogou todos os deslocamentos somente quando percorriam distâncias acima de 300 metros.

De fato, essas diferenças metodológicas refletem nos resultados. Verifica-se, na Tabela 7.1, que o percentual do padrão H (não viajou) na RMB é menor do que na cidade de Bauru e na RMSP. Além disso, o percentual dos indivíduos que saem para fazer "outras atividades” perto da residência antes do horário de almoço, fazendo o 
padrão HAH (em negrito) a pé, com viagens no período 2, é bastante superior na RMB do que na cidade de Bauru e na RMSP.

Normalmente, viagens realizadas através do modo a pé são feitas para percorrer distâncias curtas e, como há restrições dentre a catalogação dos deslocamentos nas pesquisas das regiões, era de se esperar que diferenças surgissem a partir dos padrões de viagens realizados a pé.

Segundo informações obtidas na síntese do relatório presente no anexo A, percebe-se principalmente na RMSP e na RMB a existência de indivíduos que realizam padrões de viagem do tipo “HSH”, apesar de não estarem estudando. Somando todas as combinações possíveis, tais padrões representam 1,35\% na RMSP e 1,83\% na RMB. O padrão HSHSH surge apenas na RMSP, realizado por 1,59\% dos indivíduos. Provavelmente, trata-se de mães que levam e/ou trazem filhos para escola ou falhas nos registros dos dados. Em Bauru, apenas 0,13\% dos indivíduos realizam o padrão $\mathrm{HSH}$.

O fato de se tratar de mães que levam filhos na escola fica perceptível quando se analisa o padrão de viagens na RMSP do segmento da árvore que corresponde a indivíduos que não trabalham, não estudam, não possuem automóvel e possuem mais de 2 pessoas na família e podem ser homem ou mulher. Neste caso, de acordo com o relatório, percebe-se que as mulheres realizam mais padrões do tipo HSH e HSHSH do que os homens.

A falha nos registros fica evidente principalmente na RMB, especificamente no nó terminal 64, onde indivíduos que declararam que não trabalham, não estudam, não possuem automóvel e têm idade até 12 anos afirmam, em 23,85\% dos casos, que viajam pelo motivo "escola”. Porém, vale ressaltar que este nó terminal apresenta apenas 130 pessoas e que, portanto, equivale a um percentual muito baixo em relação ao total de indivíduos presentes na análise. 
Os padrões do tipo HWH também aparecem nas amostras da RMSP e da RMB, apesar dos indivíduos pertencentes a este grupo declararem que não trabalham. Através da síntese do relatório presente no Anexo B, tais padrões consolidados, ou seja, somadas todas as combinações possíveis de modo e período, representam 2,89\% na RMB e 0,49\% na RMSP. No caso da RMB, trata-se de desempregados que são ocupados eventualmente em serviços diversos e já na RMSP, trata-se de indivíduos em licença.

Para enriquecer a análise, selecionaram-se neste grupo os indivíduos que tinham entre 18 e 60 anos de idade e que, portanto, estavam situados na faixa etária da população economicamente ativa. O resultado da análise mostra que as regiões metropolitanas apresentam mais pessoas nesta faixa etária do que a cidade de Bauru. A RMSP apresentou aproximadamente $78,00 \%$ dos indivíduos que não trabalham, não estudam e não possuem automóvel, constituído de indivíduos entre 18 e 60 anos de idade, que na sua maioria não viajaram (64,30\%), e a RMB apresentou aproximadamente $72,00 \%$ de pessoas com essas características, sendo que 48,44\% ficaram em casa. Já em Bauru apenas 56,69\% das pessoas situam-se nesta faixa etária e cerca de 65,93\% ficaram em casa. A partir desta constatação, supõe-se que taxas de desemprego são maiores na RMSP e na RMB do que na cidade de Bauru.

\section{b) Grupo das pessoas que não trabalham, não estudam e possuem automóvel}

Os indivíduos com estas características socioeconômicas constituíram um grupo homogêneo na RMB e na cidade de Bauru (nós terminais 17 e 39, respectivamente) enquanto que, na RMSP depende do sexo, do total de pessoas na família e se possui dois ou mais automóveis no domicilio. A Tabela 7.2 ilustra os padrões de viagens mais freqüentes escolhidos sob essas características.

Novamente, fica evidente que a forma da coleta de dados diferentes entre as pesquisas influenciou o resultado da análise deste grupo, já que na RMB os 
indivíduos tendem a sair mais para realizar outras atividades do que na RMSP e em Bauru.

De acordo com a Tabela 7.2, padrões de viagens a pé estão entre os mais freqüentes na RMB, diferentemente da RMSP e da cidade de Bauru. Como já dito anteriormente, tal modo de transporte é normalmente realizado para percorrer distâncias curtas e como a RMB catalogou todos os deslocamentos, diferentemente das outras regiões, é notória a diferença causada pelos métodos de pesquisa domiciliar distintos dentre as regiões em análise.

Analisando o total de pessoas nas três amostras presente na Tabela 7.2, nota-se que há menos pessoas neste grupo na RMB do que em Bauru e na RMSP. Verificando o índice de motorização das regiões, identificou-se em Bauru e na RMSP um índice maior do que na RMB, o que poderia justificar esta diferença encontrada.

Tabela 7.2: Padrões predominantes encontrados para pessoas que não trabalham, não estudam e possuem auto nas três amostras

\begin{tabular}{c|c|c|c|c|c|c|c|c|c}
\hline $\begin{array}{c}\text { Base de dados } \\
\text { (Total de pessoas) }\end{array}$ & Códigos & \multicolumn{7}{|c}{ Padrões Predominantes } \\
\hline \multirow{4}{*}{$\begin{array}{c}\text { RMSP } \\
(10.461)\end{array}$} & Motivo & H & HAH & HAH & HAH & HAH & HAH & HAH & HAH \\
\cline { 2 - 12 } & Modo & & 11 & 22 & 11 & 11 & 22 & 11 & 11 \\
\cline { 2 - 12 } & Período & & 55 & 23 & 34 & 45 & 34 & 23 & 44 \\
\cline { 2 - 12 } & $\%$ & 74,93 & 2,01 & 1,70 & 1,32 & 1,32 & 1,30 & 1,21 & 1,01 \\
\hline \multirow{4}{*}{$\begin{array}{c}\text { RMB } \\
(1.200)\end{array}$} & Motivo & H & HAH & HAH & HAH & HAH & HAH & HAH & HAH \\
\cline { 2 - 12 } & Modo & & 22 & 33 & 11 & 33 & 22 & 22 & 22 \\
\cline { 2 - 11 } & Período & & 23 & 22 & 23 & 55 & 45 & 22 & 55 \\
\cline { 2 - 11 } & Motivo & H & HAH & HAH & HAH & HAH & HAH & HAH & HAH \\
\hline \multirow{4}{*}{$\begin{array}{c}\text { BAURU } \\
(3.126)\end{array}$} & Modo & & 11 & 11 & 22 & 11 & 11 & 11 & 11 \\
\cline { 2 - 10 } & Período & & 34 & 55 & 34 & 22 & 23 & 44 & 45 \\
\cline { 2 - 10 } & \% & 65,23 & 4,29 & 3,52 & 2,91 & 2,62 & 2,53 & 2,46 & 1,98 \\
\hline
\end{tabular}

Codificação: Motivos: H (Residência); W (Trabalho); S (Escola); e A (Outras Atividades). Modos: 1 (Auto); 2 (Coletivo); e 3 (A pé). Períodos: 1 (0:00 - 08:00); 2 (08:00 - 11:30); 3 (11:30 - 14:30); 4 (14:30 - 17:30) e 5 (17:30 - 24:00).

Neste caso também verificam-se indivíduos que realizam padrões do tipo HSH, principalmente nas regiões metropolitanas. De acordo com a síntese do relatório presente no Anexo B, tais padrões consolidados, ou seja, somadas todas as 
combinações possíveis de modo e período, representam 1,72 \% na RMSP e 2,83\% na RMB. O padrão HSHSH surge somente na RMSP com o percentual de 1,34\%. Em Bauru, apenas 0,06\% dos indivíduos realizam o padrão HSH. As justificativas descritas anteriormente sobre mães que levam e/ou trazem filhos para escola e falhas nos registros também são válidas.

A evidência de que se tratam de mães que levam e/ou trazem crianças pode ser outra vez notada na árvore da RMSP, através do segmento que é função, além das características deste grupo em análise, do sexo e do total de pessoas na família. Notase que as mulheres tendem mais a buscar os filhos na escola do que os homens.

Padrões do tipo HWH novamente surgem nas amostras da RMSP e na RMB para indivíduos que declararam que não trabalham. Através da síntese do relatório, representam 2,89\% na RMB e 0,49\% na RMSP. A presença de desempregados que são ocupados eventualmente em serviços diversos na RMB e indivíduos em licença na RMSP são justificativas para este caso também.

\subsection{Parte 2: Indivíduos que não trabalham e estudam}

Inicialmente, dois grandes grupos foram formados: desta vez um sub-grupo constituído pelas bases de dados da RMSP e da RMB e outro constituído pela cidade de Bauru. Nota-se que na cidade de Bauru as pessoas que não trabalham e estudam comportam-se de maneira "homogênea”, diferentemente do outro sub-grupo das regiões metropolitanas. Nas regiões metropolitanas, os indivíduos tendem a viajar menos de automóvel do que na cidade de Bauru. A provável razão está na taxa de motorização, significativamente maior em Bauru do que nas regiões metropolitanas.

Para confirmar essa hipótese, quando se analisa os padrões de viagens de indivíduos classificados pela árvore apenas através das variáveis “trabalho” e “estudo”, verificase que 29,58\% dos indivíduos de Bauru realizam padrões do tipo HSH de modo automóvel, enquanto que, nas regiões metropolitanas este percentual cai para 5,62\%. 
Vale ressaltar que neste caso, percentuais de padrões do tipo HSH de modo coletivo e a pé ficaram relativamente parecidos dentre as três regiões.

Outro fato importante foi que, tanto na RMB quanto na cidade de Bauru, as Pesquisas O/D classificaram indivíduos como "estudante” de formas distintas, não possibilitando o autor de promover mudanças que compatibilizassem as amostras. $\mathrm{Na}$ RMB, o órgão responsável considerou como "estudante" qualquer tipo de estudo, seja ensino fundamental, médio, superior ou qualquer outro tipo de curso (línguas, técnicos etc.). Já em Bauru, somente indivíduos que cursavam escolas de ensino oficial (ensino fundamental, médio e superior), seja público ou privado, foram considerados como estudantes. Na RMSP foi possível fazer distinção entre estudantes de ensino oficial e de outros tipos de ensino. Por fim, a solução adotada considerou que indivíduos que realizavam qualquer tipo de curso foram classificados como “estudante”, prejudicando a análise da cidade de Bauru em relação às regiões metropolitanas.

Nota-se claramente que o grau de instrução dos indivíduos afeta o comportamento dos viajantes urbanos nas regiões metropolitanas. Indivíduos com grau de instrução até a $4^{\mathrm{a}}$ série tendem a ir à escola a pé, diferentemente das pessoas que estudam no $2^{\circ}$ grau e em instituições de ensino superior, que realizam um percentual maior de viagens de transporte coletivo para a escola que, por sua vez, não estão situadas nas proximidades dos locais de domicílio. De fato, as políticas das secretarias de educação estaduais vêm recomendando que estudantes de escola pública de ensino fundamental sejam matriculados em escolas próximas às suas residências, razão pela qual grande parte do grupo faz viagens a pé. Na cidade de Bauru, por ser uma cidade de porte médio, não foi detectada a influência desta variável, possivelmente devido ao fato de que as distâncias do domicílio até as escolas, sejam de ensino fundamental, médio ou superior, não serem tão grandes.

A partir do grau de instrução, foram notadas diferenças entre a RMSP e a RMB nesta parte, principalmente, nos segmentos da árvore que compreendem indivíduos que possuem renda familiar inferior a 14,95 salários mínimos e 17,85 salários mínimos. 
Optou-se então por realizar duas análises comparativas detalhadas, inclusive selecionando os respectivos grupos através de um processo feito no próprio S-Plus na cidade de Bauru, envolvendo os:

\section{a) Indivíduos que não trabalham, estudam, possuem grau de instrução 1 e 2 e renda familiar até 14,95 salários mínimos:}

Identificou-se que nas três bases de dados, este grupo de indivíduos, na sua maioria, é constituído de crianças em idade escolar até a $4^{\mathrm{a}}$ série completa, ou seja, segundo o agrupamento proposto para o grau de instrução, fazem parte da codificação 1 e 2 .

A Tabela 7.3 mostra os padrões predominantes encontrados para indivíduos com as características socioeconômicas estabelecidas.

Tabela 7.3: Padrões predominantes encontrados para pessoas que não trabalham, estudam, possuem grau de instrução 1 e 2 e renda familiar até 14,95 salários mínimos

\begin{tabular}{|c|c|c|c|c|c|c|c|c|c|}
\hline Base de dados & Códigos & & & Padrõ & es Prec & lomina & intes & & \\
\hline \multirow{4}{*}{$\begin{array}{c}\text { RMSP } \\
(11.024)\end{array}$} & Motivo & $\mathrm{H}$ & $\mathrm{HSH}$ & $\mathrm{HSH}$ & $\mathrm{HSH}$ & $\mathrm{HSH}$ & $\mathrm{HSH}$ & $\mathrm{HSH}$ & $\mathrm{HSH}$ \\
\hline & Modo & & 33 & 33 & 33 & 33 & 33 & 33 & 33 \\
\hline & Período & & 13 & 35 & 12 & 24 & 45 & 55 & 34 \\
\hline & $\%$ & 24,56 & 15,71 & 14,04 & 7,70 & 6,12 & 6,03 & 4,37 & 3,76 \\
\hline \multirow{4}{*}{$\begin{array}{c}\text { RMB } \\
(5.249)\end{array}$} & Motivo & $\mathrm{HSH}$ & $\mathrm{HSH}$ & $\mathrm{H}$ & $\mathrm{HSH}$ & $\mathrm{HSH}$ & $\mathrm{HSH}$ & $\mathrm{HSH}$ & $\mathrm{HSH}$ \\
\hline & Modo & 33 & 33 & & 33 & 22 & 33 & 33 & 33 \\
\hline & Período & 13 & 35 & & 12 & 13 & 55 & 45 & 24 \\
\hline & $\%$ & 19,53 & 14,40 & 12,27 & 11,51 & 6,48 & 6,19 & 4,84 & 4,48 \\
\hline \multirow{4}{*}{$\begin{array}{c}\text { BAURU } \\
(1.078)\end{array}$} & Motivo & $\mathrm{HSH}$ & $\mathrm{HSH}$ & $\mathrm{HSH}$ & $\mathrm{HSH}$ & $\mathrm{HSH}$ & $\mathrm{HSH}$ & $\mathrm{HSH}$ & $\mathrm{HSH}$ \\
\hline & Modo & 33 & 33 & 11 & 11 & 22 & 33 & 22 & 22 \\
\hline & Período & 12 & 34 & 12 & 34 & 12 & 55 & 34 & 55 \\
\hline & $\%$ & 29,78 & 22,82 & 10,76 & 10,30 & 6,40 & 4,82 & 4,73 & 1,76 \\
\hline
\end{tabular}

Codificação: Motivos: H (Residência); W (Trabalho); S (Escola); e A (Outras Atividades). Modos: 1 (Auto); 2 (Coletivo); e 3 (A pé). Períodos: 1 (0:00 - 08:00); 2 (08:00 - 11:30); 3 (11:30 - 14:30); 4 (14:30 - 17:30) e 5 (17:30 - 24:00).

O padrão predominante na RMSP é o $H$ (não viajou), com 24,56\%, seguido do padrão H3S3H (viagens nos períodos 1 e 3) com 15,71\%, enquanto que, na RMB o predominante foi o padrão H3S3H (viagens nos períodos 1 e 3) com 19,53\%, seguido 
do padrão H3S3H (viagens nos períodos 3 e 5), com 14,40\%. Já em Bauru os principais foram os padrões H3S3H (viagens nos períodos 1 e 2) e H3S3H (viagens nos períodos 3 e 4).

Mais uma vez cabe lembrar que os dados das regiões metropolitanas incluem os alunos que realizam cursos de línguas, computação etc., na categoria "Estudante”, que muita das vezes não possuem aulas diárias.

O que causa estranheza é a disparidade entre parcelas do grupo da RMSP e da RMB que não foram à escola. Na RMSP, 24,56\% ficaram em casa, enquanto que na RMB o percentual é aproximadamente a metade. Essa maior assiduidade na RMB pode ser explicada pelo fato de que a população carente, na época da pesquisa domiciliar, já participava de um programa assistencial denominado "Bolsa-escola”, que consiste no pagamento de um salário mínimo a cada família carente que mantiver todas as suas crianças entre 7 e 14 anos matriculadas na rede escolar pública.

Supondo que os indivíduos com renda familiar inferior a três salários mínimos participem do programa “Bolsa-escola”, verifica-se que o programa beneficiou a maioria dos indivíduos deste grupo (aprox. 55\%) na RMB, pois estes se enquadram na classe de renda até três salários mínimos.

Já os estudantes até a $4^{\mathrm{a}}$ série do ensino fundamental da cidade de Bauru se mostram bastante assíduos, já que apenas 0,19\% faltaram à escola no dia anterior à pesquisa.

É possível evidenciar pela Tabela 7.3 a predominância de padrões do tipo HSH feito a pé nas três regiões em análise. Como já foi dito anteriormente, tais padrões de viagens é o resultado da política pública implantada no setor da educação. 
b) Indivíduos que não trabalham, estudam, possuem grau de instrução 3, 4 e 5 e renda familiar até 17,85 salários mínimos:

Neste grupo incluem-se indivíduos que possuem grau de instrução a partir do $1^{\circ}$ grau completo ( $8^{\mathrm{a}}$ série completa) até aqueles que declararam ter nível superior completo e que, portanto, podem estar cursando pós-graduação ou cursos como os de línguas.

Novamente, notou-se uma baixa assiduidade dos alunos da RMSP e desta vez, um leve aumento da assiduidade na RMB. Provavelmente, isso se deve ao fato de que estudantes que realizam outros tipos de cursos, além do ensino oficial, foram considerados como estudantes nas regiões metropolitanas. Já a cidade de Bauru continuou com alta assiduidade dos seus respectivos estudantes de ensino colegial $\left(2^{\circ}\right.$ grau) e de ensino superior.

Com relação aos indivíduos que possuem grau de instrução 4 e 5, é válido ressaltar que a cidade de Bauru recebe muitos estudantes de outras localidades que desejam cursar graduação ou pós-graduação nesta cidade e que, portanto, muita das vezes concentram suas atividades, sejam acadêmicas, de saúde, ou de lazer por exemplo, nas instituições de ensino superior, diferentemente da RMSP e da RMB. Estes tipos de estudantes nas regiões metropolitanas, provavelmente, são residentes “fixos", ou seja, moram nessas regiões nas casas dos pais e dispõem de uma gama de opções para lazer, saúde etc., que são ofertadas em uma região metropolitana, diferentemente da cidade de Bauru.

Analisando todas as combinações possíveis das viagens por motivo HAH, verifica-se que elas representam 5,54\% e 5,50\% na RMSP e na RMB, respectivamente. Já em Bauru, representam apenas 0,53\%. Supõe-se que os estudantes em Bauru tendem a ir para a universidade, caracterizando o motivo “escola”, e por lá desenvolverem outras atividades além de estudo. Provavelmente, tais viagens não foram catalogadas em Bauru devido estarem no interior de campi, seja da USP, seja da UNESP.

A Tabela 7.4 mostra os padrões de viagens mais freqüentes encontrados neste caso. 
Analisando os modos utilizados da Tabela 7.4, nota-se claramente uma propensão dos indivíduos de Bauru de utilizarem o automóvel para realizar a atividade de estudo quando comparado as regiões metropolitanas. Como já dito anteriormente, o índice de motorização da população é maior em Bauru do que na RMSP e na RMB, o que pode justificar a diferença encontrada.

Tabela 7.4: Padrões predominantes encontrados para pessoas que não trabalham, estudam, possuem grau de instrução 3, 4 e 5 e renda familiar até 17,85 salários mínimos

\begin{tabular}{|c|c|c|c|c|c|c|c|c|c|}
\hline Base de dados & Códigos & & & Padrí & jes Pre & domina & ntes & & \\
\hline \multirow{4}{*}{$\begin{array}{l}\text { RMSP } \\
(2.148)\end{array}$} & Motivo & $\mathrm{H}$ & $\mathrm{HSH}$ & $\mathrm{HSH}$ & $\mathrm{HSH}$ & $\mathrm{HSH}$ & $\mathrm{HSH}$ & $\mathrm{HSH}$ & $\mathrm{HSH}$ \\
\hline & Modo & & 33 & 22 & 33 & 22 & 33 & 22 & 33 \\
\hline & Período & & 55 & 13 & 13 & 55 & 35 & 35 & 12 \\
\hline & $\%$ & 25,84 & 16,62 & 9,17 & 9,03 & 8,24 & 4,52 & 4,10 & 2,79 \\
\hline \multirow{4}{*}{$\begin{array}{c}\text { RMB } \\
(2.565)\end{array}$} & Motivo & $\mathrm{HSH}$ & $\mathrm{HSH}$ & $\mathrm{HSH}$ & $\mathrm{HSH}$ & $\mathrm{H}$ & $\mathrm{HSH}$ & $\mathrm{HSH}$ & $\mathrm{HSH}$ \\
\hline & Modo & 22 & 22 & 22 & 33 & & 33 & 33 & 22 \\
\hline & Período & 13 & 55 & 35 & 55 & & 35 & 13 & 45 \\
\hline & $\%$ & 16,53 & 13,72 & 13,65 & 13,22 & 9,67 & 6,47 & 6,00 & 1,72 \\
\hline \multirow{4}{*}{$\begin{array}{c}\text { BAURU } \\
(564)\end{array}$} & Motivo & $\mathrm{HSH}$ & $\mathrm{HSH}$ & $\mathrm{HSH}$ & $\mathrm{HSH}$ & $\mathrm{HSH}$ & $\mathrm{HSH}$ & $\mathrm{HSH}$ & $\mathrm{HSH}$ \\
\hline & Modo & 33 & 11 & 22 & 33 & 22 & 11 & 33 & 22 \\
\hline & Período & 12 & 12 & 12 & 55 & 55 & 55 & 34 & 34 \\
\hline & $\%$ & 19,15 & 15,07 & 13,83 & 11,52 & 10,28 & 7,09 & 6,21 & 2,84 \\
\hline
\end{tabular}

Codificação: Motivos: H (Residência); W (Trabalho); S (Escola); e A (Outras Atividades). Modos: 1 (Auto); 2 (Coletivo); e 3 (A pé). Períodos: 1 (0:00 - 08:00); 2 (08:00 - 11:30); 3 (11:30 - 14:30); 4 (14:30 - 17:30) e 5 (17:30 - 24:00).

De acordo com a Tabela 7.4, é possível também notar a heterogeneidade dos modos de transporte utilizados nas viagens pelos indivíduos das regiões metropolitanas, diferentemente da Tabela 7.3., onde a predominância era de padrões de viagens que utilizavam o modo de transporte a pé. É válido salientar que, em regiões metropolitanas, escolas de $2^{\circ}$ grau e instituições de ensino superior já não estão situadas tão próximas das residências quanto escolas de ensino fundamental (até $8^{a}$ série), causando a necessidade dos estudantes procurarem os modos de transportes particular e coletivo para chegar ao local da atividade. 


\section{Nós terminais similares presentes na Parte 2}

Nesta parte 2, a árvore identificou nós terminais homogêneos em relação ao padrão de viagem escolhido entre as regiões metropolitanas de São Paulo e Belém. A Figura 7.3 mostra as folhas que apresentam similaridades entre as duas bases de dados em questão.

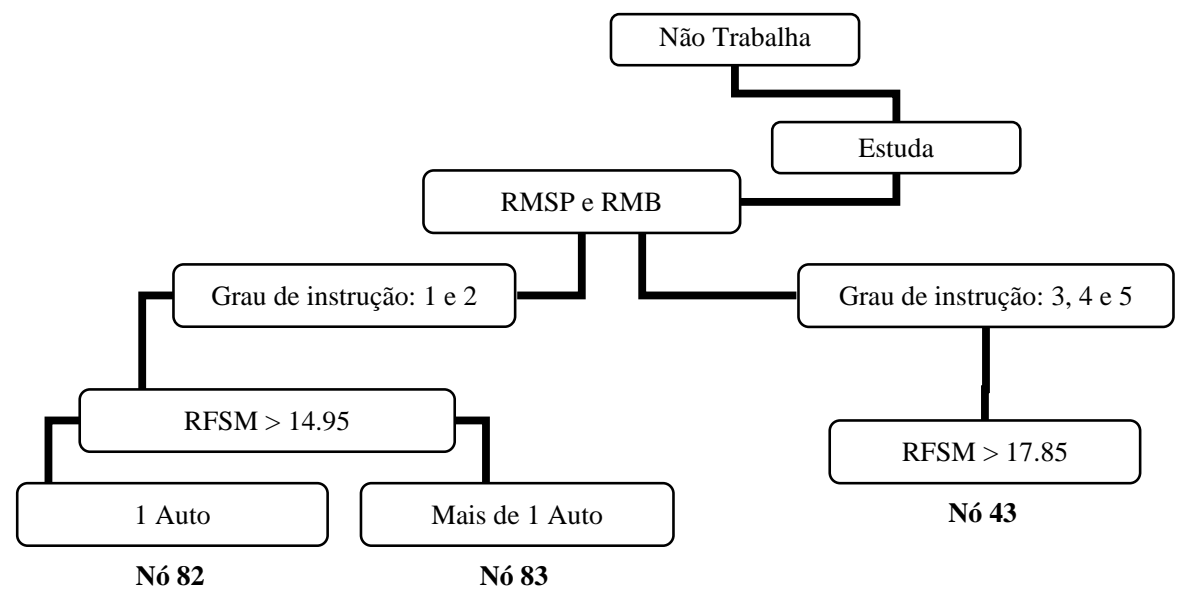

Figura 7.3: Nós terminais similares formados pela RMSP e RMB

Verifica-se que se tratam de indivíduos que possuem renda familiar, em salários mínimos da época, elevada. Os nós 82 e 83 referem-se aos indivíduos com renda familiar acima de 14,95 salários mínimos e o nó 43 aos indivíduos com renda familiar acima de 17,85 salários mínimos. Tal similaridade faz supor que indivíduos com renda familiar elevada se comportam de maneira próxima em relação aos padrões de viagem, independentemente da área urbana em que habitam. Porém, a verificação da suposição requer investigações adicionais.

Analisando os padrões de viagens do tipo "HSH” dos nós terminais similares 82 e 83, verifica-se claramente a influência da variável “auto” nas regiões metropolitanas. Indivíduos com 1 automóvel na residência (nó 82) tendem a fazer menos viagens de automóvel do que aqueles que possuem mais de 1 (nó 83). Já com relação aos padrões de viagens do nó terminal 43, devido ao fato de possuírem renda elevada, percebe-se um percentual maior de indivíduos que realizam viagens de auto e de 
modo coletivo quando comparado aos indivíduos que fazem viagens a pé. A Tabela 7.5 mostra padrões de viagens do tipo HSH consolidados por modo para indivíduos com as características socioeconômicas destes nós terminais similares.

Tabela 7.5: Características socioeconômicas e padrões consolidados do tipo HSH presentes nos nós terminais similares dentre as regiões metropolitanas

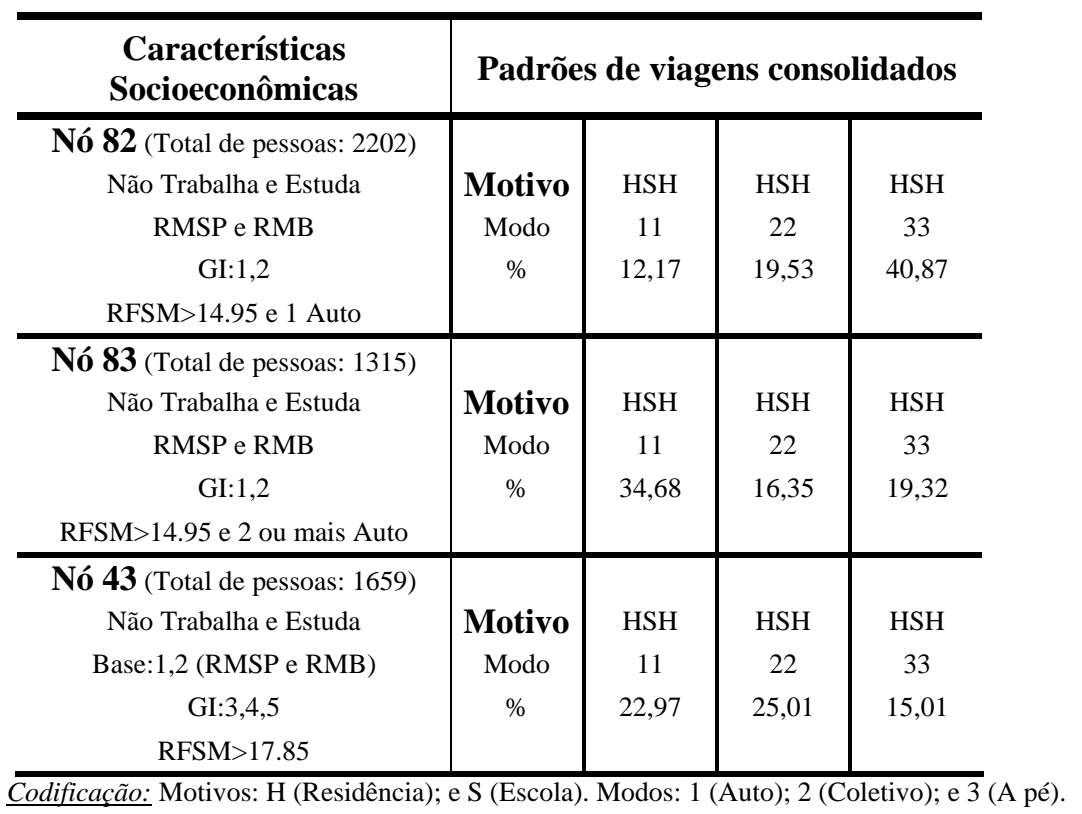

\subsection{Parte 3: Indivíduos que trabalham e não estudam}

Primeiramente, é válido salientar que a variável “Trabalha”, distinguida através de categorias mostradas no capítulo 4, foi criada pelo autor nos bancos de dados das regiões metropolitanas. Já em Bauru, o banco de dados de dados já contemplava tal variável, inclusive, na forma ideal para o processamento da árvore.

As categorias “1”, indivíduos que trabalham, e “0”, para indivíduos que não trabalham, foram obtidas através de informações referentes à "Condição de Atividade” e "Classe de Atividade” (somente no caso da RMB) presentes nos bancos de dados das regiões metropolitanas (ver Anexo C - Questionários).

Na RMSP, indivíduos que declararam, no campo referente à condição de atividade, simplesmente serem “Ocupado” e "Ocupado Eventualmente” foram considerados 
trabalhadores. Já na RMB, foi realizada uma ligação entre os campos "Classe de Atividade” e "Condição de Atividade” para que se pudesse determinar trabalhadores e não-trabalhadores (ver capítulo 4 - Dados, pág. 38). É importante ressaltar que tanto na RMSP quanto na RMB, indivíduos que declararam estar “ocupado eventualmente” foram considerados trabalhadores, exceto aqueles na RMB que declararam no campo “Classe de Atividade” estarem desempregados.

Inicialmente, percebe-se nesta etapa a formação de grandes grupos, em função da presença ou não de automóvel, formados pela RMSP e a RMB e outro grupo formado pela cidade de Bauru. Numa análise geral, fica evidente que a categorização da variável "Trabalha” feita pelo autor para as regiões metropolitanas difere da categorização feita pelo órgão responsável pela pesquisa O/D na cidade de Bauru, causando a separação da cidade de Bauru do grupo correspondente às regiões metropolitanas e, conseqüentemente, prejudicando a análise comparativa. Indivíduos que são classificados como “ocupado eventualmente” na cidade de Bauru não foram considerados como trabalhadores.

Esta parte da análise apresentou maior segregação entre os bancos de dados. Foram identificados 24 grupos homogêneos em relação ao padrão de viagem escolhido, dentre eles 7 apresentando nós terminais similares entre a RMSP e a RMB.

Com relação às diferenças, elas surgem principalmente a partir da variável "Auto” entre as regiões em análise. Optou-se por analisar então detalhadamente os grupos de indivíduos que trabalham, não estudam e possuem ou não automóvel.

\section{a) Indivíduos que trabalham, sem auto e não estudam:}

Este grupo de indivíduos constituiu um grupo homogêneo na cidade de Bauru, representado pelo nó terminal 25. Já nas regiões metropolitanas é dependente do sexo, grau de instrução, idade, total de pessoas na família e renda familiar em salários mínimos da época. 
Verifica-se que na RMSP, os indivíduos pertencentes a este grupo são, na sua maioria, prestadores de serviços autônomos e empregados do comércio assalariados com ou sem carteira assinada. Esta classificação também se estende aos indivíduos da RMB. Já em Bauru, a predominância são de indivíduos empregados da indústria e do comércio assalariados com carteira.

Percebe-se que, atualmente, grande parte da população trabalhadora nas regiões metropolitanas brasileiras está no mercado informal que, muitas vezes, pode não requerer regularidade diária e pontualidade.

Segundo Ramos (2002), a evolução da informalidade nas relações trabalhistas das regiões metropolitanas do Brasil cresceu continuamente ao longo da década de 90, inclusive superando as relações formais.

A Tabela 7.6 mostra os padrões predominantes para este grupo de indivíduos. Verifica-se que o padrão H é o mais freqüente na RMSP e o segundo mais freqüente na RMB. A justificativa pode estar na grande presença de indivíduos do mercado informal nas duas regiões metropolitanas, além daqueles que trabalham eventualmente.

Apesar do padrão H ser o mais freqüente, é preciso ressaltar que somando todas as combinações possíveis do padrão HWH nas regiões metropolitanas, verifica-se que na RMSP o percentual atinge 64,65\% e na RMB cerca de 60,16\%. Em Bauru, 94,31\% dos indivíduos fazem o padrão HWH. Na cidade de Bauru, verifica-se que as relações trabalhistas formais ainda prevalecem, diferentemente das regiões metropolitanas, contribuindo para maior assiduidade dos trabalhadores nesta área urbana. 
Tabela 7.6: Padrões predominantes encontrados para pessoas que trabalham, não possuem auto e não estudam

\begin{tabular}{|c|c|c|c|c|c|c|c|c|c|}
\hline $\begin{array}{l}\text { Base de dados } \\
\text { (Total de pessoas) }\end{array}$ & Códigos & & & Pad & rões Pre & edomina & ntes & & \\
\hline \multirow{4}{*}{$\begin{array}{c}\text { RMSP } \\
(12.126)\end{array}$} & Motivo & $\mathrm{H}$ & $\mathrm{HWH}$ & $\mathrm{HWH}$ & $\mathrm{HWH}$ & $\mathrm{HWH}$ & $\mathrm{HWH}$ & $\mathrm{HWH}$ & HWH \\
\hline & Modo & & 22 & 22 & 22 & 33 & 33 & 22 & 33 \\
\hline & Período & & 15 & 25 & 14 & 15 & 14 & 35 & 25 \\
\hline & $\%$ & 24,43 & 20,79 & 9,47 & 7,57 & 5,42 & 4,09 & 3,30 & 3,13 \\
\hline \multirow{4}{*}{$\begin{array}{l}\text { RMB } \\
(6.426)\end{array}$} & Motivo & HWH & $\mathrm{H}$ & $\mathrm{HWH}$ & $\mathrm{HWH}$ & HWH & $\mathrm{HWH}$ & HWH & $\mathrm{HWH}$ \\
\hline & Modo & 22 & & 22 & 33 & 22 & 22 & 22 & 33 \\
\hline & Período & 15 & & 25 & 15 & 14 & 13 & 35 & 13 \\
\hline & $\%$ & 20,42 & 17,23 & 7,00 & 5,10 & 5,03 & 3,92 & 2,72 & 2,52 \\
\hline \multirow{4}{*}{$\begin{array}{l}\text { BAURU } \\
\text { (1.125) }\end{array}$} & Motivo & $\mathrm{HWH}$ & $\mathrm{HWH}$ & $\mathrm{HWH}$ & $\mathrm{HWH}$ & HWH & $\mathrm{HWH}$ & HWH & $\mathrm{HWH}$ \\
\hline & Modo & 22 & 33 & 22 & 22 & 11 & 22 & 22 & 22 \\
\hline & Período & 14 & 14 & 15 & 25 & 14 & 24 & 35 & 55 \\
\hline & $\%$ & 30,93 & 12,62 & 8,09 & 7,20 & 7,11 & 5,60 & 4,09 & 3,11 \\
\hline
\end{tabular}

(A pé). Períodos: 1 (0:00 - 08:00); 2 (08:00 - 11:30); 3 (11:30 - 14:30); 4 (14:30 - 17:30) e 5 (17:30 - 24:00).

De acordo com a Tabela 7.6, nota-se que os padrões predominantes em Bauru são realizados nos períodos 1 e 4, ou seja, os indivíduos saem de suas residências entre 0:00h e 08:00h e retornam para a mesma, após trabalhar, no período compreendido entre 14:30h e 17:30h. O grande número de indústrias na região de Bauru que, geralmente, exigem que o empregado entre no emprego antes das 08:00h e que saia a partir das 17:00h, contribui para aumentar o percentual de indivíduos que realizam tais padrões.

O padrão HWHWH, que não surgiu entre os oito padrões predominantes, apresenta diferentes freqüências entre as três amostras que, possivelmente, podem ter sido influenciadas pelas distâncias e tempos de viagens maiores ou menores requeridos, dentre as regiões em análise, para retornar ao domicílio e depois sair novamente para o trabalho. Ressalta-se que as viagens intermediárias "WH" e "HW" foram realizadas nos períodos 3 ou 4, ou seja, nos intervalos entre 11:30 - 14:30 e 14:30 $17: 30$.

De acordo com a síntese do relatório, presente no Anexo B, nota-se que se somadas todas as combinações possíveis, o padrão HWHWH na RMB e em Bauru é mais freqüente (5,76\% e 5,33\%, respectivamente) do que na RMSP (2,76\%). Um fato que 
pode justificar a diferença encontrada é que a RMB e a cidade de Bauru permitem, graças às distâncias e tempos médios menores, que muitos indivíduos retornem ao domicílio no intervalo do almoço, diferentemente da RMSP.

Um fato interessante notado entre os indivíduos que fazem o padrão $\mathrm{HWHWH}$ na RMSP é que, no intervalo do almoço, os indivíduos tendem a retornar para o domicílio a pé $(0,08 \%)$ ou de automóvel (2,68\%), provavelmente como passageiro, não utilizando transporte coletivo pois o mesmo não deve permitir realizar a atividade “almoço” em tempo hábil de retornar ao trabalho.

Tanto na RMB quanto na cidade de Bauru, a predominância é o padrão HWHWH feito a pé (3,64\% e 2,93\%, respectivamente), seguido do transporte coletivo (1,93\% e $1,87 \%)$ e, por fim, do modo automóvel (0,19\% e $0,53 \%)$.

\section{b) Indivíduos que trabalham, com auto e não estudam:}

Este grupo de indivíduos foi obtido nas três amostras através de um processo de seleção realizado no próprio S-Plus. A Tabela 7.7 ilustra os padrões predominantes encontrados nas amostras em análise.

De acordo com a Tabela 7.7, novamente o padrão $\mathrm{H}$ foi mais freqüente na RMSP e, desta vez, também na RMB. Analisando os indivíduos que realizam este padrão de viagem, verificou-se que se tratam de profissionais autônomos nas duas regiões metropolitanas. Tais profissionais podem optar por viajar ou não diariamente ao trabalho. 
Tabela 7.7: Padrões predominantes encontrados para pessoas que trabalham, possuem auto e não estudam

\begin{tabular}{|c|c|c|c|c|c|c|c|c|c|}
\hline $\begin{array}{l}\text { Base de dados } \\
\text { (Total de pessoas) }\end{array}$ & Códigos & & & & Padrões $P$ & Predom & inantes & & \\
\hline \multirow{4}{*}{$\begin{array}{c}\text { RMSP } \\
(14.183)\end{array}$} & Motivo & $\mathrm{H}$ & $\mathrm{HWH}$ & $\mathrm{HWH}$ & $\mathrm{HWH}$ & $\mathrm{HWH}$ & HWH & $\mathrm{HWH}$ & $\mathrm{HWH}$ \\
\hline & Modo & & 11 & 22 & 11 & 22 & 22 & 11 & 33 \\
\hline & Período & & 15 & 15 & 25 & 25 & 14 & 14 & 15 \\
\hline & $\%$ & 27,19 & 12,30 & 9,51 & 9,02 & 5,89 & 2,93 & 2,93 & 2,18 \\
\hline \multirow{4}{*}{$\begin{array}{c}\text { RMB } \\
(1.431)\end{array}$} & Motivo & $\mathrm{H}$ & $\mathrm{HWH}$ & $\mathrm{HWH}$ & HWH & $\mathrm{HWH}$ & $\mathrm{HWH}$ & HWHWH & $\mathrm{HWH}$ \\
\hline & Modo & & 22 & 11 & 11 & 22 & 11 & 1111 & 22 \\
\hline & Período & & 15 & 15 & 25 & 25 & 13 & 1335 & 14 \\
\hline & $\%$ & 22,43 & 9,71 & 8,04 & 4,75 & 4,61 & 3,63 & 3,14 & 2,66 \\
\hline \multirow{4}{*}{$\begin{array}{l}\text { BAURU } \\
(1.983)\end{array}$} & Motivo & $\mathrm{HWH}$ & $\mathrm{HWH}$ & $\mathrm{HWH}$ & HWHWH & $\mathrm{HWH}$ & $\mathrm{HWH}$ & $\mathrm{HWH}$ & HWHWH \\
\hline & Modo & 11 & 22 & 11 & 1111 & 11 & 33 & 11 & 1111 \\
\hline & Período & 14 & 14 & 24 & 1335 & 25 & 14 & 35 & 2335 \\
\hline & $\%$ & 28,14 & 9,23 & 8,12 & 7,77 & 6,91 & 5,19 & 4,59 & 4,44 \\
\hline
\end{tabular}

Codificação: Motivos: H (Residência); W (Trabalho); S (Escola); e A (Outras Atividades). Modos: 1 (Auto); 2 (Coletivo); e 3 (A pé). Períodos: 1 (0:00 - 08:00); 2 (08:00 - 11:30); 3 (11:30 - 14:30); 4 (14:30 - 17:30) e 5 (17:30 - 24:00).

Se somadas todas as combinações possíveis do padrão HWH, verifica-se que este padrão de viagem caracterizado somente pelo motivo da viagem é o mais freqüente nas três regiões. Na RMSP e na RMB representam 59,75\% e 56,04\%, respectivamente, e na cidade de Bauru 83,61\%.

Desta vez, o padrão HWHWH surgiu entre os oito padrões mais freqüentes na RMB e em Bauru. Se somadas todas as combinações possíveis, o padrão HWHWH representa 3,14\% na RMSP, 8,32\% na RMB e 15,03\% na cidade de Bauru. A causa dessa diferença é, novamente, a facilidade de os indivíduos de Bauru e Belém retornarem ao domicílio para almoçar. Provavelmente isso se deve às distâncias médias de viagem que são menores em Belém e em Bauru.

O padrão HWHAH, onde as viagens de retorno ao domicílio após o dia de trabalho e referentes ao motivo “A” (compras, saúde, lazer etc.) foram realizadas no período 5 (17:30 - 24:00), representam 0,34\% e 0,00\% na RMSP e RMB, respectivamente, e 1,36\% na cidade de Bauru. A violência, reconhecidamente maior nas regiões metropolitanas, e congestionamentos vividos no momento de retorno ao domicílio após o dia de trabalho, podem inibir parte das pessoas de saírem no período noturno para realizarem outras atividades nas regiões metropolitanas neste caso. 
Vale ressaltar que padrões de viagens do tipo HWAWH (padrão período 2335), feito de automóvel nas viagens "HW" e "WH” e a pé nas viagens "WA” e “AW”, e HWAH (padrão período 155), onde todas as viagens foram feitas de automóvel, mais comuns na Região Metropolitana de São Paulo, foram eliminados da análise por não estarem entre os 128 padrões de viagens encadeadas mais freqüentes, prejudicando a análise desta parte.

\section{Nós terminais similares presentes na Parte 3}

Esta parte apresentou 7 nós terminais similares entre a RMSP e a RMB. Novamente, tratam-se de indivíduos com renda familiar elevada. Tal fato é interessante pois na árvore em geral, os grupos que apresentaram maior similaridade foram os indivíduos que possuem renda familiar elevada. As Figuras 7.4 e 7.5. destacam os segmentos da árvore referentes aos nós terminais similares.

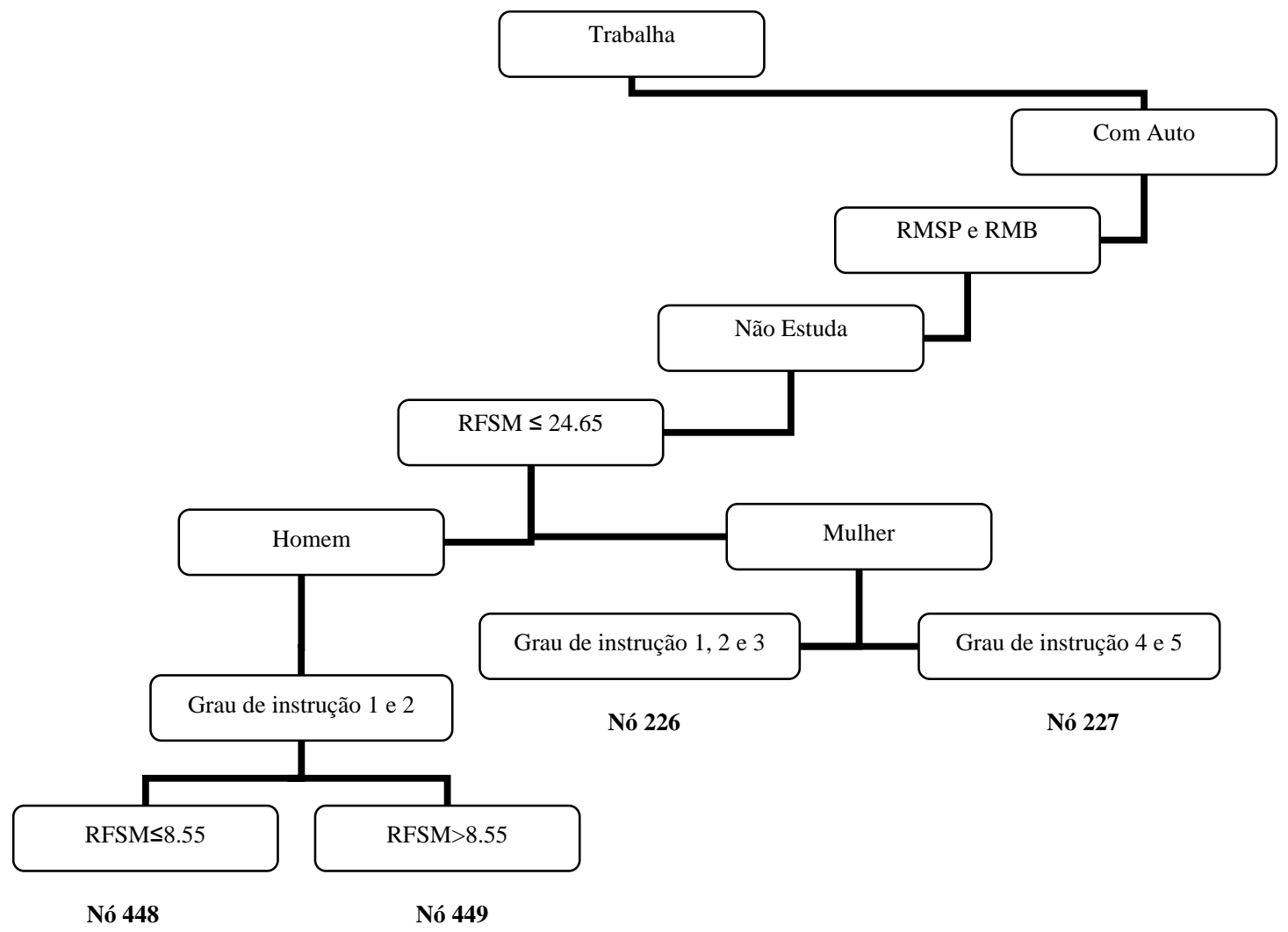

Figura 7.4: Grupos similares e homogêneos em relação aos padrões de viagens escolhidos formados pela RMSP e RMB 
Analisando os padrões de viagens destes nós terminais similares até a variável "sexo”, ou seja, o grupo que corresponde aos indivíduos que trabalham, com auto, não estudam e possuem renda familiar abaixo de 24,65 salários mínimos, percebe-se que papéis tradicionalmente alocados a homens e mulheres permanecem. Apesar de trabalharem, as mulheres ainda continuam exercendo um papel de maior responsabilidade em relação a tarefas domésticas e afazeres relacionados ao domicílio do que os homens. Tal fato fica claro quando, através de informações obtidas no relatório presente no Anexo A, verifica-se que neste caso as mulheres viajam menos do que os homens por motivo trabalho e também, retornam mais cedo ao domicílio.

Para reforçar a hipótese anterior, nota-se que os padrões de viagens dos nós terminais similares 230 e 231 presentes na Figura 7.5., que diferem somente pelo sexo, também mostram que as mulheres viajam menos por motivo trabalho e retornam mais cedo ao domicílio do que os homens. Além disso, como no caso anterior também, utilizam menos o automóvel do que os homens.

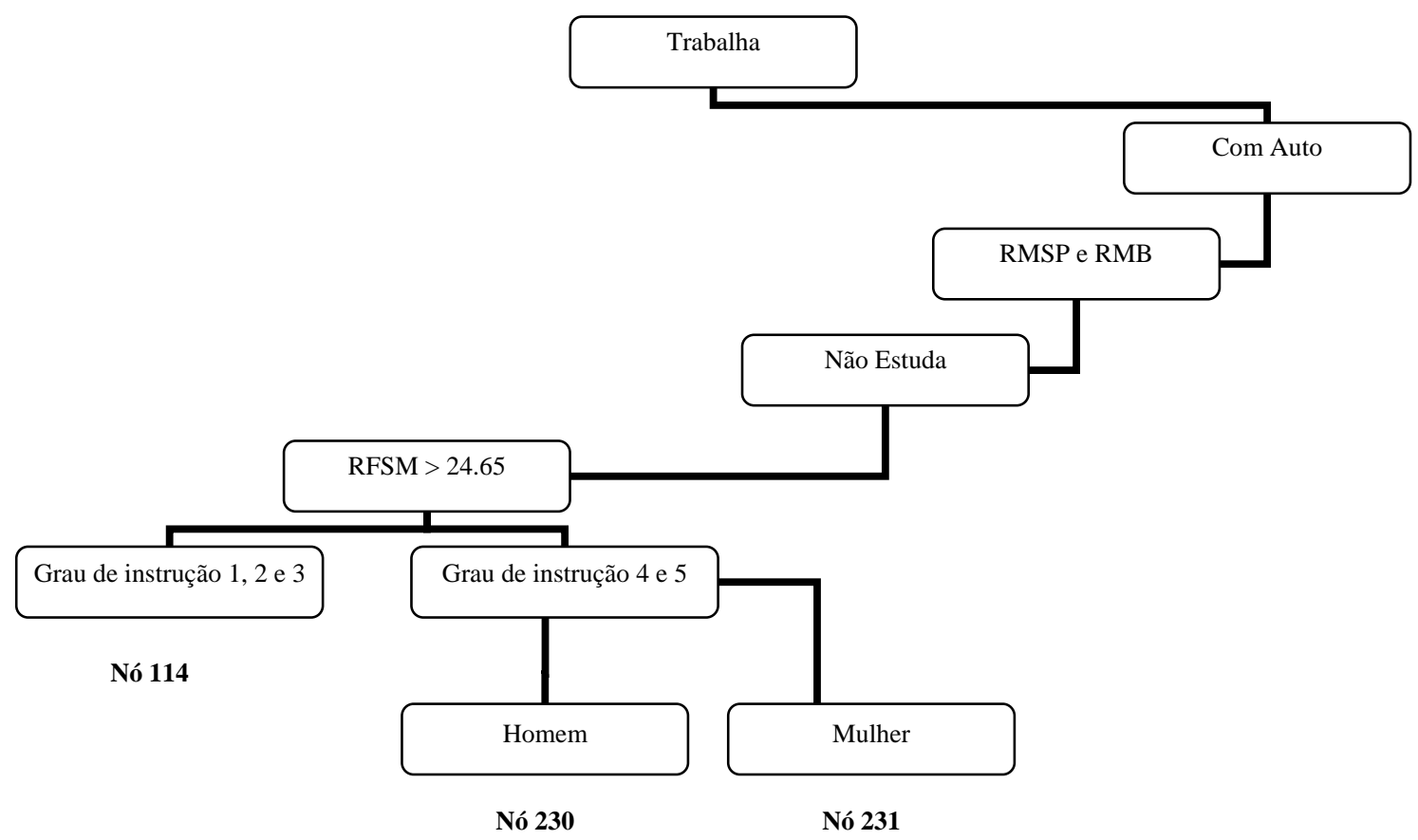

Figura 7.5: Grupos similares e homogêneos em relação aos padrões de viagens escolhidos formados pela RMSP e RMB 


\subsection{Parte 4: Indivíduos que trabalham e estudam}

Novamente a análise dentre as regiões metropolitanas e a cidade de Bauru ficou prejudicada devido as diferentes formas de classificar as atividades “estudo" e “trabalho”. Como já foi dito anteriormente, apenas pessoas que estudavam no ensino oficial foram considerados como “estudantes” na amostra de Bauru descartando, por exemplo, aqueles indivíduos que trabalhavam durante o dia e faziam cursos de línguas à noite.

Cabe aqui salientar que esta parte corresponde aos indivíduos que realizam padrões de viagens mais complexos, já que necessitam realizar atividades de estudo e trabalho, e que foi bastante prejudicada devido a eliminação de indivíduos que realizam mais de quatro viagens.

A Figura 7.6 a seguir ilustra os segmentos em discussão nesta parte da análise.

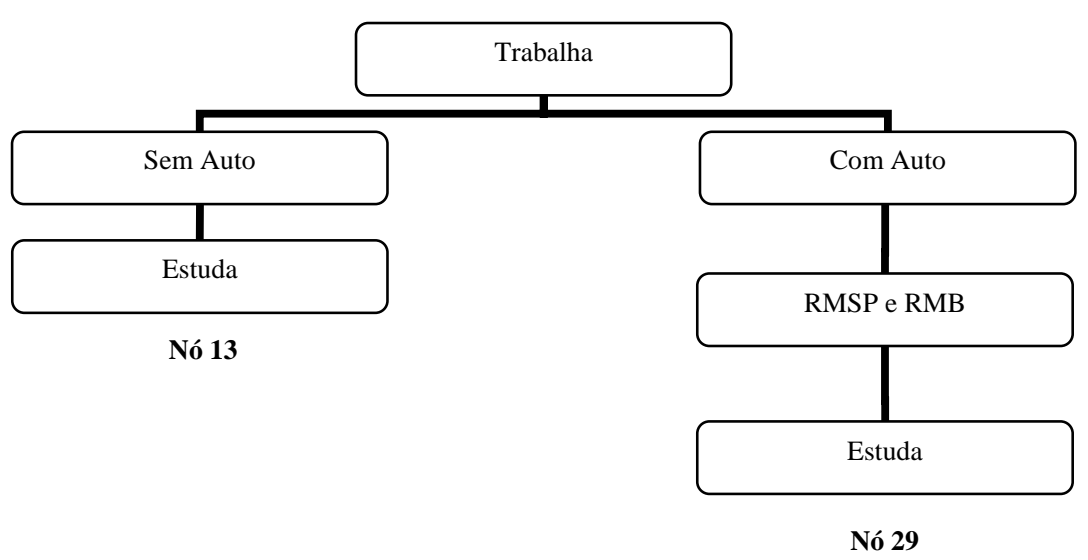

Figura 7.6: Grupos homogêneos em relação aos padrões de viagens

Como a árvore não mostrou distinção entre as regiões metropolitanas, supõem-se que indivíduos que trabalham e estudam e podem possuir ou não automóvel se comportam de maneira parecida na RMSP e na RMB. Com certeza, a compatibilização possível de ser feita entre as bases de dados das regiões metropolitanas permitiu obter tal resultado. 
Já a cidade de Bauru constituiu um grupo homogêneo com as regiões metropolitanas referente aos indivíduos que trabalham, estudam e não possuem automóvel (nó terminal 13). Tal resultado causou surpresa, principalmente devido a incompatibilização das variáveis Estuda e Trabalha, e foram investigados então o total de pessoas presentes nesta parte da análise e os respectivos padrões de viagens.

Após seleção, feita no próprio S-Plus, das pessoas que trabalham e estudam presente nas amostras nesta parte da análise, verificou-se que 2.407 pessoas pertencem ao banco de dados da RMSP, 192 pessoas ao banco de dados da RMB e 34 pessoas ao banco de dados da cidade de Bauru, totalizando 2.633 pessoas. Nota-se uma proporção menor na RMB e, principalmente, em Bauru em relação a RMSP. O método adotado, que inclui todos os conjuntos de dados em um só e posterior seleção dos 128 padrões de viagens mais freqüentes, provavelmente pode ter causado a eliminação, na cidade de Bauru e na RMB, de indivíduos que realizavam padrões de viagens importantes que englobavam trabalho e estudo. Já em relação à distribuição dos padrões de viagens de indivíduos que trabalham, estudam e não possuem automóvel, verifica-se as três áreas urbanas apresentaram distribuição próximas.

Analisando os padrões de viagens do tipo HWSH/HSWH referentes aos nós terminais 13 e 29, presentes no anexo B, nota-se a influência da variável "auto” no comportamento dos viajantes urbanos. Todos os padrões do tipo HWSH/HSWH representam na folha 13 cerca de 9,05\%. Já na folha 29, a totalidade dos padrões HWSH/HSWH representa 14,69\%. Verifica-se que os habitantes têm uma maior propensão de ligar diretamente as viagens por motivo trabalho e estudo, permitido graças à disponibilidade do automóvel para indivíduos pertencentes ao nó terminal 29.

As análises realizadas neste capítulo tentam justificar as causas das similaridades e das diferenças encontradas entre os bancos de dados detectadas pela árvore de decisão e classificação. É importante destacar que a análise foi bastante proveitosa entre as regiões metropolitanas, no entanto, deixou a desejar quando comparada a cidade de Bauru devido a incompatibilidade das variáveis Estuda e Trabalha. 


\section{CONCLUSÕES E RECOMENDAÇÕES PARA}

\section{TRABALHOS FUTUROS}

Capítulo

\subsection{Principais Conclusões}

Este trabalho segue uma das linhas de pesquisa em desenvolvimento na EESC/USP relacionada à análise de demanda por transporte baseada em atividades. Esta linha de pesquisa procura relacionar os múltiplos aspectos das viagens encadeadas com as características socioeconômicas dos habitantes de áreas urbanas através da técnica de mineração de dados denominada Árvore de Decisão e Classificação.

Desta vez, a técnica foi aplicada aos dados coletados em três áreas urbanas (Região Metropolitana de São Paulo, Região Metropolitana de Belém e Bauru, uma cidade de porte médio, situada na região central do Estado de São Paulo), reunidas em um único banco de dados, onde cada área foi identificada de acordo com a área urbana de origem.

Verificou-se que foram distinguidos grupos socioeconômicos intrínsecos de cada região, bem como grupos que apresentaram similaridades dentre as amostras das regiões que se comportam homogeneamente em relação aos padrões de viagens.

Através de informações relacionadas às políticas regionais, diferenças socioeconômicas e de características espaciais das respectivas áreas, foi possível analisar, em geral, as causas das similaridades e diferenças encontradas. 
Foi possível notar que políticas regionais do setor de educação, que recomendam que estudantes de ensino fundamental sejam matriculados em escolas próximas, afetam o comportamento referente às viagens destes estudantes. Devido a proximidade de tais escolas do domicílio, estes estudantes tendem a utilizar mais o modo de transporte a pé.

A política assistencial denominada "Bolsa-escola” presente na Região Metropolitana de Belém na época de sua pesquisa domiciliar, que consiste no pagamento de um salário mínimo a cada família que manter todas as suas crianças entre 7 e 14 anos matriculadas na rede escolar pública, colabora para que se aumente a assiduidade e, conseqüentemente, o número de viagens à escola dos estudantes que lá residem.

O efeito das características espaciais das regiões no comportamento dos viajantes urbanos foi notado, principalmente, quando se analisaram os padrões de viagens de trabalhadores das três áreas urbanas. Notou-se que em Bauru e na RMB, por serem cidades de porte inferior ao da RMSP, uma proporção maior de trabalhadores retornam ao domicílio no intervalo do almoço do que na RMSP.

As diferenças socioeconômicas também colaboram para distinguir os padrões de viagens das três regiões. A atual conjuntura das relações trabalhistas presentes nas regiões metropolitanas, onde a informalidade supera as relações formais, colabora para que diminuam as viagens por motivo trabalho. Em Bauru, onde as relações formais prevalecem, percebe-se o aumento deste tipo de viagem em relação as regiões metropolitanas.

A variável socioeconômica “auto”, que corresponde ao número de automóveis no domicílio, se mostrou relevante quando se compara os padrões de viagens das três áreas urbanas. Devido ao maior índice de motorização, os habitantes da cidade de Bauru utilizam mais o automóvel do que nas regiões metropolitanas.

Contudo, é valido salientar que diferenças metodológicas existentes entre as pesquisas refletiram no resultado da análise comparativa das três áreas urbanas. 
Especificamente no caso das variáveis Trabalha e Estuda, nota-se diferenças consideráveis causadas pela falta de compatibilização destas variáveis entre as regiões metropolitanas e a cidade de Bauru, prejudicando a análise de resultados. Almejando publicações futuras, tentará se compatibilizar tais variáveis entre as três áreas urbanas.

Através da análise especifica de alguns grupos socioeconômicos similares, foi possível perceber que papéis tradicionalmente alocados a homens e mulheres permanecem. Apesar de atualmente mais mulheres estarem no mercado de trabalho, elas ainda continuam exercendo um papel de maior responsabilidade em relação a tarefas domésticas e afazeres relacionados ao domicílio do que os homens, independentemente da área urbana.

Vale destacar que a proposta do trabalho é de analisar de uma maneira geral as diferenças e as similaridades detectadas pela Árvore de Decisão e Classificação dentre as três áreas urbanas. As análises foram feitas em termos de grupos principais e nem todos os membros pertencentes a estes grupos se comportam como a média, variando em função das preferências e gostos pessoais, das variáveis socioeconômicas e das áreas urbanas em que moram.

Foi possível notar que a árvore mostrou com certa clareza as relações entre as diversas características socioeconômicas individuais e familiares e os padrões de viagem dentre grupos específicos de habitantes das três urbanas, possibilitando de certa forma auxiliar os planejadores de transportes na adoção de políticas de transportes eficazes sobre diferentes grupos de indivíduos.

Cabe aqui salientar que o trabalho foi um passo inicial a análise comparativa dos padrões de viagens encadeadas de indivíduos residentes em áreas urbanas diferentes e que alguns conhecimentos que transcendem a análise de dados de uma única cidade puderam ser obtidos ao longo da elaboração do trabalho. No entanto, mais estudos devem ser realizados em busca de uma maior compreensão do comportamento de viajantes urbanos. 


\subsection{Recomendações para Futuros Trabalhos}

Como recomendação para pesquisas futuras pode-se citar:

Desenvolvimento de outros métodos para comparação dos padrões de encadeamento de viagens de habitantes residentes em áreas urbanas diferentes

Transferibilidade espacial dos parâmetros de classificação obtidos a partir de uma única área urbana e que, posteriormente, serão aplicados aos dados de outras áreas;

Análise comparativa de bancos de dados uniformes, ou possíveis de serem compatibilizados, em relação as variáveis socioeconômicas e de características de viagens de interesse;

Incluir a distância de viagem na caracterização de padrões de viagens com intuito de ter melhor percepção da influência das características espaciais das áreas urbanas;

Analisar a possibilidade de incluir outras variáveis de interesse que possam auxiliar no entendimento de alguns resultados como o número de crianças ou de trabalhadores no domicílio;

Desenvolver uma metodologia que demonstre a variabilidade ou não do comportamento referente ao encadeamento de viagens encadeadas de grupos socioeconômicos de indivíduos. 


\section{REFERÊNCIAS BIBLIOGRÁFICAS}

ADLER, T.; BEN-AKIVA, M. E. (1979) A Theoretical and Empirical Model of Trip Chaining Behavior. Transportation Research B., 13B., p.243-257

ALLAMAN, P. M.; TARDIFF, T.J.; DUNBAR, F.C. (1982) New Approaches to Understanding Travel Behavior. National Cooperative Highway Research Program Report, Washington D.C., v. 250.

ARENTZE, T.; HOFMAN, F.; KALFS, N.; TIMMERMANS, H. (1997) Data needs, Data Collection, and Data Quality Requirements of Activity-based Transport Models. Proceedings of the Internacional Conference on Transport Survey Quality and Innovation (Transport Surveys: Raising the Standard), Grainau, Germany.

ARENTZE, T.; TIMMERMANS, H. (2000) ALBATROSS: A Learning Based Transportation Oriented Simulation System, European Institute of Retailing and Service Studies.

ARENTZE, T.; HOFMAN, F.; MOURIK, H.V.; TIMMERMANS, H.; WETS, G. (2000) Using Decision Tree Induction Systems for Modeling Space-Time Behavior. Geographical Analysis, v. 32, N.4 ,p.330-350.

BHAT, C.R.; KOPPELMAN, F.S. (1991) A Conceptual Framework of Individual Activity Program Generation . Transportation Research, Part A, v. 27A, N.6 , p.433-446.

BHAT, C. R.; KOPPELMAN, F. S. (2000) Activity-based Travel Demand Analysis: History, Results and Future Directions. Transportation Research Board, 79th Annual Meeting. January 9-13, 2000. Washington, D.C. 
BHAT, C. R.; SINGH, S. K. (2000) A Comprehensive Daily Activity-travel Generation Model System for Workers. Transportation Research 34A, p 1-22.

BISPO, C.A.F. (1998) Uma Análise de Nova Geração de Sistemas de Apoio à Decisão. São Carlos. Dissertação (Mestrado) - Escola de Engenharia de São Carlos, USP.

BOWMAN, J. L. (1998) The Day Activity Schedule Approach to Travel Demand analysis. Tese (Doutorado) - Massachusetts Institute of Technology.

BOWMAN, J. L.; BEN-AKIVA, M. (1997) Activity Based Travel Forecasting. Summary, Recommendations and Compendium of Papers, Activity-based Travel Forecasting Conference, New Orleans, p. 3-37.

BOWMAN, J. L.; BEN-AKIVA, M. (2000) Activity Based Disaggregate Travel Demand Model System with Activity Schedules, Transportation Research A , 35, p 1-28.

BREIMAN, L.; FRIEDMAN, J.H; OLSHEN, R.A.; STONE, C..J. (1984) Classification and Regression Trees. Wadsworth International Group, Califórnia.

CIRILLO, C.; AUXHAUSEN, K. W. (2002) Comparing Urban Activity Travel Behavior. Transportation Research Board, $81^{\text {th }}$ Annual Meeting. January 1317, 2002. Washington, D. C.

CHAPIN, F.S. (1971) Free-time Activities and the Quality of Urban Life. Journal of the American Institute of Planners, n. 37, p. 411-417.

COSTA NETO, P. L. (1985) Estatística. São Paulo, ed. Edgard Blücher. 
CULLEN, I.; GODSON, V. (1975) Urban Networks: The Structure of Activity Patterns. Progress in Planning, 4, p. 1-96.

FAYYAD, U. M.; PIATETSKY-SHAPIRO, G.; SMYTH, P.; UTHURUSAMY, R. (1996) Advances in Knowledge Discovery and Data Mining. AAAI Press / The MIT Press, Menlo Park, CA.

FOX, M. B. (1983) Working Women and Travel: The Access of Women to Work and Community Facilities.

GETTING STARTED WITH S-PLUS 2000. (1999) Data Analysis Products Division. MathSoft, Seattle.WA.

GOLOB; T.F. (1999) A Simultaneous Model of Household Activity Participation and Trip Chain Generation. Special issue of Transportation Research B : Methodological developments in travel behavior research.

GOMIDE, A. A. (2003) Transporte Urbano e Inclusão Social: Elementos para Políticas Públicas. IPEA - Instituto de Pesquisa Econômica Aplicada, Texto $\begin{array}{lllll}\text { para discussão } & n^{\circ} & 960 . & \text { Disponível }\end{array}$ http://www.ipea.gov.br/pub/td/2003/td_0960.pdf (17/09/2003)

GONZALEZ TACO, P. W. (2003) Redes Neurais Artificiais Aplicadas na Modelagem Individual de Padrões de Viagens Encadeadas a Pé. São Carlos. 209 p. Tese (Doutorado) - Escola de Engenharia de São Carlos, USP.

GOODWIN, P.; KITAMURA, R.; MEURS, H. (1990) Some Principles of Dynamic Analysis of Travel Behavior.In development in dynamic and activity-based approaches to travel analysis, England, Gower.

HÄGERSTRAND, T. (1970) What About People in Regional Science? Papers of the Regional Science Association, v. 24, p. 7-21. 
HAN, J.; KAMBER, M. (2000) Data Mining: Concepts and Techniques. Ed. New York: Morgan Kaufmann, 550p.

HANSON S.; HANSON P. (1981) The Travel-Activity Patterns Of Urban Residents: Dimensions and Relationships To Sociodemographic Characteristics. Economic Geography, v. 57, p. 332-347.

HANSON, P. (1977) The Activity Patterns Of Elderly Households. Geografiska Annaler, v.59, p. $109-124$.

ICHIKAWA, S.M. (2002) Aplicação de Minerador de Dados na Obtenção de Relações entre Padrões de Encadeamento de Viagens Codificados e Características Sócio-econômicas. São Carlos. 136 p. Dissertação (Mestrado) Escola de Engenharia de São Carlos, USP.

ICHIKAWA, S.M; PITOMBO, C.S.; KAWAMOTO, E. (2002) Aplicação de Minerador de Dados na Obtenção de Relações entre Padrões de Viagens Encadeadas e Características Sócio-econômicas. Panorama Nacional de Pesquisa em Transportes, XVI Anpet, v.2, p.175-186.

JONES, P.M. (1977) New Approaches to Understanding Travel Behaviour: The Human Activity Approach. Working Paper 28. Transport Studies Unit, Oxford.

JONES, P.; DIX, M.C.;CLARKE, M.I ; HEGGIE I.G. (1983) Understanding Travel Behaviour. Gower Publishing, Aldershot.

JONES, P.; KOPPELMAN, F.; ORFUEIL, J.P (1990) Activity analysis: State-of-theart and future directions. Developments in Dynamic and Activity-Based Approaches to Travel Analysis, Gower Publishing, Brookfield, Vermont. 
JOU, R.; MAHMASSANI, H. S. (1997) Comparative Analysis of Day-to-Day TripChaining Behavior of Urban Commuters in Two Cities. Transportation Research Board, $76^{\text {th }}$ Annual Meeting. January, 1997. Washington, D.C.

KASS, G.V. (1980) An Exploratory Technique for Investigating Large Quantities of Categorical Data, Applied Statistics 29, p.119-127.

KASTURIRANGAN, K.; PENDYALA, R. M. (2001) A Comparison of Commuter Activity Scheduling and Sequencing Behavior Across Geographical Contexts. Transportation Research Board, 80 ${ }^{\text {th }}$ Annual Meeting. January 7-11, 2001. Washington, D.C.

KITAMURA, R.; FUJII, S. (1996) Two Computational Process Models of Activitytravel Behavior. Theoretical Foundations of Travel Choice Modeling Conference. Estocolmo. Agosto 7-11.

KITAMURA , R.; KOSTYNIUK, L. P.; UYENO, M. J. (1981) Basic Properties of Urban Time-space Paths: empirical tests. Transportation Research Record, 794. p. 1-7.

KUMAR, A.; LEVINSON, D. (1995) Chained Trips in Montgomery County, Maryland. Disponível em: http://www.ce.umn.edu/ levinson/papers-pdf/docchains.pdf $(27 / 07 / 2003)$

MCGUCKIN, N.; MURAKAMI, E. (1999) Examining Trip-chaining Behavior - A Comparison of Travel by Men and Women. Transportation Research Record 1683. Transportation Research Board, Washington, D.C.

MESA, D.M; TSAI, P.; CHAMBERS, R.L. (2000) Using Tree-Based Models for Missing Data Imputation: Na Evaluation Using UK Census Data. Forthcoming in Research Papers of Statistics Netherlands. 
METRÔ (1990) Pesquisa origem e destino 1987: Região Metropolitana de São Paulo, Síntese das informações.

OI, W.Y; SHUILDINER, P.W. (1962) An Analysis of Urban Travel Demands. Northwestern University Press, Evanston, IL.

PAS, E.I. (1985) State-of-the-art and research opportunities in travel demand: Another perspective.Transportation Research A, 19, p. 460-464.

PAS, E.I.; HARVEY, A.S. (1991) Time use research and travel demand analysis and modeling. Paper presented at the Sixth Internacional Conference on Travel Behavior, Quebec City, Quebec.

PDTU/2001 - Plano Diretor de Transporte Urbano da Região Metropolitana de Belém (2001). Relatório Final. Belém - PA, Brasil.

PENDYALA, R.M.; KITAMURA, R.; CHEN, C.; PAS, E.I. (1997) An Activitybased Microsimulation Analysis of Transportation Control Measures, Transport Policy, 4, p. 183-192.

PITOMBO, C. S. (2003) Análise do Comportamento Subjacente ao Encadeamento de Viagens através do Uso de Minerador de Dados. São Carlos. 149 p. Dissertação (Mestrado) - Escola de Engenharia de São Carlos, USP.

QUINLAN, J.R. (1993) C4.5: Programs for Machine Learning. Morgan Kaufmann Publishers, San Mateo, California.

QUINLAN, J.R. (1983) Learning Efficient Classification Procedures and their Application to Chess end-Games. Machine Learning: An Artificial Intelligence Approach, p. 463-482. 
RAIA JR., A. A. (2000) Acessibilidade e Mobilidade na Estimativa de um Índice de Potencial de Viagens Utilizando Redes Neurais Artificiais e Sistemas de Informações Geográficas. São Carlos. 196 p. Tese (Doutorado) - Escola de Engenharia de São Carlos, USP.

RAMOS, L. (2002) A Evolução da Informalidade no Brasil Metropolitanos: 19912001. IPEA - Instituto de Pesquisa Econômica Aplicada, Texto para discussão $n^{o}$ 914. Disponível em: http://www.ipea.gov.br/pub/td/2002/td_0914.pdf $(17 / 09 / 2003)$

RECKER, W. W.; MCNALLY, M. G.; ROOT, G. S. (1986a) A Model of Complex Travel Behavior: part i. Theoretical Development. Transportation Research, 20A, p. 307-318.

RECKER, W. W.; MCNALLY, M. G.; ROOT, G. S. (1986a) A Model of Complex Travel Behavior: part ii. An Operational Model. Transportation Research, 20A, p. 319-330.

SAFAVIAN, S.R.; LANDGREBE, D. (1991) A Survey of Decision Tree Classifier Methodology, Man ad Cybernetics, v.21, p. 660-674.

STRAMBI, O.; VAN DE BILT, K. (1998) Tendências sócio-demográficas das mulheres e suas implicações para análise da demanda e elaboração de políticas de transportes. Ingeniería de Tránsito y Transporte, $X$ Congresso Panamericano, p. 57-68.

STRAMBI, O.; VAN DE BILT, K.; PIETRANTONIO, H. (1995) Utilização do CHAID - Método de Detecção Automática de Interações - Para Análise de Taxas de Produção de Viagens. Anais IX ANPET,v.2, p.492-506.

STRATHMAN, J. G.; DUEKER, K .J. (1995) Understanting Trip Chaining. 1990 NPTS Special Reports on Trip and Vehicle Attributes Report FHWA-PL-95-33 
TANDEL, M. C. F. F. (1997) Geração de Viagens de Passageiros Urbanos: Modelo Individual com a Inclusão das Características do Domicílio. São Carlos. 242 p. Tese (Doutorado) - Escola de Engenharia de São Carlos, USP.

VAN DE BILT, K. (2002) Desenvolvimento e Validação de um Procedimento de Projeção Desagregada da População Associado a um Modelo de Geração de Viagens Baseado em Análise de Segmentação. São Paulo. 164 p. Tese (Doutorado) - Escola Politécnica - USP. 